
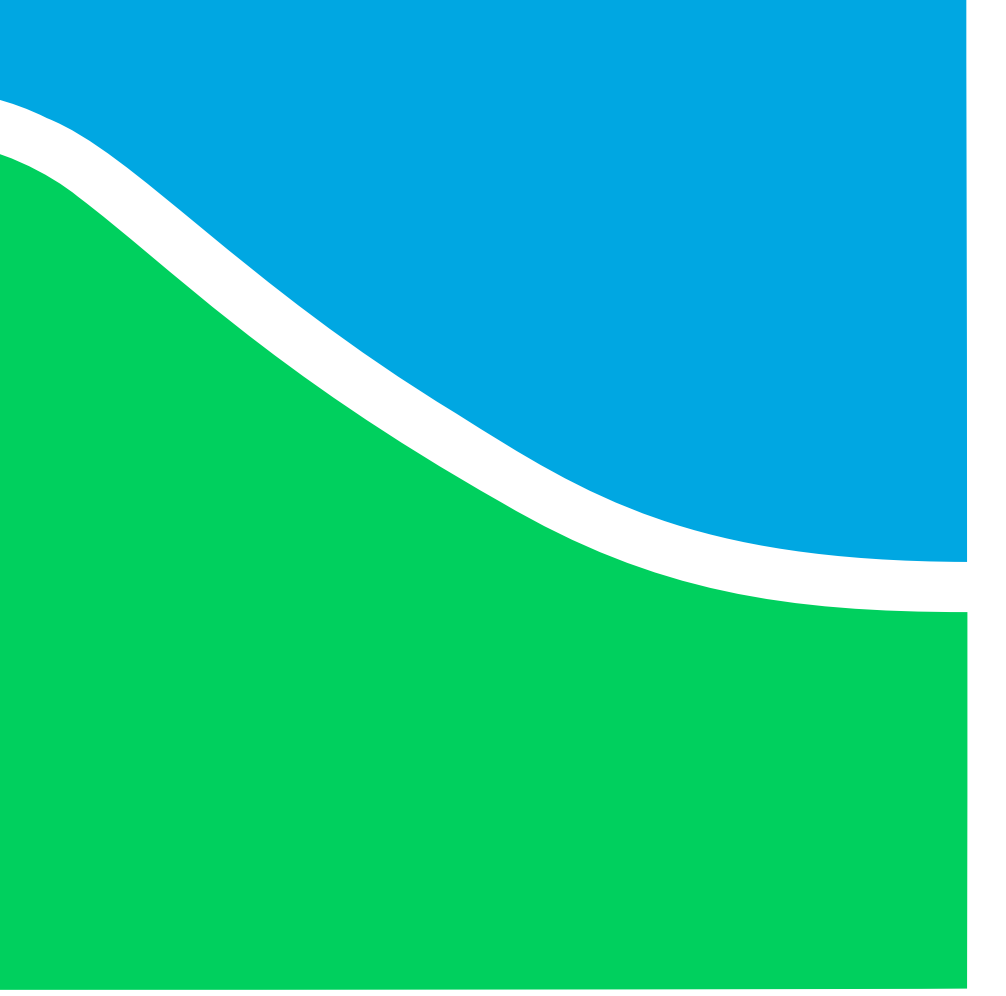

\title{
REDUÇÃO DE DIMENSÕES PELO USO DE TRANSFORMAÇÕES LINEARES EM SISTEMAS MIMO MASSIVO DISTRIBUÍDOS COM FRONTHAUL LIMITADO
}

RICARDO DE SOUZA CERQUEIRA

DISSERTAÇÃO DE MESTRADO EM ENGENHARIA ELÉTRICA 
UNIVERSIDADE DE BRASÍLIA

FACULDADE DE TECNOLOGIA

DEPARTAMENTO DE ENGENHARIA ELÉTRICA

\author{
REDUÇÃO DE DIMENSÕES PELO USO DE \\ TRANSFORMAÇÕES LINEARES EM SISTEMAS \\ MIMO MASSIVO DISTRIBUÍDOS COM FRONTHAUL \\ LIMITADO
}

RICARDO DE SOUZA CERQUEIRA

ORIENTADOR: ANDRÉ NOLL BARRETO

DISSERTAÇÃO DE MESTRADO EM ENGENHARIA ELÉTRICA

PUBLICAÇÃO: PPGEE.DM - 620/2016 MD BRASÍLIA/DF: OUTUBRO - 2016 


\title{
UNIVERSIDADE DE BRASÍLIA \\ FACULDADE DE TECNOLOGIA DEPARTAMENTO DE ENGENHARIA ELÉTRICA
}

\author{
REDUÇÃO DE DIMENSÕES PELO DE TRANSFORMAÇÕES \\ LINEARES EM SISTEMAS MIMO MASSIVO DISTRIBUÍDOS COM \\ FRONTHAUL LIMITADO
}

\section{RICARDO DE SOUZA CERQUEIRA}

\begin{abstract}
DISSERTAÇÃO DE MESTRADO SUBMETIDA AO DEPARTAMENTO DE ENGENHARIA ELÉTRICA DA FACULDADE DE TECNOLOGIA DA UNIVERSIDADE DE BRASÍLIA, COMO PARTE DOS REQUISITOS NECESSÁRIOS PARA A OBTENÇÃO DO GRAU DE MESTRE.
\end{abstract}

APROVADA POR:

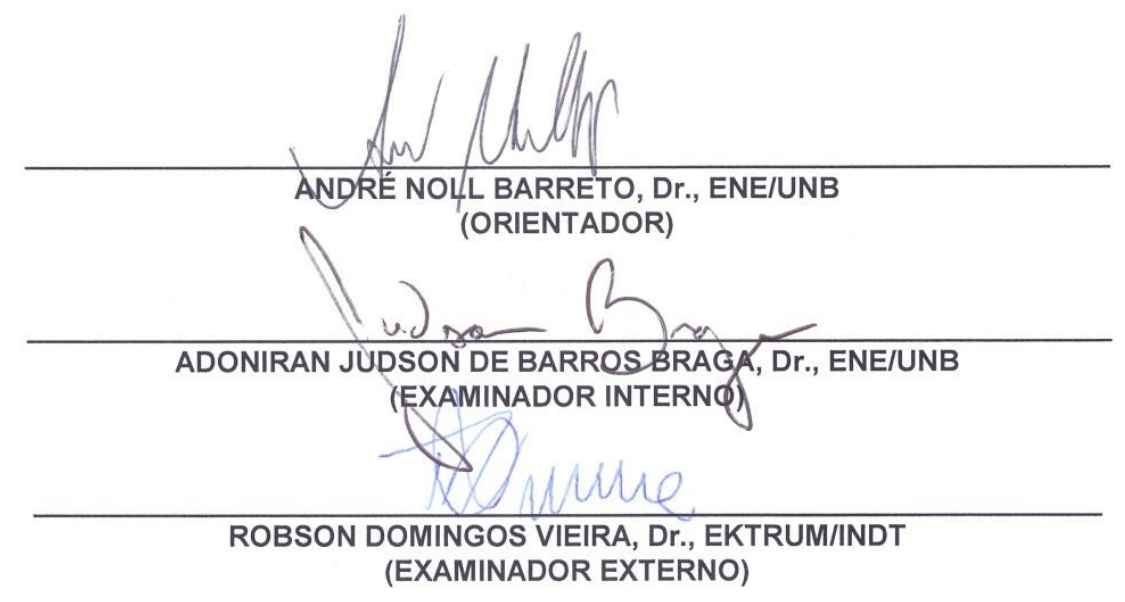

Brasília, 29 de outubro de 2016. 


\section{FICHA CATALOGRÁFICA}

CERQUEIRA, RICARDO DE SOUZA

Redução de Dimensões pelo Uso de Transformações Lineares em Sistemas MIMO Massivo Distribuídos com Fronthaul Limitado [Distrito Federal] 2016.

xvi, 75p, 210 x 297 mm (ENE/FT/UnB, Mestre, Engenharia Elétrica, 2016).

Dissertação de Mestrado - Universidade de Brasília. Faculdade de Tecnologia.

Departamento de Engenharia Elétrica.

1. MIMO Massivo Distribuído

3. Redução de dimensões

5. Transformada de Karhunen-Loève

I. ENE/FT/UnB
2. Transformações Lineares

4. Fronthaul limitado

6. Transformada Discreta de Cossenos

II. Título (série)

\section{REFERÊNCIA BIBLIOGRÁFICA}

CERQUEIRA, R. S. (2016). Redução de Dimensões pelo Uso de Transformações Lineares em Sistemas MIMO Massivo Distribuídos com Fronthaul Limitado. Dissertação de Mestrado em Engenharia Elétrica, Publicação PPGEE.DM-620/2016 MD, Departamento de Engenharia Elétrica, Universidade de Brasília, Brasília, DF, 75p.

\section{CESSÃO DE DIREITOS}

AUTOR: Ricardo de Souza Cerqueira.

TÍTULO: Redução de Dimensões pelo Uso de Transformações Lineares em Sistemas MIMO Massivo Distribuídos com Fronthaul Limitado.

GRAU: Mestre ANO: 2016

É concedida à Universidade de Brasília permissão para reproduzir cópias desta dissertação de mestrado e para emprestar ou vender tais cópias somente para propósitos acadêmicos e científicos. $\mathrm{O}$ autor reserva outros direitos de publicação e nenhuma parte dessa dissertação de mestrado pode ser reproduzida sem autorização por escrito do autor.

Ricardo de Souza Cerqueira

Campus Universitário Darcy Ribeiro, Asa Norte

Universidade de Brasília - Faculdade de Tecnologia - Dep. de Engenharia Elétrica CEP 70.910-900 - Brasília - DF - Brasil. 


\section{DEDICATÓRIA}

À Sabrina e ao pequeno Vinícius, pelo amor, apoio e compreensão. 


\section{AGRADECIMENTOS}

A Deus, pela sua presença constante na minha vida.

À minha mãe e meu pai (in memoriam), por minha existência.

À minha esposa, pelo amor incondicional, paciência e compreensão pelo tempo que me dediquei a este curso.

Ao pequeno Vinícius, pelo amor e alegria.

Ao professor André, meu orientador, pela paciência, confiança, coordenação e orientações. Sempre seus ensinamentos me foram muito valiosos e sempre esteve disponível a qualquer momento para me auxiliar, seja para ensinar coisas novas ou para esclarecer dúvidas.

À todos do Departamento de Engenharia Elétrica, professores e funcionários, em especial ao prof. Ugo e à Adriana, pelo exemplo de dedicação e profissionalismo.

Ao grande amigo Antônio Celso, pelas produtivas discussões e cuidadosas revisões.

Aos colegas da UnB, em especial ao Adriano, Jairo, Samir e Tiago, pela convivência e amizade.

À todos aqueles que, direta ou indiretamente, me ajudaram de alguma forma. 
"A mente que se abre a uma nova ideia jamais voltará ao seu tamanho original." Albert Einstein 


\section{RESUMO}

\section{REDUÇÃO DE DIMENSÕES PELO USO DE TRANSFORMAÇÕES LINEARES EM SISTEMAS MIMO MASSIVO DISTRIBUÍDOS COM FRONTHAUL LIMITADO}

Sistemas MIMO massivo distribuídos são amplamente considerados como uma das principais tecnologias para sistemas de comunicação sem fio 5G. No entanto, um dos aspectos críticos desta técnica é a necessidade de grande capacidade dos enlaces de fronthaul, que são as conexões que transmitem a informação de cada arranjo de antenas ao decodificador central, devido à vasta quantidade de dados recebidos, cujos volumes são proporcionais ao número de antenas.

Este trabalho verifica a viabilidade do uso de duas transformadas lineares, a transformada de Karhunen-Loève (KLT) e a transformada discreta de cossenos (DCT), para se reduzir o número de dimensões do sinal recebido nos uplinks e, assim, reduzir os requisitos de taxa de dados dos enlaces de fronthaul mediante uma perda admissível no desempenho da transmissão.

Estes métodos descorrelacionam as amostras e as listam em ordem decrescente de energia. A partir disso, é realizada uma seleção de dimensões, na qual é selecionado um reduzido número de amostras e descartado as demais, equivalendo a uma compressão com perdas. Apesar disso, é possível estimar um sinal muito próximo ao original, já que os sinais descartados não possuem tanta relevância.

Por fim, simulações também foram realizadas para a comprovação de desempenho em vários cenários e permitir a comparação de métodos. 


\section{ABSTRACT \\ DIMENSION REDUCTION USING LINEAR TRANSFORMS IN DISTRIBUTED MASSIVE MIMO SYSTEMS WITH CONSTRAINED FRONTHAUL}

Distributed Massive MIMO systems are widely regarded as one of the key technologies for $5 \mathrm{G}$ wireless communications systems. However, one of the limiting aspects of this technique is the capacity of the fronthaul links that convey the information from each individual antenna array to a centralized decoder, due to a huge amount of data, whose volumes are proportional to the number of antennas.

This work addresses the use of two linear transforms, the Karhunen-Loève transform (KLT) and the discrete cosine transform (DCT), to reduce the number of dimensions of received signal at the uplink, and thus reduce the data rate requirements of fronthaul links with an acceptable loss in transmission performance.

From this, a selection of dimensions is performed, in which a small number of samples is selected and the remaining are discarded, which results in a lossy compression. Nevertheless, we can still obtain a signal close to the original, since discarded signals do not have much relevance due to their small power.

Finally, simulations were performed to check performance of several scenarios, in order to compare both methods. 
1 - INTRODUÇÃ $O$............................................................................................................

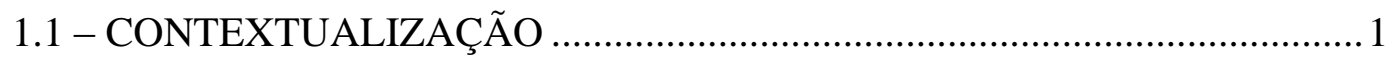

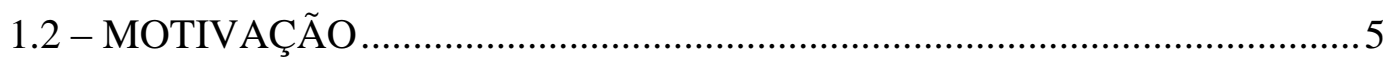

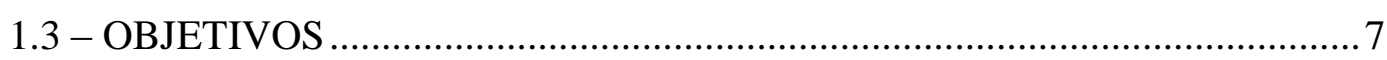

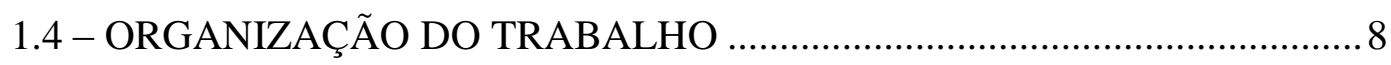

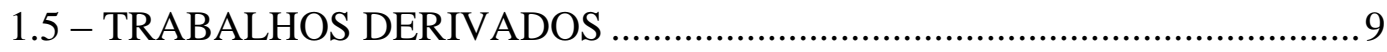

2 - SISTEMAS DE MÚLTIPLAS ANTENAS ......................................................10

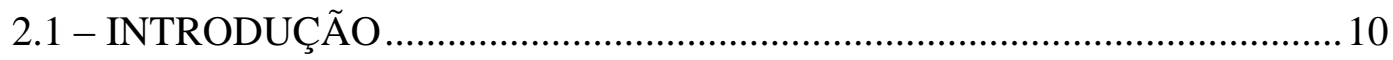

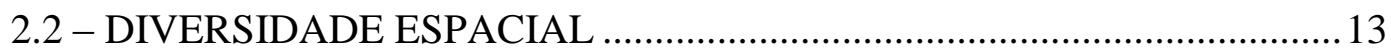

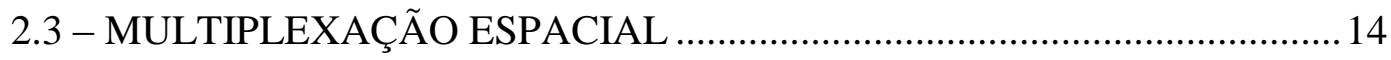

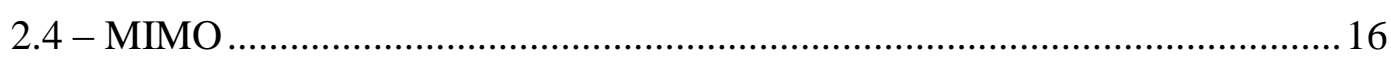

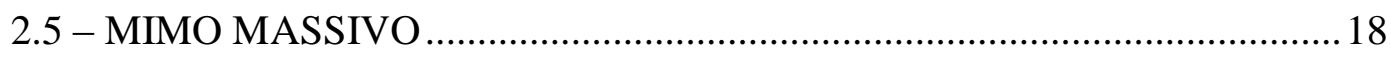

2.6 - CLOUD-RADIO ACCESS NETWORK ………………………………..... 20

2.7 - MIMO MASSIVO DISTRIBUÍDO ........................................................... 21

3 - CONCEITUAÇÃO DO SISTEMA.......................................................................24

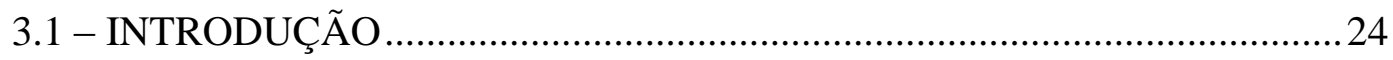

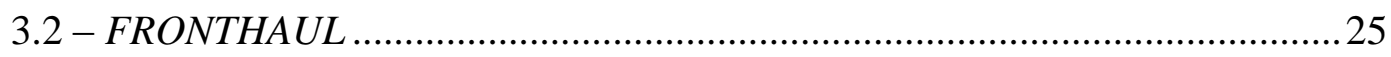

3.3 - TRANSFORMADA DE KARHUNEN-LOÈVE ………………………........ 26

3.4 - DECOMPOSIÇÃO EM VALORES SINGULARES ……………………..... 27

3.5 - TRANSFORMADA DISCRETA DE COSSENOS .......................................2

4 - CARACTERIZAÇÃO DO MODELO UTILIZADO .........................................30

4.1 - MODELO DE CANAL MIMO …………………………………………..... 30

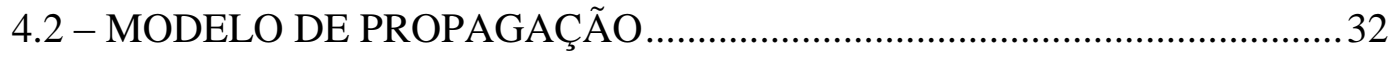

4.3 - MATRIZ DE COVARIÂNCIA DO CANAL …………………………......... 33

4.4 - MATRIZ DE COVARIÂNCIA PARA ARRANJO LINEAR DE

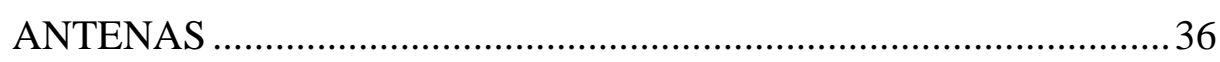

4.5 - MATRIZ DE COVARIÂNCIA PARA PAINEL QUADRADO DE

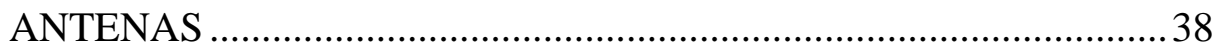

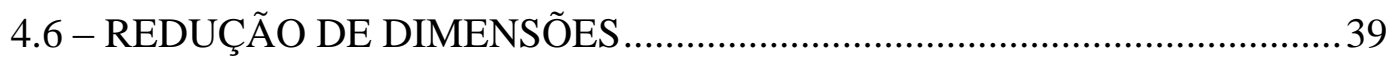

4.7 - DETECÇÃO DE SINAL …………………………………………….... 42 
5 - SIMULAÇÕES DO MODELO........................................................................45

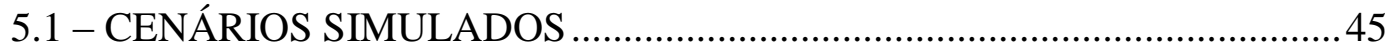

5.2 - RESULTADOS DAS SIMULAÇÕES COM O USO DA KLT ....................4 48

5.3 - RESULTADOS DAS SIMULAÇÕES COM O USO DA DCT ....................57

5.4 - RESUlTAdOS DAS SIMULAÇÕES COM REDUÇÃO DE

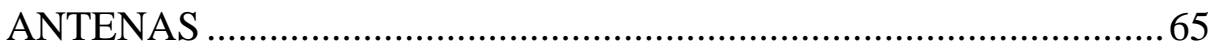

5.5 - COMPARAÇÃO ENTRE AS TRANSFORMAÇÕES ..............................6 68

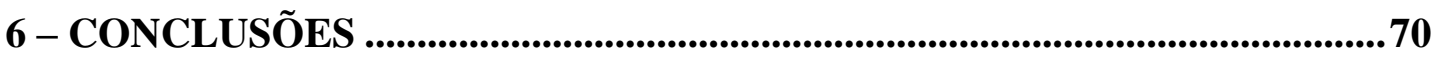

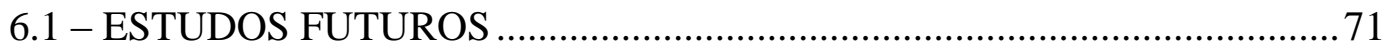

REFERÊNCIAS BIBLIOGRÁFICAS .......................................................................72 


\section{LISTA DE FIGURAS}

Figura 1.1 - Topologia de um sistema MIMO massivo distribuído..................................... 3

Figura 2.1 - Classificação quanto às antenas a) SISO b) SIMO c) MISO d) MIMO ..... 10

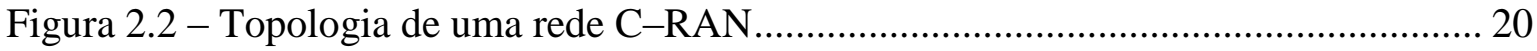

Figura 2.3 - Tipos de arranjos de antenas (adaptado de [36])......................................... 22

Figura 3.1 - Enlaces de fronthaul e backhaul .................................................................. 25

Figura 4.1 - Representação do modelo de canais MIMO …............................................. 30

Figura 4.2 - Tipos de arranjos de antenas a) Linear b) Painel quadrado .......................... 35

Figura 4.3 - Redução de dimensões no MIMO massivo distribuído ................................... 41

Figura 5.1 - Cenário simulado com usuário único ................................................................ 46

Figura 5.2 - Cenário simulado com multiusuários........................................................... 47

Figura 5.3 - BER para arranjos lineares de antenas com $\rho=0,50$, utilizando-se a KLT.

Figura 5.4 - BER para arranjos lineares de antenas com $\rho=0,25$, utilizando-se a KLT.

Figura 5.5 - BER para arranjos lineares de antenas com $\rho=0,75$, utilizando-se a

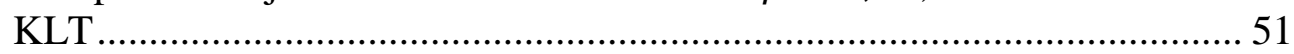

Figura 5.6 - BER para painéis de antenas $\operatorname{com} \rho=0,50$, utilizando-se a KLT ................. 52

Figura 5.7 - BER para painéis de antenas $\operatorname{com} \rho=0,25$, utilizando-se a KLT ................. 52

Figura 5.8 - BER para painéis de antenas $\operatorname{com} \rho=0,75$, utilizando-se a KLT ................. 53

Figura 5.9 - BER em função do número de dimensões, para arranjos lineares de antenas, $\rho=0,50$ e $E_{b} / N_{0}$ fixos, utilizando-se a KLT...............................5 54

Figura 5.10 - BER para arranjos lineares de antenas com $\rho=0,50$, utilizando-se a

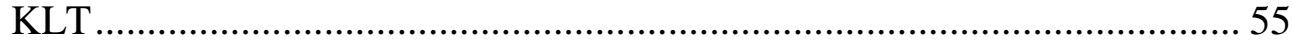

Figura 5.11 - BER para painéis de antenas $\operatorname{com} \rho=0,50$, utilizando-se a KLT ............... 56

Figura 5.12 - BER para arranjos lineares de antenas com $\rho=0,25$, utilizando-se a

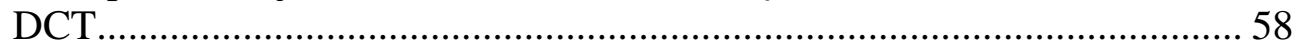

Figura 5.13 - BER para arranjos lineares de antenas com $\rho=0,50$, utilizando-se a DCT.

Figura 5.14 - BER para arranjos lineares de antenas com $\rho=0,75$, utilizando-se a DCT.

Figura 5.15 - BER para painéis de antenas $\operatorname{com} \rho=0,25$, utilizando-se a DCT.............. 61

Figura 5.16 - BER para painéis de antenas $\operatorname{com} \rho=0,50$, utilizando-se a DCT............... 62

Figura 5.17 - BER para painéis de antenas $\operatorname{com} \rho=0,75$, utilizando-se a DCT............... 63

Figura 5.18 - BER em função do número de dimensões, para arranjos lineares de antenas, $\rho=0,50$ e $E_{b} / N_{o}$ fixo, utilizando-se a DCT 
Figura 5.19 - BER para painéis de antenas $\operatorname{com} \rho=0,50$, utilizando-se a KLT, DCT

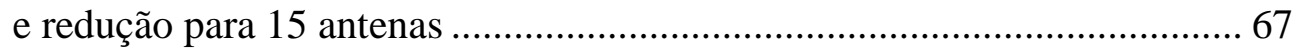

Figura 5.20 - BER para painéis de antenas $\operatorname{com} \rho=0,50$, utilizando-se a KLT, DCT

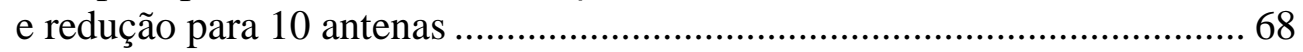

Figura 5.21 - Concentração de energia para a KLT e a DCT ........................................... 69 


\section{LISTA DE ABREVIATURAS}

$\bigotimes$ - produto de Kronecker

$|(\cdot)|$ - módulo ou valor absoluto de $(\cdot)$

$(\cdot)^{\dagger}$ - pseudo-inversa de Moore-Penrose de $(\cdot)$

$(\cdot)^{\mathrm{H}}$ - transposta Hermitiana, conjugado transposto ou matriz adjunta de $(\cdot)$

$(\cdot)^{\mathrm{T}}-$ matriz transposta de $(\cdot)$

$E_{b} / N_{0}$ - razão entre a energia por bit e a densidade espectral da potência do ruído

$E_{S} / N_{0}$ - razão entre a energia por símbolo e a densidade espectral da potência do ruído

$\operatorname{cov}(\cdot)$ - covariância de $(\cdot)$

$\operatorname{diag}(\cdot)$ - matriz diagonal com os valores $(\cdot)$

$\min (\cdot)-$ menor valor entre $(\cdot)$

$x$ - variável $x$

$\boldsymbol{x}$ - vetor $\boldsymbol{x}$

$\boldsymbol{X}$ - matriz $\boldsymbol{X}$

$\hat{X}$ - valor estimado de $X$

$3 \mathrm{G}-3^{\text {rd }}$ generation

$3 \mathrm{GPP}-3^{\text {rd }}$ generation partnership project

$4 \mathrm{G}-4^{\text {th }}$ generation

$5 \mathrm{G}-5^{\text {th }}$ generation

AWGN - additive white gaussian noise

$\mathrm{BBU}$ - base band unit

BLAST - Bell Laboratories layered space-time

BPSK - binary phase-shift keying

$\mathrm{BER}$ - bit error rate

$\mathrm{BS}$ - base station

CAPEX - capital expenditure

cloud-RAN - cloud-radio access network

CoMP - coordinated multipoint

COST-coopération européenne dans le domaine de la recherche scientifique et technique

$\mathrm{CPRI}$ - common public radio interface 
C-RAN - cloud-radio access network

CSI - channel state information

DAS - distributed antenna system

DCT - discrete cosine transform

DCT-II - discrete cosine transform type-II

$d$-KLT - distributed Karhunen-Loève transform

EGC - equal-gain combining

$\mathrm{EHF}$ - extremely high frequency

FD-MIMO - full dimension MIMO

FSO - free-space optics

IEEE - institute of electrical and electronics engineers

i.i.d. - independent and identically distributed

JPEG - joint photographic experts group

KLT - Karhunen-Loève transform

LTE - long-term evolution

LTE-A - long-term evolution advanced

LSAS - large-scale antenna systems

LS-MIMO - large-scale MIMO

LOS - line-of-sight

MAP - maximum a posteriori

MIMO - multiple-input multiple-output

MISO - multiple-input single-output

ML - maximum likelihood

MMSE - minimum mean square error

$\mathrm{mmW}$ - millimeter-wave

mmWave - millimeter-wave

MPEG - moving picture experts group

MRC - maximal-ratio combining

MSE - mean square error

NLOS - non-line-of-sight

OBSAI - open base station architecture initiative

OPEX - operational expenditure

ORI - open radio interface

PCA - principal component analysis 
$\mathrm{RF}$ - radiofrequência

$\mathrm{RRH}$ - remote radio head

RRU - remote radio unit

SCM - spatial channel model

$\mathrm{SHF}$ - super high frequency

SIMO - single-input multiple-output

SISO - single-input single-output

SNR - signal-to-noise ratio

SVD - single value decomposition

TDD - time division duplex

TD-SCDMA - time division synchronous code division multiple access

$\mathrm{UMi}$ - urban microcell scenario

UDN - ultra-dense network

$\mathrm{UE}$ - user equipment

WINNER - wireless world initiative new radio

$\mathrm{ZF}$ - zero forcing 


\section{1 - INTRODUÇÃO}

\section{1 - CONTEXTUALIZAÇÃo}

Atualmente, a demanda por transmissão de dados em sistemas móveis tem crescido a taxas muito altas e a indústria prevê que o crescimento do volume de tráfego será vertiginosamente maior nos próximos anos [1] [2].

Estudos mostram a previsão de grande crescimento de tráfego e de dispositivos conectados a redes IP até o ano de 2020 , devendo atingir um volume de $2,3 \mathrm{ZB}^{1}$ e 3,4 vezes o número de habitantes, respectivamente, em 2020 [3].

$\mathrm{Na}$ mesma linha, os requisitos apresentados por consórcios, empresas e entidades para a próxima geração de sistemas de comunicação móvel mostram enormes desafios. Alguns requisitos definidos para a $5^{\mathrm{a}}$ geração (5G) em 2020 são [4] [5] [6] [7] [8]:

- aumento de tráfego da ordem de 1.000 vezes;

- redução de latência da ordem de 5 a 10 vezes;

- aumento da taxa de dados da ordem de 10 a 100 vezes;

- aumento do número de dispositivos conectados da ordem de 10 a 100 vezes;

- aumento de densidade de conexão da ordem de 100 vezes;

- redução do consumo da ordem de 10 vezes.

Dentre as várias tecnologias atualmente consideradas para redes de $5^{\mathrm{a}}$ geração, o massive multiple-input multiple-output (massive MIMO) ${ }^{2}$, ou MIMO massivo, é amplamente considerado como uma das mais promissoras, pois permite aumentos substanciais de alcance e de taxa de dados [9]. Os sistemas MIMO massivo são arranjos que possuem grande número de antenas [9], tendo, pelo menos, várias dezenas ou centenas de antenas em sua composição.

Segundo [10], o MIMO massivo é uma tecnologia nova que ainda tem de ser colocada em prática. Apesar disso, seus princípios de operação são bem compreendidos.

\footnotetext{
${ }^{1} 1 \mathrm{ZB}=1$ zettabyte $=10^{21}$ bytes.

2 Neste trabalho foi adotado o termo da língua portuguesa "MIMO massivo" como a tradução do
} termo da língua inglesa "massive MIMO". 
Esta tecnologia, também conhecida como large-scale antenna systems (LSAS) ou full dimension MIMO (FD-MIMO), é uma promissora candidata a atender a demanda de requisitos da próxima geração de redes móveis. De forma a suprir esse volume de crescimento de tráfego sem fio estimado em 1.000 vezes, a quinta geração das redes celulares traz muitos desafios, em especial, a necessidade de aumento expressivo da eficiência espectral dos sistemas. Melhorias na eficiência espectral da ordem de 50 vezes ou mais que a da $4^{\mathrm{a}}$ geração (4G) são frequentemente mencionadas na literatura [10].

Com relação à densidade das células, segundo [11], na $3^{\mathrm{a}}$ geração $(3 \mathrm{G})$ de redes celulares a densificação de estações base, ou base stations (BSs) objetivava melhorar as taxas de transmissão em áreas limitadas, como as BSs implementadas em áreas urbanas. Para evitar interferências em macrocélulas adjacentes, as tecnologias de reuso de frequência e setorização permitem uma densidade de macrocélula de cerca de 4 a $5 \mathrm{BS} / \mathrm{km}^{2}$.

Já nas redes celulares de quarta geração, como nos sistemas de comunicação móvel long-term evolution advanced (LTE-A), as microcélulas, tais como hotspots e femtocélulas, são implementadas para satisfazer altas taxas de transmissões de dados em regiões específicas, e a densidade de microcélulas é de aproximadamente 8 a $10 \mathrm{BS} / \mathrm{km}^{2}$.

Nas redes 5G que propõem o uso do MIMO massivo para melhorar a eficiência de espectro, centenas de antenas serão integradas às estações base e utilizadas para transmissão de tráfego da ordem de Gbits/s. A densidade desses sistemas será da ordem de 40 a $50 \mathrm{BS} / \mathrm{km}^{2}$ e a potência transmitida em cada antena reduzida de 10 a 20 vezes em relação à potência das estações base de 4G.

As antenas do sistema MIMO podem também ser distribuídas em diferentes painéis localizados em lugares distintos, onde cada arranjo é ligado a um decodificador central através de um enlace, o fronthaul ${ }^{3}$, conforme ilustrado na Figura 1.1, podendo ser cabeado ou sem fio. Este cenário é conhecido como MIMO massivo distribuído (distributed massive MIMO), e esses sistemas proporcionam não só multiplexação espacial e microdiversidade, mas também ganhos de macrodiversidade, já que as respostas de canal

${ }^{3} \mathrm{O}$ termo da língua inglesa "fronthaul" será adotado neste trabalho pois não possui uma boa tradução direta para a língua portuguesa. 
de diferentes antenas têm diferentes fatores de sombreamento e são tipicamente descorrelatadas [12].

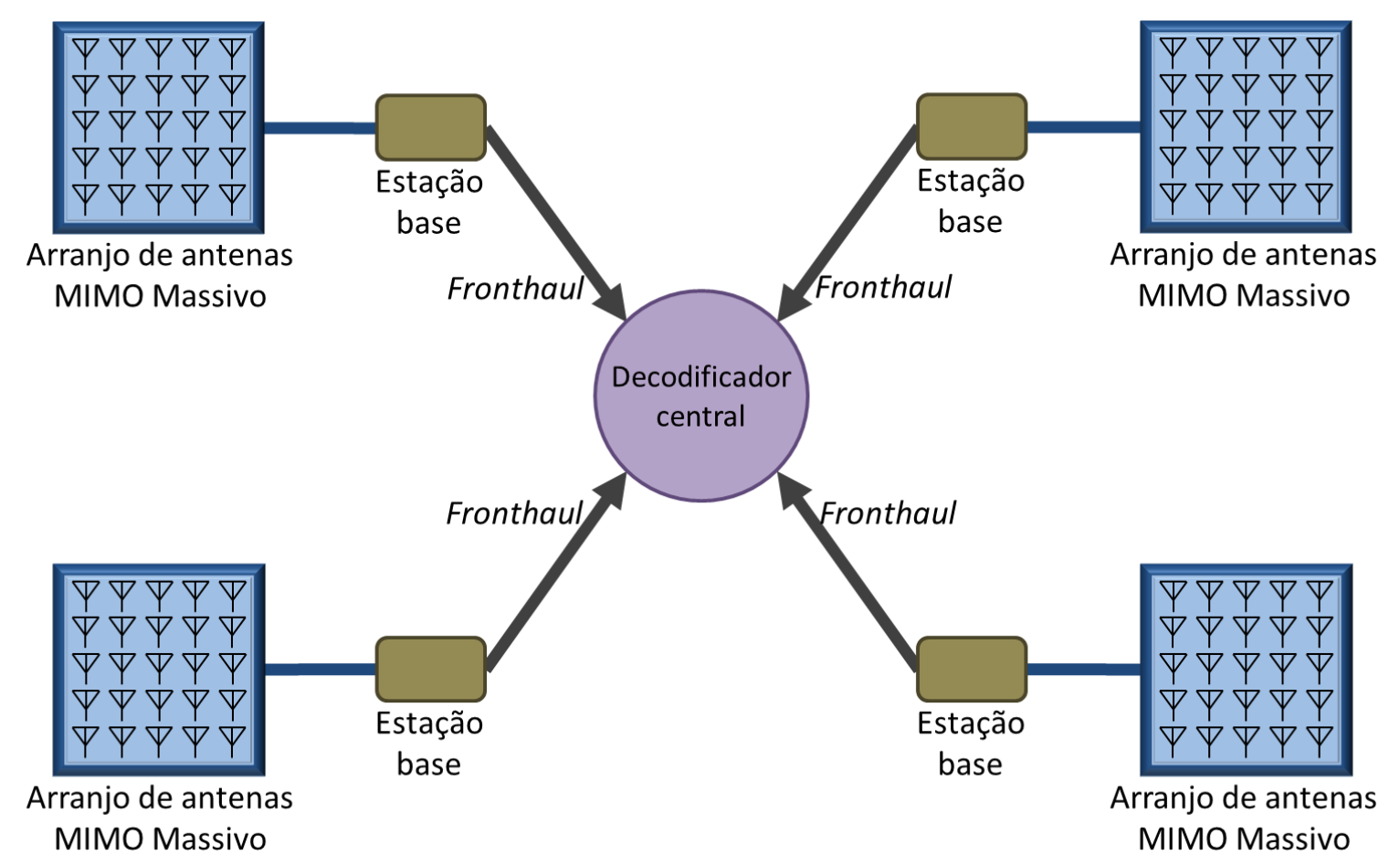

Figura 1.1 - Topologia de um sistema MIMO massivo distribuído

Em sistemas práticos, os enlaces de fronthaul têm limitações de banda e são um grande desafio para a implementação do MIMO massivo distribuído, pois a quantidade de dados é mais elevada que um sistema tradicional.

Os enlaces ópticos de fronthaul, que tipicamente possuem taxas de 2,5 Gbits/s, $10 \mathrm{Gbits} / \mathrm{s}$ ou $40 \mathrm{Gbits} / \mathrm{s}$, não são capazes de comportar todo o aumento de tráfego produzido pelos arranjos de antenas, visto que tal acréscimo é proporcional ao número de antenas empregadas, conforme apresentado nas seções posteriores.

Essa demanda por altas taxas representa aumento de custo, já que é necessária a expansão dos enlaces. Segundo [13], outro importante fator a ser considerado é o custo da rede, já que o adensamento da rede pressupõe a instalação de mais estações base, que resultam em mais despesas para as operadoras.

O custo desta densificação da rede pode ser categorizado como despesas com capital, ou capital expenditure (CAPEX), e despesas operacionais, ou operational 
expenditure (OPEX). Os custos com CAPEX incluem toda a implantação da rede, ou seja, infraestrutura e equipamentos. Os custos com OPEX incluem, por exemplo, a operação e manutenção das redes, despesas com energia elétrica, transmissão de dados em redes de backhaul e aluguel de espaço físico.

Apesar dos custos, essa densificação de rede também pode ter vantagens, pois, por exemplo, em redes do tipo small cell, tanto o CAPEX, quanto o OPEX são muito menores que os das redes tradicionais. Além do que, nesse caso, na implantação de small cells em ambientes internos, os custos de instalação e operação da estação são compartilhados entre as operadoras de telecomunicações e os usuários.

Para suportar o grande aumento da quantidade de dados trafegados na próxima geração de redes móveis, a ampliação da capacidade dos enlaces de fronthaul é uma solução dispendiosa que geralmente não é praticável, pois habitualmente necessita de grandes investimentos em infraestrutura de redes, tais como lançamento de novos cabos de fibras ópticas e substituição de equipamentos.

Uma solução mais plausível e econômica é a redução da quantidade de informação incorporada nas portadoras por meio da diminuição do volume de dados transportados. Esta redução pode ser feita por meio de compressão, podendo ser sem ou com perdas.

No caso do enlace de fronthaul por radiofrequência (RF), a faixa de frequências utilizada tem influência na construção dos painéis porque o tamanho das antenas é proporcional ao comprimento de onda utilizado.

Assim, frequências mais altas permitem acomodar mais antenas, como na faixa extremely high frequency (EHF) que vai de 30 a $300 \mathrm{GHz}$, pois têm dimensões e espaçamentos proporcionais aos comprimentos de onda.

Devido à característica destes sistemas estudados, com ganho de arranjo e com elementos de antenas muito próximos uns dos outros, os sinais recebidos pelas diversas antenas possuem grande correlação. Por causa disso, esses dados possuem muita redundância, decorrente de uma reduzida variedade dos sinais recebidos, e é isto que possibilita uma compressão mais eficiente. 
Outro importante fator que se aplica ao tipo dos sistemas abordados, é que esta redundância também habilita o uso da compressão com perdas sem grande degradação do desempenho do mesmo, conforme explorado no decurso deste trabalho.

Um método factível de compressão com perdas é o emprego da transformada de Karhunen-Loève, ou Karhunen-Loève transform (KLT), para redução da quantidade de informação dos dados de usuários a ser transmitida nos enlaces de fronthaul.

Nesta transformada, que é linear, o sinal é decomposto em componentes descorrelatados. Após a transformada somente alguns componentes de maior energia são selecionados, resultando na redução das dimensões da representação matricial do sinal original. Apesar de haver perdas, o sinal original pode ser reconstituído sem grandes implicações no desempenho.

Outra transformada linear que pode ser empregada na compressão com perdas é a transformada discreta de cossenos, ou discrete cosine transform (DCT). Com ela o sinal primitivo é decomposto em cossenos e, posteriormente, são selecionados alguns componentes de maior energia. Apesar da existência de perdas, a reconstituição do sinal original também é possível.

Nesse contexto, a redução de dimensões com o uso da KLT ou da DCT é uma solução factível para lidar com o aumento da taxa de dados decorrente do aumento de tráfego previsto para a próxima geração de redes móveis.

Do ponto de vista financeiro, apesar dos custos decorrentes da necessidade de atualização da rede com novos equipamentos, por outro lado, há uma economia de recursos, relacionados a não existência ou pequena necessidade de expansão dos enlaces de fronthaul.

\section{2 - MOTIVAÇÃO}

O MIMO massivo é uma tecnologia emergente cotada para integrar as futuras redes móveis. Em razão disso, especialmente em ondas milimétricas, ou millimeter-wave (mmW ou mmWave), é considerado uma possível tecnologia para o fronthaul ou backhaul da futura $5^{\text {a }}$ geração de redes ultradensas, ou ultra-dense networks (UDN) [14] [15], de 
forma a prover uma solução de fronthaul sem fio similar em capacidade, latência e em custos a de um enlace de fibra óptica.

Outro fator motivador é o desafio de aumento de capacidade e redução de custo de implantação encontrado para os enlaces de fronthaul e, similarmente aos de backhaul, já que este último é frequentemente citado pelos operadores como um dos aspectos mais desafiadores na implantação de small cells [16].

Outro importante aspecto é que muitos trabalhos sobre MIMO distribuído consideraram um fronthaul ideal, sem limitações de capacidade [17]. Todavia, o fronthaul com limitações é um problema fundamental nas redes sem fio futuras [18], particularmente se o número de antenas em cada painel for grande. Desta forma, a investigação de enlaces com limitação de capacidade apresenta-se como uma pertinente contribuição nesta área.

O uso da KLT em sistemas de múltiplas antenas foi sugerido em [19], em que se propõe que alguns componentes de maior energia sejam selecionados após a KLT para redução de dimensões do sinal. A KLT também foi empregada em um sistema MIMO em [20], mas para reduzir a informação de estado de canal, ou channel state information (CSI), no canal de retorno e não nos dados em si.

Assim, no uplink é esperado que o uso de arranjos com grande quantidade de antenas resulte em um proporcional aumento da quantidade de dados, quando comparado a um sistema tradicional.

A quantidade de dados trafegados por cada usuário aumenta muito com o MIMO massivo, conforme pode ser constatado no próximo capítulo. O crescimento segue uma escala proporcional ao número de antenas no painel, o que significa que poucos usuários são suficientes para atingir a capacidade do enlace de fronthaul, que é a premissa adotada nesta investigação.

Com relação aos métodos de transformação, foram escolhidas transformadas lineares visto que são mais fáceis de se implementar e necessitam menos recursos computacionais que as transformadas não lineares, fator importante de ser ponderado considerando as limitações dos equipamentos de usuários, ou user equipments (UEs).

A respeito da escolha das transformadas, a KLT é uma transformação linear que necessita da estimação da matriz de covariância das antenas e já é consolidada no meio 
acadêmico. Já a DCT não requer essa matriz de covariância e também é considerada uma transformada linear subótima, cujo desempenho fica imediatamente atrás da KLT.

Segundo [21] a DCT tem excelente capacidade de compactação de energia e também se aproxima da KLT que é a transformada estatisticamente ótima para descorrelacionamento de um sinal. Tais razões levaram à escolha dessas transformações lineares.

No caso estudado, o grande número de antenas proporciona o correlacionamento que viabiliza o uso da redução de dimensões. Os métodos investigados fazem a seleção de um pequeno número de sinais de maior energia e os demais componentes de menor energia são descartados, ou seja, uma compressão com perdas.

Tais técnicas possibilitam uma redução significativa da quantidade de dados sem que haja uma considerável perda de desempenho quando comparadas a um sistema sem compressão, permitindo que o tráfego seja comportado em enlaces de fronthaul com restrição de banda. Com isso é possível a economia de custos de expansão da rede.

A limitação de banda nos enlaces de fronthaul é uma premissa considerada, mesmo não havendo a especificação de uma taxa limite, já que esta depende de vários fatores do sistema. Porém, esta restrição norteia a necessidade de redução da taxa de dados e a comparação entre as técnicas empregadas neste trabalho.

\section{3 - OBJETIVOS}

Este trabalho tem como principal objetivo investigar a viabilidade da compressão com perdas em enlaces de fronthaul com limitação de banda. Essa redução de dimensões de sinais recebidos por arranjos de antenas é realizada por meio da seleção de componentes após a realização da transformada de Karhunen-Loève ou da transformada discreta de cossenos em sistemas MIMO massivo distribuídos.

O trabalho de [19] explora as propriedades da correlação espacial dos sinais recebidos pelas antenas pela ortogonalização dos sinais recebidos por meio da KLT, e após isso, uma seleção de um reduzido número de dimensões. O método proposto também tem 
uma estimação de canal mais robusta devido à redução das dimensões espaciais e à limitação dos parâmetros de estimação.

Neste trabalho é desenvolvido o estudo em um sistema com antenas distribuídas, semelhante à KLT distribuída, ou distributed Karhunen-Loève transform ( $d$-KLT) estudada por [22].

Também é proposta a utilização da transformada discreta de cossenos como outra forma de realização da compactação de energia dos sinais, pois não depende da matriz de covariância, e a comparação de desempenho entre os métodos.

Por fim, é verificado o comportamento de sistemas com a utilização da KLT e da DCT, tanto em sistemas monousuários como multiusuários, de forma a conferir a degradação e a consequente viabilidade de aplicação das técnicas.

\section{4 - ORGANIZAÇÃO DO TRABALHO}

Este trabalho está dividido em seis capítulos, da seguinte forma.

No Capítulo 2 são apresentados conceitos dos sistemas de múltiplas antenas, diversidade espacial, multiplexação espacial, MIMO, MIMO massivo, MIMO massivo distribuído e cloud-radio access network.

No Capítulo 3 são apresentados alguns fundamentos da tecnologia do MIMO massivo, fronthaul, transformada de Karhunen-Loève, decomposição em valores singulares e a transformada discreta de cossenos.

O Capítulo 4 descreve a caracterização do modelo utilizado neste trabalho, que inclui o modelo de canal MIMO, o modelo de propagação, a matriz de covariância do canal, a matriz de covariância para arranjo linear de antenas, a matriz de covariância para painel quadrado de antenas, a redução de dimensões e a detecção de sinal.

No Capítulo 5 são apresentados os resultados das simulações realizadas com o uso da KLT, da DCT e com a redução de antenas, juntamente com análises dos resultados dos modelos utilizados neste trabalho. 
No Capítulo 6 são apresentadas as conclusões decorrentes deste trabalho, bem como algumas propostas de temas para estudos e pesquisas posteriores.

\section{5 - TRABALHOS DERIVADOS}

Partes deste trabalho foram submetidas e aceitas no XXXIV Simpósio Brasileiro de Telecomunicações (SBrT2016), com realização entre 30 de agosto a 2 de setembro de 2016, em Santarém-PA. 


\section{2 - SISTEMAS DE MÚLTIPLAS ANTENAS}

\section{1 - INTRODUÇÃO}

Os sistemas de comunicação podem ser classificados quanto à topologia de suas antenas, na qual recebem as denominações de: single input single output (SISO), Figura 2.1a, quando há apenas uma antena de transmissão e uma antena de recepção; single input multiple output (SIMO), Figura 2.1b, quando possui uma antena transmissora e mais de uma antena receptora; multiple input single output (MISO), Figura 2.1c, quando apresenta múltiplas antenas transmissoras e somente uma receptora; e multiple input multiple output (MIMO), Figura 2.1d, quando possui múltiplas antenas na transmissão e na recepção.
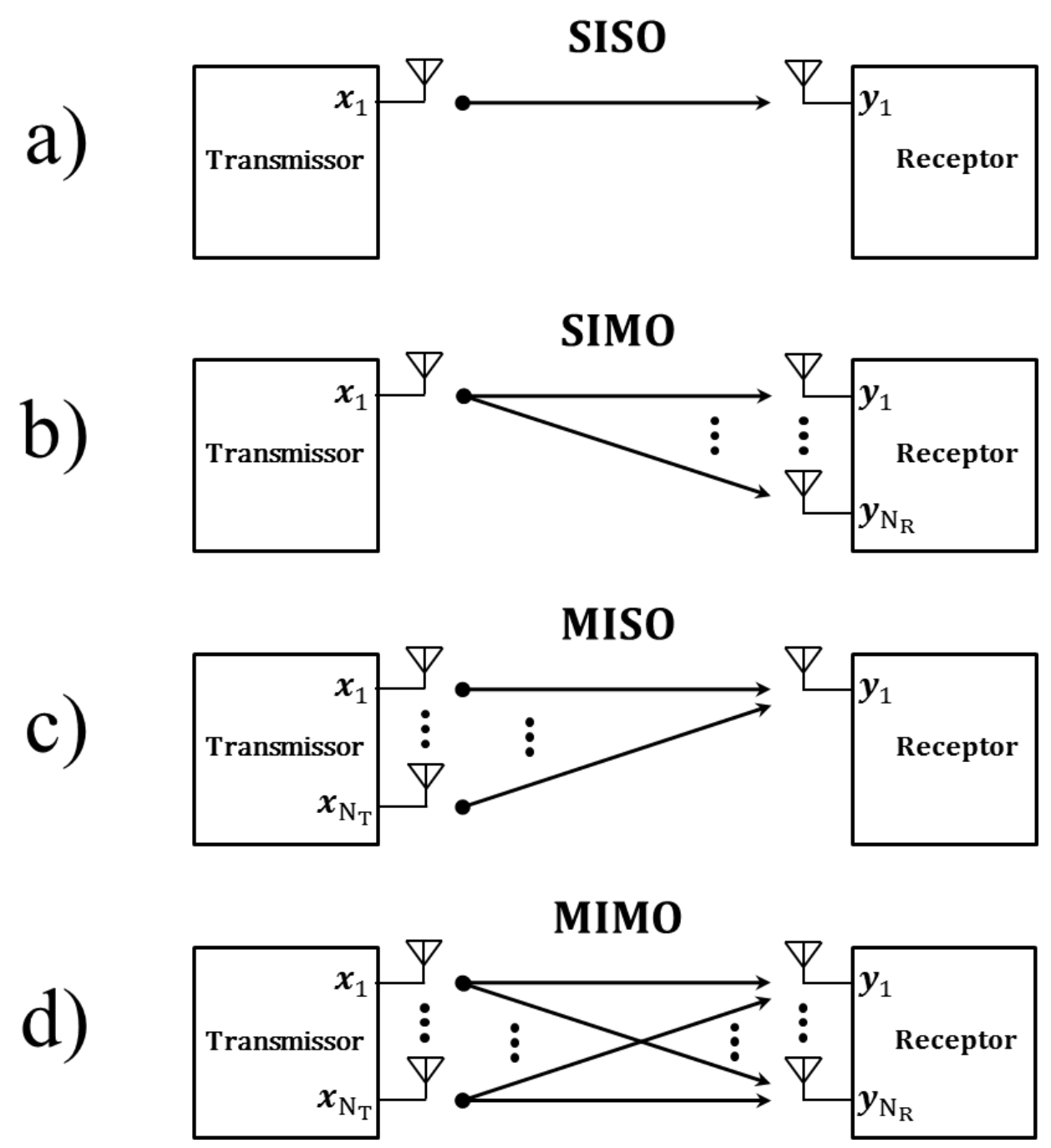

Figura 2.1 - Classificação quanto às antenas a) SISO b) SIMO c) MISO d) MIMO 
As técnicas de diversidade são empregadas para tornar os sistemas mais robustos e confiáveis por meio da minimização das variações do canal devido ao desvanecimento e são muito usadas quando não se tem conhecimento dos canais e os desvanecimentos entre os elementos são independentes. Essas técnicas exploram características dos canais de transmissão ao invés de tentar mitigá-las.

Diversidade tem como base o emprego da redundância, na qual a mesma informação é repetida e enviada em outros domínios, sendo as técnicas mais usuais em sistemas de comunicações móveis as do tipo temporal, de frequência e espacial.

A diversidade temporal pode ser obtida por meio da codificação e entrelaçamento, na qual a informação é codificada em símbolos e dispersada no domínio do tempo em diferentes períodos de coerência. Assim, diferentes partes dos símbolos estarão sujeitos a desvanecimentos independentes ao longo do tempo.

Na diversidade de frequência a sequência de bits é fracionada e transmitida em diferentes canais no espectro. Desta forma, somente partes da informação estarão sujeitas ao desvanecimento seletivo em frequência, já que diferentes portadoras sofrerão desvanecimentos distintos.

$\mathrm{Na}$ diversidade espacial múltiplas antenas de transmissão e/ou de recepção garantem que réplicas da mesma informação percorram caminhos diferentes, proporcionando cópias descorrelatadas da informação no receptor, reduzindo assim a probabilidade de que sinal resultante sofra desvanecimento profundo.

As diversidades também podem ser classificadas de acordo com sua implementação, se estão no lado do transmissor ou do receptor.

A diversidade de transmissão, como ilustrado na Figura 2.1c, se caracteriza pelo envio de múltiplos sinais independentes com a mesma informação por meio de diferentes canais de comunicação descorrelatados. Com isso, a probabilidade que esses sinais simultaneamente sofram desvanecimento profundo é significantemente reduzida $[23][24][25]$.

A diversidade de recepção se caracteriza pela recepção de várias cópias do mesmo sinal, como ilustrado na Figura 2.1b, o que faz com que, assim como na diversidade de transmissão, seja reduzida a probabilidade que simultaneamente ocorra o desvanecimento 
profundo. Os domínios em que essa diversidade pode ocorrer são, por exemplo, espaço, tempo, frequência, polarização ou código.

A utilização de múltiplas antenas também habilita o uso da multiplexação espacial, além da diversidade especial, e tal uso permite o aumento das taxas atingíveis pelo sistema.

Caso a multiplexação espacial seja empregada em conjunto com a diversidade espacial, é possível que o sistema tenha seu desempenho melhorado sem redução das taxas, ou ainda que haja um aumento simultâneo de confiabilidade e de taxas alcançáveis.

As técnicas de transmissão de sistemas convencionais de antena única, tanto na transmissão quanto na recepção, são sistemas simples e não apresentam nenhum ganho de diversidade ou multiplexação espacial. O seu desempenho também é limitado, pois a simplicidade se reflete na suscetibilidade a desvanecimentos e interferências, e também a capacidade é restrita ao limite de capacidade do canal, dada pelo teorema de Shannon

$$
C=B \cdot \log _{2}\left(1+\frac{S}{N}\right)
$$

onde $C$ é a capacidade máxima do canal em bits $/ s, B$ é a largura de banda, $S$ é a potência do sinal e $N$ é a potência do ruído.

A partir da Equação 2.1 e valendo-se de parâmetros típicos de um sistema SISO de redes long-term evolution (LTE) que, por exemplo, faça uso de um canal de $20 \mathrm{MHz}$ e possua uma relação sinal ruído de $10 \mathrm{~dB}$, poderá atingir uma taxa máxima de 69,19 Mbits/s.

Os sistemas SISO fazem uso de técnicas baseadas no domínio do tempo e/ou da frequência e por vezes também de codificação de canal para se compensar os efeitos dos múltiplos percursos.

Em sistemas com diversas antenas, o domínio espacial também é explorado, pois a existência dessas múltiplas antenas se reflete em correspondentes canais de comunicação.

Os sistemas SIMO, que possuem mais de uma antena receptora, fazem uso da diversidade de recepção, tais como as técnicas de switched combining, de selection combining ou a maximal-ratio combining (MRC). 
Contudo, em sistemas do tipo MISO, a existência de mais antenas de transmissão permite que, com a adoção de redundância e codificação na transmissão, o processamento requerido seja transferido do receptor para o transmissor.

Por sua vez, em sistemas MIMO a utilização de múltiplas antenas permite a obtenção de diversos ganhos, tais como: o de multiplexação (que permite obter taxas de dados mais elevadas), o de diversidade (que melhora o desempenho de taxa de erro de bit, ou bit error rate (BER)), ou o de antena, também conhecido como ganho de arranjo (que melhora a relação sinal ruído, ou signal-to-noise ratio (SNR)).

Assim, esses ganhos de diversidade obtidos a partir do emprego de múltiplas antenas permitem que os enlaces sejam menos suscetíveis às variações dos canais. Em contrapartida, o uso de múltiplas antenas também permite o emprego da multiplexação espacial, que difere da diversidade espacial no fato de que cada antena transmite sequências distintas de informação, fazendo com que seja possível alcançar taxas mais altas sem aumento da largura de banda utilizada.

Maiores detalhes sobre a diversidade espacial e multiplexação espacial, incluindo a implementação conjunta das técnicas, bem como MIMO e MIMO massivo são apresentados nos itens subsequentes.

\section{2 - DIVERSIDADE ESPACIAL}

A diversidade espacial é um tipo de diversidade de antena na qual múltiplas antenas transmitem a mesma informação, no caso da diversidade de transmissão, ou em que cópias de uma mesma informação chegam às várias antenas receptoras, no caso da diversidade de recepção. Como exemplo de diversidade na transmissão estão os métodos de Alamouti [26] [27] e códigos espaço-temporais de treliça [27]. Como exemplo de diversidade na recepção, tem-se as técnicas citadas anteriormente para o SIMO e o equalgain combining (EGC).

Essas várias réplicas transmitidas ou recebidas são sequências de bits idênticas que percorrem trajetos distintos e independentes, o que faz com que estejam sujeitas a diferentes tipos de desvanecimentos. Desta forma, essa multiplicidade de réplicas da 
informação permite que o sinal seja melhor estimado no receptor, resultando na redução da taxa de erro do sistema.

Outra vantagem da diversidade espacial em relação à codificação de canal convencional é que a redundância adicionada pelo código nos sistemas tradicionais pode ser acomodada no domínio espacial, em vez do domínio temporal.

O ganho de diversidade é o ganho obtido com a implementação da diversidade em relação a um sistema sem a mesma. Como há o aumento de cópias independentes do sinal, aumenta também a probabilidade de que sinais não sofram desvanecimento profundo, melhorando assim a confiabilidade do sistema.

Com relação ao ganho de diversidade de um sistema de comunicação, pode-se dizer que este depende do número de antenas de transmissão e de recepção, e que corresponde no máximo ao número de canais existentes no sistema, sendo equivalente ao número de combinações de enlaces entre as antenas transmissoras e as receptoras, da forma que [28]

$$
d=N_{\mathrm{T}} \cdot N_{\mathrm{R}},
$$

onde $d$ é o ganho de diversidade do sistema, $N_{\mathrm{T}}$ é o total de antenas transmissoras e $N_{\mathrm{R}}$ é o total de antenas receptoras.

Na diversidade espacial, como os diversos sinais transmitidos ou recebidos são réplicas da sequência de bits da informação original, a implementação simultânea dessa diversidade e a multiplexação espacial permite que a redundância inserida ao sistema seja compensada.

A abordagem da capacidade de sistemas de múltiplas antenas é apresentada na Seção 2.4 .

\section{3 - MULTIPLEXAÇÃO ESPACIAL}

Multiplexação espacial é a técnica na qual diversas sequências distintas de informação são transmitidas por cada antena com o objetivo de aumentar a taxa de dados do sistema. 
Esta técnica permite o aumento da eficiência espectral do sistema, visto que são estabelecidos enlaces independentes com tráfego de informações distintas em canais na mesma faixa de frequências.

O uso de alguma técnica de multiplexação implica em um ganho de multiplexação, se comparado com o mesmo sistema sem sua implementação. Este ganho depende da correlação entre os canais, ou seja, quanto menor o correlacionamento, maior será a taxa atingível.

Na multiplexação espacial, considerando o ambiente de propagação sem linha de visada, ou non-line-of-sight (NLOS), é desejado que os canais de transmissão sejam independentes e identicamente distribuídos, ou independent and identically distributed (i.i.d.), porém, é sabido que em sistemas de múltiplas antenas, devido à proximidade entre as antenas do arranjo, a correlação entre os elementos é alta, fazendo com que os vários canais também possuam grande correlação. Em virtude disso, nem toda a capacidade máxima do canal pode ser atingida.

Em ambientes ricos em espalhamento a capacidade atingível do sistema depende do grau de liberdade do sistema, que é dado por [28]

$$
d_{f}=\min \left(N_{\mathrm{T}}, N_{\mathrm{R}}\right),
$$

onde $d_{f}$ é o grau de liberdade, $N_{\mathrm{T}}$ é o total de antenas transmissoras e $N_{\mathrm{R}}$ é o total de antenas receptoras.

Segundo [29] a capacidade de um sistema cresce linearmente com o aumento do número de antenas transmissoras, desde que tenham número equivalente de antenas receptoras, como mostrado na Equação 2.3. Esta condição se aplica aos sistemas MIMO e é abordada na Seção 2.4 .

Além do aumento de capacidade proporcionado pelo emprego da multiplexação espacial, os sistemas MIMO, por possuírem várias antenas na transmissão e na recepção, permitem implementação concomitante de diversidade espacial e multiplexação espacial. Para tal, é necessário estabelecer o balanceamento destas técnicas.

O compromisso, ou trade-off, entre aumento de confiabilidade e de taxa de transferência pode ser tal que, o máximo de uma técnica resulta em mínimo da outra. Este 
compromisso também pode ser balanceado com a utilização de códigos espaço-temporais, tais como o código de Alamouti.

\section{4 - MIMO}

Em sistemas de comunicação deseja-se que os enlaces tenham um desempenho adequado a altas taxas de dados, porém, devido às características dos canais sem fio em radiofrequências, principalmente causados pela propagação dos sinais por múltiplos percursos e também pelos efeitos de desvanecimento, os desafios são grandes para obtenção de alta eficiência espectral e energética.

O MIMO é uma técnica que auxilia na obtenção de altas taxas de dados e baixas taxas de erro, já que possibilita a existência de múltiplas antenas no transmissor e no receptor. Conforme explanado previamente, esta característica permite o emprego da multiplexação espacial, que se caracteriza pelo envio simultâneo de sequências distintas. Por causa disso, pode-se obter uma taxa proporcional ao número de antenas de transmissão, quando comparada a um sistema SISO, sem aumento de largura banda de frequências [29].

Esse ganho de multiplexação espacial possibilita uma maior eficiência espectral, pois faz o uso de outra dimensão, o espaço, uma vez que cada antena transmite sequências de bits distintas e independentes na mesma faixa de frequências.

A eficiência espectral é dada por

$$
\eta=\frac{R}{B}
$$

onde $\eta$ é a eficiência espectral em $\frac{\text { bits } / s}{H z}, R$ é a taxa de dados em bits $/ s$ e $B$ é a largura de banda em $\mathrm{Hz}$.

Assim, o aumento da capacidade deste tipo de sistema é limitado ao grau de liberdade do sistema, ou seja, o menor valor entre número total de antenas de transmissão ou de recepção, assim como mostrado na Equação 2.3. 
Consequentemente, o limite de capacidade de um sistema MIMO é proporcional ao grau de liberdade do sistema, sendo dado por

$$
C=B \sum_{i=1}^{d_{f}} \log _{2}\left(1+\frac{S_{i}}{N_{i}}\right)
$$

onde $C$ é a capacidade máxima do canal, $B$ é a largura de banda, $d_{f}$ é o grau de liberdade do sistema, $S$ é a potência do sinal e $N$ é a potência do ruído.

Em comparação ao sistema SISO cuja taxa máxima foi calculada na Seção 2.1, um sistema MIMO na configuração $4 \times 4$ com os mesmos parâmetros, apresenta taxa máxima quatro vezes maior que a taxa do sistema de antenas singulares, resultando em 276,75 Mbits/s.

A eficiência espectral do sistema SISO exemplificado na Seção 2.1, típico de um sistema LTE, com um canal de $20 \mathrm{MHz}$ e taxa máxima de 69,19 Mbits/s, de acordo com a Equação 2.4, é de 3,46 $\frac{\mathrm{bits} / \mathrm{s}}{\mathrm{Hz}}$. Já o sistema MIMO na configuração $4 \times 4$ exemplificado acima, a eficiência espectral será, conforme esperado, quatro vezes maior, ou seja, $13,84 \frac{\mathrm{bits} / \mathrm{s}}{\mathrm{Hz}}$.

Apesar de saber que tais taxas não são obtidas em condições reais, devido à existência de desvanecimentos e interferências de demais usuários, entre outros, é possível vislumbrar o aumento de eficiência do sistema.

Com o emprego de múltiplas antenas a combinação entre capacidade e confiabilidade determina o compromisso do sistema, podendo favorecer o aumento da taxa de dados ou redução da taxa de erros, conforme explicado nos itens anteriores. Com relação ao aumento de confiabilidade, o MIMO permite o uso de diversidade de transmissão e recepção. Já o aumento da taxa é propiciado pelo emprego da multiplexação espacial.

Os sistemas MIMO podem ser divididos em três categorias [30]: os que fazem uso da codificação espaço-temporal e obtém ganho de diversidade, tal como o código de Alamouti; os sistemas que têm conhecimento do canal no lado de transmissão e fazem uso da decomposição em valores singulares para obter ganho de capacidade; e os que fazem 
uso da multiplexação espacial e obtém aumento da taxa de dados sem, necessariamente, diversidade na transmissão, tal como o método BLAST.

Uma forma de potencializar essa eficiência é aumentando-se o ganho de escala, ou seja, aumentando o número de antenas. Uma técnica que permite isso, e é extensão do MIMO, é o MIMO massivo, apresentado na próxima seção.

\section{5 - MIMO MASSIVO}

O MIMO massivo, também referido na literatura como full dimension MIMO ou large-scale MIMO (LS-MIMO), se difere da tecnologia MIMO pela grande quantidade de antenas, que é da ordem de dezenas ou centenas de elementos.

O MIMO massivo, assim como as tecnologias de small cells, são estudadas como potenciais esquemas que permitem atender aos requisitos de eficiência espectral e energética considerados para a $5^{\mathrm{a}}$ geração de redes celulares.

Esta tecnologia amplia as vantagens do MIMO, tais como o aumento das taxas de dados, aumento de confiabilidade, aumento de eficiência energética, redução de interferências, e se destaca pela maior eficiência espectral, resultando em melhor uso do espectro, que é um recurso escasso.

A grande quantidade de antenas também possibilita a redução da potência transmitida pelo uso do beamforming, que permite auxiliar na redução de interferências e também comportar mais usuários por células. De forma geral, a técnica do beamforming equivale a um filtro no domínio espacial, uma vez que realiza uma seletividade espacial.

Nesta tecnologia, com um número ainda maior de antenas do lado transmissor e receptor, haverá um maior grau de liberdade, e mais canais de propagação podem ser estabelecidos, permitindo aumento de confiabilidade e de desempenho do sistema.

Em contraste ao ganho proporcionado pela utilização do MIMO massivo, a complexidade de detecção do sistema também aumenta e cresce exponencialmente com o número de antenas transmissoras [31]. Assim, em equipamentos de usuário, que têm recursos limitados, esta complexidade pode resultar na restrição da capacidade de 
processamento, na limitação do número de antenas ou no aumento de consumo de energia, por exemplo.

Com relação às taxas de dados, considerando o sistema utilizado nas simulações do fronthaul deste trabalho, um sistema MIMO massivo com 25 antenas, a taxa máxima e a eficiência espectral, em condições ideais, seria 25 vezes maior que a de um sistema SISO com iguais parâmetros.

Tal configuração, assim como utilizada nas simulações dos capítulos posteriores, poderia atingir uma taxa máxima de $1,73 \mathrm{Gbits} / \mathrm{s}$ e eficiência espectral máxima de $86,49 \frac{\mathrm{bits} / \mathrm{s}}{\mathrm{Hz}}$, caso seja empregada multiplexação espacial em condições ideais.

Se não for considerado o tráfego de controle das BSs, mas somente a carga útil de dados de usuários, os enlaces de fronthaul encontrariam-se saturados com o tráfego de alguns poucos usuários.

Esta técnica tem grandes benefícios, mas também conta com grandes desafios tal como a necessidade de conhecimento do canal de transmissão. Uma vez que a quantidade de antenas e canais é grande, também há a necessidade de uso constante de recursos de rede para realimentação de medidas realizadas no outro lado do canal.

Uma alternativa para esta situação, segundo [32], é explorar a reciprocidade de canal de sistemas time division duplex (TDD). Assim, as medidas do canal de uplink fornecem informações sobre o canal de downlink.

O MIMO massivo tem características de implantação semelhantes às do MIMO, porém em uma escala maior e, apesar de apresentar as vantagens anteriormente listadas, apresenta desvantagens como: o fato de necessitar de mais espaço para o arranjo de antenas, principalmente nas estações base, que possuem um número maior de antenas; a complexidade de hardware; e o aumento do consumo de energia. 


\section{6 - CLOUD-RADIO ACCESS NETWORK}

A cloud-radio access network (cloud-RAN ou C-RAN), algumas vezes chamada de centralized-RAN, é um tipo de arquitetura na qual parte de recursos de rede são virtualizados e centralizados, de forma semelhante a aplicações de computação em nuvem.

Numa estação base com arquitetura com cabeças de rádio remotas, ou remote radio heads (RRHs), a estação é dividida entre a unidade de rádio e a unidade de processamento de sinal. A unidade de rádio é conhecida como RRH ou como unidades de banda base, remote radio unit (RRU).

Na C-RAN, a estrutura tradicional das estações base é dissociada, de forma que as RRHs continuam nas estações base, distribuídas na região de cobertura de RF. Já as BBUs, que são os elementos de processamento de sinal de banda base, são virtualizadas e agrupadas em algum ponto centralizado da rede, conforme ilustrado na Figura 2.2.

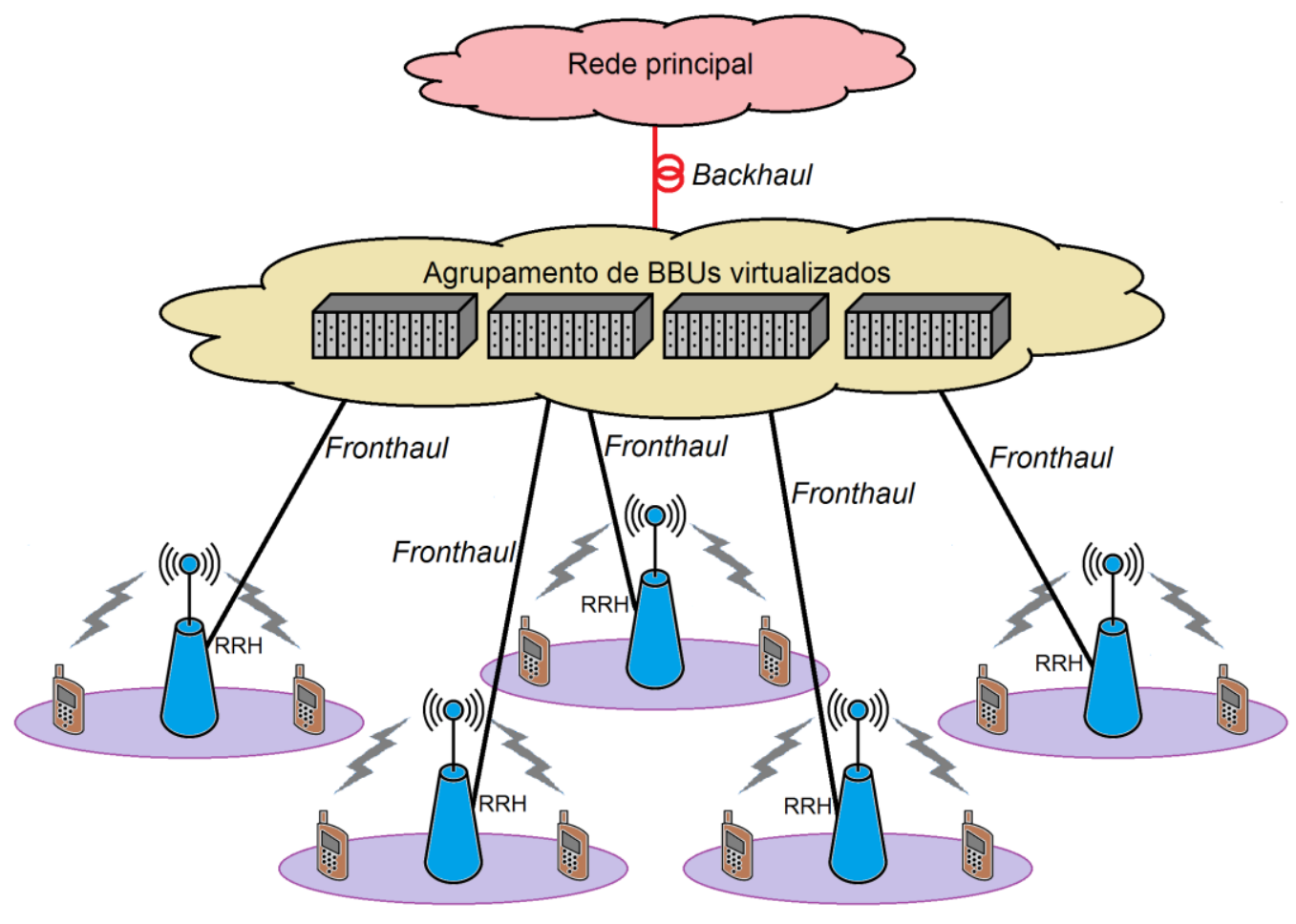

Figura 2.2 - Topologia de uma rede C-RAN

Uma das vantagens do agrupamento, virtualização e compartilhamento das BBUs é que o processamento pode ser realizado de forma colaborativa em grande escala, otimizando os recursos alocados para toda a rede. 
Esse arranjo de BBUs em nuvem se comunica com as RRHs por meio de protocolos específicos, tais como o common public radio interface (CPRI), o open base station architecture initiative (OBSAI) ou o open radio interface (ORI), e garante a transmissão dos componentes dos sinais em fase e em quadratura (I/Q), controle e sincronismo às unidades de rádio [33].

Como as RRHs somente possuem interfaces de RF e o processamento é centralizado nos arranjos de BBUs virtuais, nas C-RANs, a atualização da rede para novos padrões é simplificada, já que não há necessidade de atualização de hardware nas estações base, sendo necessária somente atualização de software nas BBUs centralizadas [34].

O emprego desta arquitetura permite a redução de espaço e consumo de energia, em relação à estrutura convencional. Além disso, a manutenção necessária nas estações é significantemente menor. Segundo [34] o CAPEX por $\mathrm{km}^{2}$ de área de cobertura é de $10 \mathrm{a}$ $15 \%$ menor que redes tradicionais LTE.

Conforme estudo da China Mobile Research Institute [35] a C-RAN pode reduzir significativamente as despesas de implantação e operação da rede, diminuindo o CAPEX em 30\% e o OPEX em 53\%, quando comparado à implantação de novas células em redes do tipo time division synchronous code division multiple access (TD-SCDMA).

Os benefícios proporcionados pelas redes C-RANs também podem ser obtidos nos sistemas MIMO distribuídos, porque possuem semelhanças neste tipo de arquitetura centralizada (os painéis de antenas são distribuídos dentro da área de cobertura e o processamento é centralizado em algum ponto da rede).

Os detalhes do MIMO massivo distribuído são apresentados na seção subsequente.

\section{7 - MIMO MASSIVO DISTRIBUÍDO}

A topologia de um sistema MIMO massivo distribuído, algumas vezes referido como sistema de antenas distribuídas, ou distributed antenna system (DAS), é similar aos sistemas distribuídos convencionais, ou seja, em vez de ter um único elemento central em cada célula, existem vários elementos geograficamente distribuídos em cada célula. 
Estes elementos são arranjos de antenas que podem ser, por exemplo, do tipo linear, retangular, cilíndrico ou esférico, como ilustrado na Figura 2.3. Tais arranjos de antenas também são conectados a uma estação base central, conforme ilustrado.

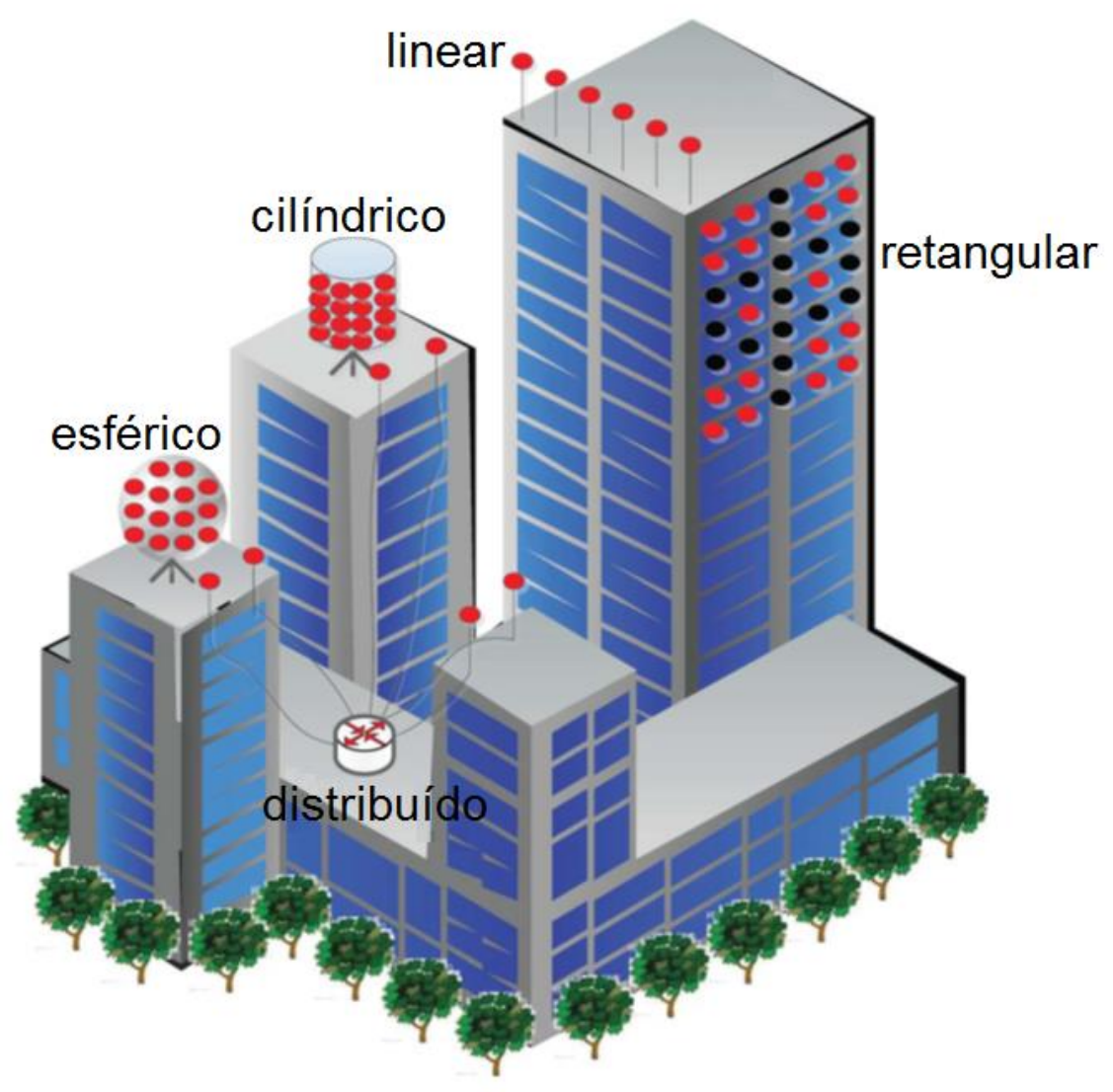

Figura 2.3 - Tipos de arranjos de antenas (adaptado de [36])

Estes arranjos de antenas devem ser suficientemente separados para que haja desvanecimentos de larga escala independentes em cada enlace, entre os equipamentos de usuários e os arranjos de antenas.

Um sistema com esta topologia permite que, com uma menor distância entre UEs e arranjos de antenas, a cobertura seja mais uniforme, que as potências de transmissão nos uplinks e downlinks sejam menores e que a capacidade de tráfego de dados oferecida aos usuários também seja maior. 
Sistemas MIMO massivo distribuídos e small cells são tecnologias que competem no que diz a respeito de densificação de rede. No MIMO massivo distribuído a implantação centralizada é mais barata [13] e é realizada pelas operadoras de telecomunicações. Por sua vez, as redes de small cells são geralmente instaladas pelos assinantes para melhorar a cobertura e capacidade em áreas residenciais [13]. 


\section{3 - CONCEITUAÇÃO DO SISTEMA}

\section{1 - INTRODUÇÃO}

Esta pesquisa tem como objetivo estudar o desempenho de técnicas de redução de dimensões em uplinks de sistemas MIMO massivo distribuído que possuam enlaces de fronthaul com limitações de banda.

Devido às limitações de capacidade no fronthaul, os enlaces podem não ser capazes de transmitir as informações de todas as antenas para a unidade central de processamento. Por esta razão, se for realizada uma compressão em cada painel antes do envio à unidade centralizada, haveria uma significativa redução do tráfego de dados.

Neste contexto, alguns autores propuseram diferentes técnicas de compressão, como, por exemplo, o uso da compressão distribuída com perdas Wyner-Ziv [37] [38] para lidar com ofronthaul com restrições de capacidade.

Neste trabalho é proposta a utilização de duas técnicas lineares, a transformada de Karhunen-Loève e a transformada discreta de cossenos. Ambas realizam uma transformação de domínios da matriz, e depois é realizada uma seleção de um pequeno número de componentes, reduzindo a quantidade de informação a ser transmitida pelos enlaces de fronthaul.

A KLT baseia-se nas matrizes de covariância de longo prazo das antenas, as quais separam o sinal em componentes descorrelatados. Outras técnicas de transformação equivalentes à KLT são encontradas na literatura [39], tais como a decomposição em valores singulares e análise de componentes principais. Apesar de possuírem nomenclaturas diferentes, são técnicas equivalentes. Neste trabalho será adotado o termo transformada de Karhunen-Loève, para se referir a este grupo de transformação.

A transformada discreta de cossenos, por sua vez, não se enquadra neste grupo e será tratada individualmente na Seção 3.5. 


\section{2 - FRONTHAUL}

Este trabalho, cujo cerne são os enlaces de uplink do fronthaul com limitações de banda, apresenta estudos que possibilitam a redução das taxas de dados, sem grandes perdas de desempenho no sistema, e que podem ser aplicados em enlaces que possuem restrições de banda.

A definição de fronthaul é a de qualquer conexão de rede entre o remote radio head, e as base band units [40] [41], ou então entre a remote radio unit (RRU) e a BBU [42], assim como mostrado na Figura 3.1. O termo backhaul refere-se a quaisquer conexões de rede entre as estações de base e a rede principal [40] [41], ou core network, conforme ilustrado também na Figura 3.1.

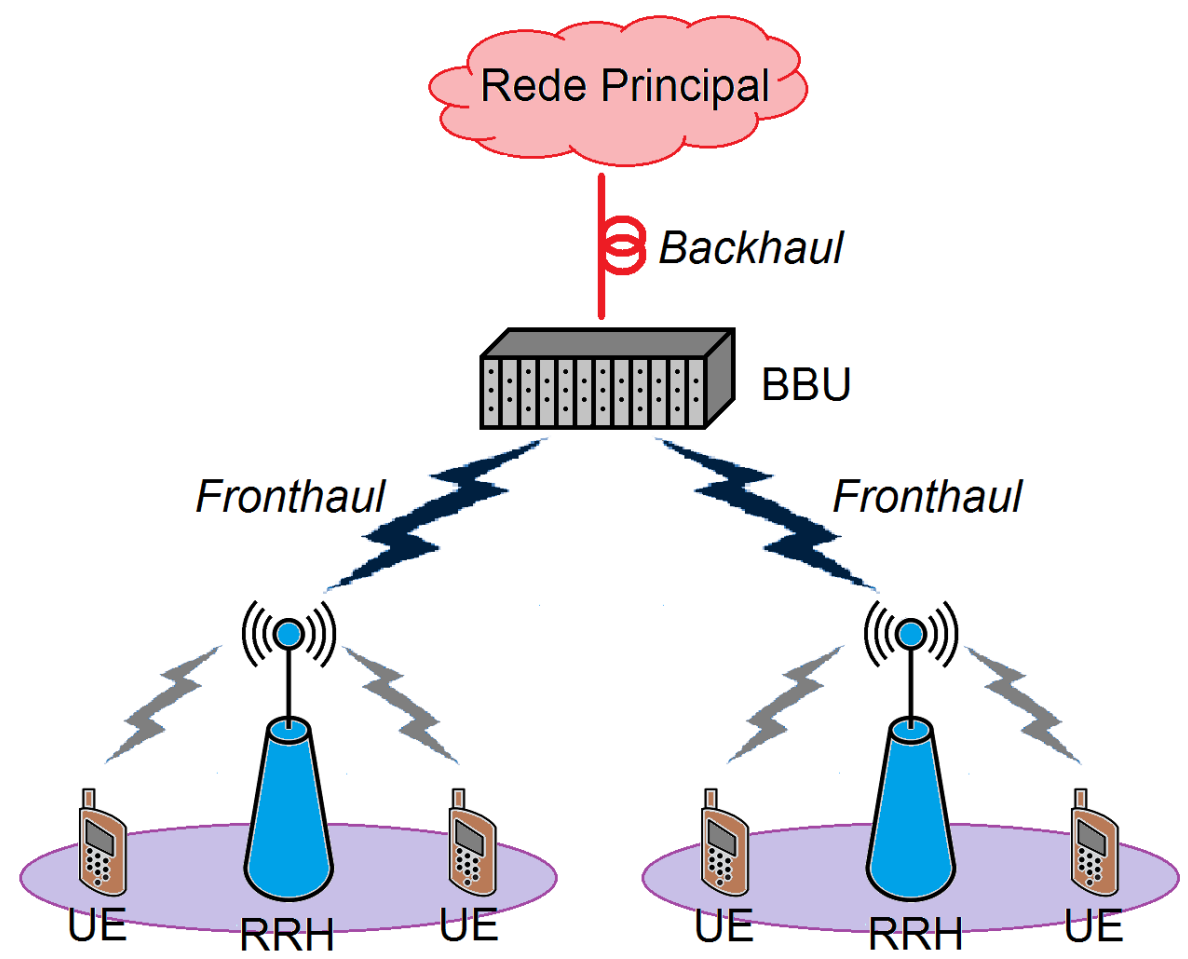

Figura 3.1 - Enlaces de fronthaul e backhaul

Esses enlaces de fronthaul podem ser cabeados ou sem fio, podendo ser implementados com fibras ópticas, radiofrequência ou free-space optics (FSO), por exemplo. 


\section{3 - TRANSFORMADA DE KARHUNEN-LOÈVE}

Métodos de transformação, ou transformadas, são usados para a redução da complexidade de problemas matemáticos. Por exemplo, equações diferenciais e integrais podem ser transformadas em equações algébricas cujas soluções são resolvidas mais facilmente [21].

Os métodos de transformação são muito usados em várias áreas de aplicação de processamento digital de sinais, tais como em técnicas de compressão de imagens, pois proporcionam um domínio no qual os dados são mais apropriados à quantização e codificação [43].

Existem várias técnicas com o propósito de descorrelacionar, ou ortogonalizar, os sinais. Cada uma realiza um tipo de processamento e tem aplicações distintas.

A transformada de Karhunen-Loève ${ }^{4}$ é um método de transformação linear nominada em homenagem a Kari Karhunen [44] e Michel Loève [45], que publicaram artigos desenvolvidos de forma independente, é uma transformada que diagonaliza a matriz de correlação de qualquer sinal [21], ou seja, que descorrelaciona os sinais. Outro método, a análise de componentes principais, ou principal component analysis (PCA), de Harold Hotelling [46], foi publicada antes e também é uma abordagem equivalente à KLT.

A decomposição é obtida pela transformação do conjunto de dados original em um novo conjunto com componentes descorrelatados. Estes valores são então organizados em ordem decrescente de energia.

Após a transformação linear, na etapa de redução de dimensões, é selecionado um discreto número de componentes que possuam mais energia. Esses primeiros valores conterão a maior parte da variação presente em todos os valores originais [47].

A KLT é uma representação de séries de um sinal aleatório cuja base de funções ortogonais é obtida como autovetores da matriz de autocorrelação correspondente [21].

${ }^{4}$ A transformada de Karhunen-Loève também é conhecida por outro nome mais genérico, decomposição em valores singulares, ou singular value decomposition (SVD), porém neste estudo será referida apenas como transformada de Karhunen-Loève, sem que haja prejuízo no entendimento. 
Baseado na diagonalização da matriz de correlação, a KLT é a transformada estatisticamente ótima [21], pois:

1. descorrelaciona completamente o sinal no domínio da transformada;

2. minimiza o erro quadrático médio, ou mean square error (MSE), na redução de largura de banda ou compressão de dados;

3. contém a maior variância, ou seja, energia, no menor número de coeficientes de transformada; e

4. minimiza a entropia total de uma sequência de dados.

Para reduzir o número de dados, os coeficientes devem ser reduzidos, incorrendo em alguma perda irreversível. Se o conjunto de dados for descorrelatado, ao se utilizar a KLT, uma maior compactação de dados será alcançada [48].

\section{4 - DECOMPOSIÇÃO EM VALORES SINGULARES}

A definição da decomposição em valores singulares da matriz $\boldsymbol{A} \in \mathbb{C}^{M \times N}$, segundo [49], é a fatorização

$$
\boldsymbol{A}=\boldsymbol{U} \boldsymbol{\Sigma} \boldsymbol{V}^{\mathrm{H}},
$$

onde $\boldsymbol{A}$ é uma matriz com dimensões $M \times N, \boldsymbol{U}$ é uma matriz com dimensões $M \times M, \boldsymbol{\Sigma}$ é uma matriz diagonal e $\boldsymbol{V}$ é um vetor unitário com dimensões $N \times N$.

Os vetores singulares $\boldsymbol{u}_{i}$ são obtidos como os autovetores de $\boldsymbol{A} \boldsymbol{A}^{\mathrm{H}}$ [50], e a matriz $\boldsymbol{U}$ é conhecida como matriz de vetores singulares à esquerda da matriz $\boldsymbol{A}$, e suas colunas são os vetores à esquerda de $\boldsymbol{A}$, da forma que

$$
\boldsymbol{U}=\left[\boldsymbol{u}_{1}, \boldsymbol{u}_{2}, \cdots, \boldsymbol{u}_{M}\right]
$$

A matriz $\boldsymbol{\Sigma}$, cujos valores da diagonal são conhecidos como os valores singulares de $\boldsymbol{A}$, é definida como

$$
\boldsymbol{\Sigma}=\operatorname{diag}\left(\sigma_{1} \geq \sigma_{2} \geq \cdots \geq \sigma_{p}\right),
$$

onde $p$ é o menor valor entre $M$ e $N$ e $\operatorname{diag}(\cdot)$ é a diagonal com $p$ dimensões. 
Os autovalores componentes da matriz $\boldsymbol{\Sigma}$ devem ser dispostos em ordem decrescente pelo posto da matriz, ou rank da matriz, e o número de elementos dessa matriz diagonal é dado por

$$
p=\min (M, N),
$$

onde $\min (\cdot)$ é o valor mínimo.

Os autovalores $\sigma_{i}$ são obtidos a partir da raiz quadrada dos autovalores não nulos de $\boldsymbol{A} \boldsymbol{A}^{\mathrm{H}}$ e $\boldsymbol{A}^{\mathrm{H}} \boldsymbol{A}[50]$.

A matriz diagonal $\boldsymbol{\Sigma}$ também pode ser representada como

$$
\boldsymbol{\Sigma}=\boldsymbol{U}^{\mathrm{H}} \boldsymbol{A} \boldsymbol{V}
$$

Os vetores singulares $\boldsymbol{v}_{i}$ são obtidos como os autovetores de $\boldsymbol{A}^{\mathrm{H}} \boldsymbol{A}$ [50]. A matriz $\boldsymbol{V}$ é conhecida como vetores singulares à direita da matriz $\boldsymbol{A}$, e suas colunas são os vetores à direita de $\boldsymbol{A}$, da forma que

$$
\boldsymbol{V}=\left[\boldsymbol{v}_{1}, \boldsymbol{v}_{2}, \cdots, \boldsymbol{v}_{N}\right]
$$

\section{5 - TRANSFORMADA DISCRETA DE COSSENOS}

As DCTs são transformadas trigonométricas discretas e a família de transformadas de cossenos pertence à classe de transformadas unitárias senoidais, que são transformadas lineares que possuem inversa e cujo núcleo descreve um conjunto completo de funções base ortogonais discretas de senos e/ou cossenos. Todas DCTs são transformadas separáveis e multidimensionais que podem ser decompostas em sucessivas transformadas unidimensionais.

Essa família de transformações trigonométricas discretas consiste em 8 versões de DCTs, sendo que as do tipo II, ou discrete cosine transform type-II (DCT-II), e tipo III (DCT-III) são muito empregadas em processamento digital de sinais e imagens, assim como em sistemas de codificação, compressão e descompressão de dados.

A transformada DCT-II tem como inversa a transformada DCT-III e ambas têm como propriedade a excelente compactação de energia, dentre as atuais transformadas unitárias, além de ser a melhor aproximação da KLT [21]. 
Por serem ortogonais e separáveis, suas propriedades são relevantes para a compressão de dados e na implementação de algoritmos rápidos. As aplicações das DCTs incluem, por exemplo, a codificação de áudio dos padrões MPEG-1 e MPEG-2 e a compressão de imagens do padrão JPEG.

A transformada discreta de cossenos tipo II é definida como [48]

$$
\left(C_{N}^{I I}\right)_{j k}=\sqrt{\frac{2}{N}} \sigma_{k} \cos \left[\left(j+\frac{1}{2}\right) \frac{k \pi}{N}\right]
$$

onde $j, k=0,1, \cdots, N-1, j$ é o $j$-ésimo componente do $k$-ésimo vetor base, e $N$ é a dimensão do matriz.

Uma das principais características desejáveis das DCTs é sua rápida execução computacional. Dentre a família das DCTs, o desempenho da DCT-II se aproxima da KLT [21], que é a transformada estatisticamente ótima, no descorrelacionamento de um sinal. A importância da DCT-II é acentuada por sua superioridade de compressão, ou seja, redução de redundância. 


\section{4 - CARACTERIZAÇÃO DO MODELO UTILIZADO}

\section{1 - MODELO DE CANAL MIMO}

MIMO e MIMO massivo, conforme abordagem prévia, são sistemas compostos por múltiplas antenas no transmissor e no receptor. Neste trabalho foram considerados ambientes ricos em espalhamento, ou seja, cenário tipicamente urbano e composto por muitas edificações.

O sinal recebido, representado pelo vetor $\boldsymbol{y}$, pode então ser descrito pelo produto da matriz de ganhos de canal pelo vetor do sinal transmitido, somado ao vetor do ruído gaussiano branco aditivo, ou additive white gaussian noise (AWGN), que é intrínseco aos sistemas de comunicação, da forma

$$
\boldsymbol{y}=\boldsymbol{H} \boldsymbol{x}+\boldsymbol{n},
$$

onde $\boldsymbol{y}$ é o vetor do sinal recebido, $\boldsymbol{H}$ é a matriz de ganhos de canal, $\boldsymbol{x}$ é o vetor do sinal transmitido e $\boldsymbol{n}$ é o vetor do AWGN.

A representação do modelo de canais MIMO considerado neste trabalho é ilustrada na Figura 4.1 e nela devem ser contemplados todos os canais de transmissão existentes entre cada antena transmissora e receptora, assim como deve ser considerado o ruído gaussiano branco aditivo em cada sinal recebido.

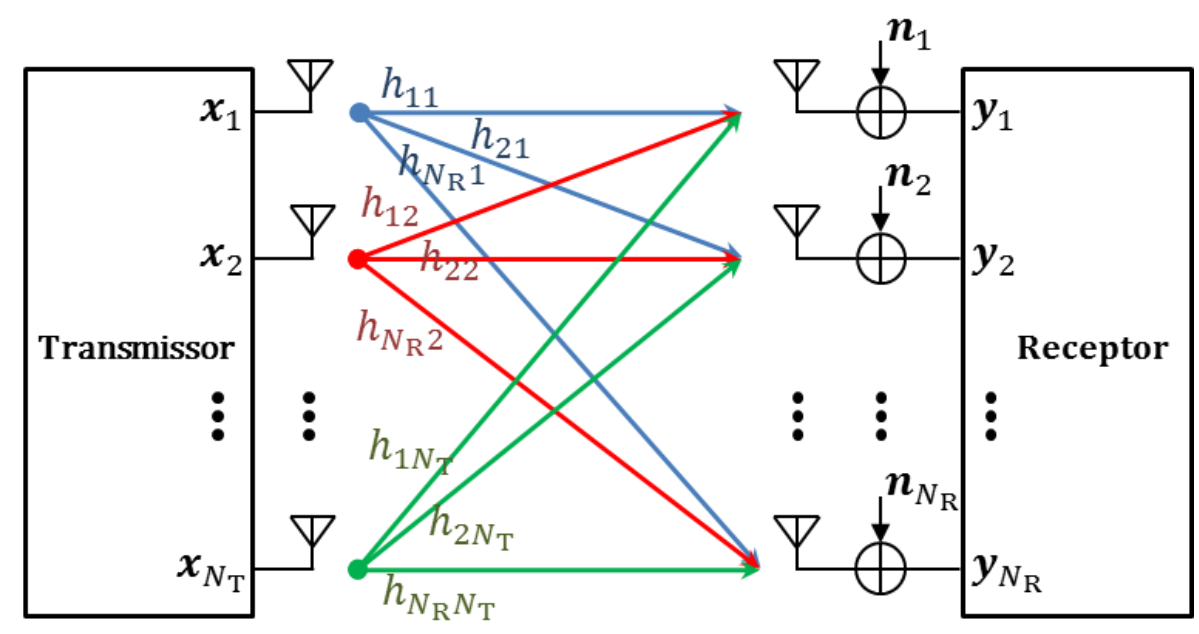

Figura 4.1 - Representação do modelo de canais MIMO 
Todas as combinações possíveis entre antenas transmissoras e receptoras são agrupadas em uma matriz global, a matriz de ganhos de canal $\boldsymbol{H}$, descrita como

$$
\boldsymbol{H}=\left[\begin{array}{cccc}
h_{11} & h_{12} & \cdots & h_{1 N_{\mathrm{T}}} \\
h_{21} & h_{22} & \cdots & h_{2 N_{\mathrm{T}}} \\
\vdots & \vdots & & \vdots \\
h_{N_{\mathrm{R}} 1} & h_{N_{\mathrm{R}} 2} & \cdots & h_{N_{\mathrm{R}} N_{\mathrm{T}}}
\end{array}\right]
$$

onde $\boldsymbol{H}$ é a matriz de canal, $h_{i j}$ é o ganho de canal estabelecido entre a antena de recepção $i$ e a antena de transmissão $j, N_{\mathrm{T}}$ é o número total de antenas de transmissão e $N_{\mathrm{R}}$ é o número total de antenas de recepção.

Neste trabalho foram considerados canais sem fio de banda estreita, invariantes no tempo, em que sequências aleatórias de bits são enviadas de um transmissor para um receptor, por meio de um canal ruidoso, em um cenário de propagação urbano com múltiplos percursos no qual os equipamentos fazem uso da técnica MIMO massivo.

O modelo considera $N_{\mathrm{T}}$ antenas transmissoras nos equipamentos de usuário e um total de $K$ painéis com $N_{\mathrm{R}}$ antenas receptoras em cada arranjo de antenas das estações base.

No lado do transmissor, a cada intervalo de símbolo foi considerada a transmissão de um vetor $\boldsymbol{x}$, mapeado em $N_{\mathrm{T}}$ diferentes antenas de transmissão.

No lado da recepção, existem K painéis de antenas identificados pelo índice $k$, cada um com $N_{\mathrm{R}}$ antenas receptoras. Como este trabalho considera um sistema MIMO massivo distribuído, os sinais recebidos podem ser representados pela expansão da Equação 4.1, da forma

$$
\boldsymbol{y}_{k}=\boldsymbol{H}_{k} \boldsymbol{x}+\boldsymbol{n}_{k},
$$

onde $\boldsymbol{y}_{k}$ é o vetor do sinal recebido pelo painel $k, k$ é o índice identificador do painel de antenas, $\boldsymbol{H}_{k}$ é a matriz de ganho de canal do painel $k$ com dimensões $N_{\mathrm{R}} \times N_{\mathrm{T}}, \boldsymbol{x}$ é o vetor do sinal transmitido, e $\boldsymbol{n}_{k}$ é o vetor do ruído gaussiano branco aditivo do painel $k$.

Por sua arquitetura distribuída, os vetores dos sinais recebidos por cada um dos $\mathrm{K}$ painéis são enviados a um decodificador central, onde são concatenados em um vetor global definido por 


$$
\boldsymbol{y}_{\text {CONCAT }}=\left[\begin{array}{c}
\boldsymbol{y}_{0} \\
\boldsymbol{y}_{1} \\
\vdots \\
\boldsymbol{y}_{\mathrm{K}-1}
\end{array}\right]
$$

Portanto, a matriz concatenada, sem redução, é obtida pela substituição da Equação 4.3 na Equação 4.4, resultando em

$$
\boldsymbol{y}_{\text {CONCAT }}=\left[\begin{array}{c}
\boldsymbol{H}_{0} \\
\boldsymbol{H}_{1} \\
\vdots \\
\boldsymbol{H}_{\mathrm{K}-1}
\end{array}\right] \boldsymbol{x}+\left[\begin{array}{c}
\boldsymbol{n}_{0} \\
\boldsymbol{n}_{1} \\
\vdots \\
\boldsymbol{n}_{\mathrm{K}-1}
\end{array}\right]
$$

\section{2 - MODELO DE PROPAGAÇÃO}

Neste trabalho foram considerados enlaces de fronthaul em radiofrequências na faixa super high frequency (SHF), que vai de 3 a $30 \mathrm{GHz}$, por meio de uplinks de curta distância em cenário de propagação urbano sem linha de visada. Neste ambiente adotado, rico em espalhamento, também foi considerado que as matrizes de canal de diferentes painéis de antenas são descorrelatadas.

Em simulações alguns modelos de propagação são comumente utilizados em sistemas MIMO, tais como o $3^{\text {rd }}$ generation partnership project (3GPP) spatial channel model (SCM), o coopération européenne dans le domaine de la recherche scientifique et technique (COST) 249, COST 273, o IEEE 802.16e/SUI e o wireless world initiative new radio (WINNER) [51].

Os modelos de canal WINNER+ especificam vários cenários de propagação, que dependem do tipo de ambiente, da faixa de frequências, da altura das antenas e das distâncias, dentre outros. Esses modelos de canal são resultantes de medições e estudos de propagação e são bastante realistas.

Nas simulações deste estudo, foi adotado o modelo de propagação WINNER+ [51] com as seguintes características:

- cenário de NLOS, ou seja, cenário urban microcell scenario (UMi) - B1;

- disposição hexagonal;

- frequência central da portadora de $6 \mathrm{GHz}$; e

- altura da estação base de $10 \mathrm{~m}$. 
Neste modelo, a perda por percurso para a faixa de frequências de 2,0 a 6,0 GHz é dada por

$$
\begin{gathered}
P L=\left(44,9-6,55 \log _{10}\left(h_{\mathrm{BS}}\right)\right) \log _{10}(d)+5,83 \log _{10}\left(h_{\mathrm{BS}}\right)+18,38+ \\
23 \log _{10}\left(f_{\mathrm{c}}\right),
\end{gathered}
$$

onde $P L$ é a perda por percurso em $\mathrm{dB}, h_{\mathrm{BS}}$ é a altura da antena da estação base em $\mathrm{m}, d$ é a distância entre a UE e a BS em m, e $f_{\mathrm{c}}$ é a frequência central da portadora em GHz.

Nas simulações do Capítulo 5, no cálculo de perda por percurso foram usados os seguintes valores padrão deste modelo: $h_{\mathrm{BS}}=10 m$ e $f_{\mathrm{c}}=6 \mathrm{GHz}$.

\section{3 - MATRIZ DE COVARIÂNCIA DO CANAL}

Conforme descrito anteriormente, este trabalho considera um sistema MIMO massivo distribuído em RF. Os arranjos de antenas tipicamente usados possuem uma grande quantidade de elementos e são, usualmente, dispostos contiguamente.

Para o modelo analisado neste estudo, devido à proximidade entre as antenas do arranjo, é muito provável que as mesmas tenham uma grande correlação, tanto nas matrizes de covariância das antenas de recepção, quanto nas de transmissão, $\boldsymbol{R}_{\mathrm{H}, \mathrm{Rx}}$ e $\boldsymbol{R}_{\mathrm{H}, \mathrm{Tx}}$, respectivamente.

Também, foi adotado que a matriz de covariância da recepção é concebida da mesma forma que a da transmissão.

Por definição a matriz de covariância, $\boldsymbol{R}$, é dada por

$$
\operatorname{cov}(\boldsymbol{R})=\mathrm{E}\left((\boldsymbol{R}-\mathrm{E}(\boldsymbol{R}))(\boldsymbol{R}-\mathrm{E}(\boldsymbol{R}))^{\mathrm{T}}\right)
$$

Sabendo que essas matrizes de covariância representam a correlação entre cada antena individual em relação a todas as outras antenas vizinhas de um arranjo ou painel, essa matriz tem grande importância na execução das operações propostas neste trabalho.

Cada valor da diagonal da matriz de covariância é a variância de um elemento em particular. Já cada valor fora da diagonal dessa matriz é a covariância entre os pares de elementos, computando todas as combinações possíveis entre os mesmos. 
Os valores da referida matriz de covariância retratam o comportamento das amostras, de forma que:

- na diagonal, valores altos correspondem à condição desejada, pois poucas amostras podem dar uma boa representação do conjunto de dados original a partir de sua variância;

- fora da diagonal, valores altos correspondem à alta redundância do conjunto de dados.

Caso o conjunto de amostras possua um alto nível de redundância, é possível, por meio de poucas amostras de maior energia, a estimação do sinal original, já que estas poucas amostras são selecionadas para maximizar a variância.

Conforme descrito anteriormente, o grau de correlação entre as antenas influencia no desempenho da transformação linear, sendo que o resultado esperado desta operação é a existência de poucos componentes que concentrem a maior parte da energia do sinal. Uma vez selecionados apenas os elementos com maior energia, descarta-se os demais, caracterizando uma grande compressão.

Assim, quanto maior a correlação, maior será o efeito desejado de concentrar a energia em poucos componentes, por outro lado, pior será o desempenho, e menor será a diversidade e o número de canais independentes. Desta forma, as matrizes de covariância das antenas representam a correlação entre cada antena individual em relação a todas as outras antenas vizinhas de um arranjo ou painel.

A covariância entre as antenas sofre influência de fatores como a geometria do arranjo de antenas, na qual a covariância entre os elementos da extremidade de um arranjo linear será menor que a covariância entre os elementos extremos de um arranjo quadrado, devido à distância entre as antenas; o espaçamento entre os elementos; e a frequência do sinal.

Neste trabalho foram implementados dois pares de matrizes de covariância das antenas, uma para o lado da transmissão e outra para a recepção, tanto para arranjos lineares, quanto para painéis quadrados de antenas. A Figura 4.2a ilustra a topologia de um arranjo linear e a Figura 4.2b ilustra a de um painel quadrado. Estes arranjos de antenas 
foram utilizados nas simulações, de forma a permitir a comparação de desempenho entre as duas formas.

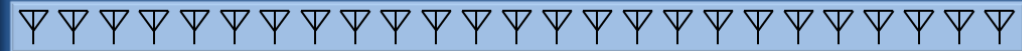

Arranjo linear de antenas

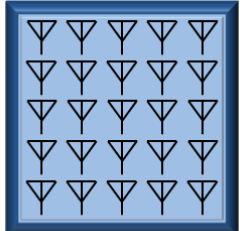

Painel quadrado de antenas

\section{a)}

b)

Figura 4.2 - Tipos de arranjos de antenas a) Linear b) Painel quadrado

A concepção da matriz de covariância do canal foi elaborada com base num modelo simplificado, porém bastante massificado na literatura, fundamentada no produto de Kronecker das matrizes de covariância no lado do transmissor e do receptor.

Este modelo de Kronecker é validado por meio de medições para arranjos de tamanhos $2 \times 2$ e $3 \times 3$, na faixa de frequências de 5,2 GHz [52] e também é corroborado pelo estudo de [53], na qual é demonstrado que o modelo estima arranjos de tamanho $8 \times 8$, com erros inferiores a $20 \%$, e pelo estudo de [54], que investigou arranjos de tamanho $8 \times 8$, e verificou que o modelo se encaixa muito bem quando a correlação entre recepção e transmissão é baixa, mas apresenta discrepância para altas correlações.

Considerando que este estudo opera com arranjos de tamanho $5 \times 5$ e frequência de $6 \mathrm{GHz}$, é possível inferir que os resultados decorrentes das simulações do Capítulo 5 são admissíveis.

Destarte, em cenários NLOS típicos e para tamanhos de matriz moderados, a matriz de covariância do canal $\boldsymbol{R}_{\mathrm{H}}$ pode ser bem aproximada pelo produto de Kronecker das matrizes de covariância no lado do transmissor e do receptor [55] 


$$
\boldsymbol{R}_{\mathrm{H}}=\boldsymbol{R}_{\mathrm{H}, \mathrm{Tx}} \otimes \boldsymbol{R}_{\mathrm{H}, \mathrm{Rx}}
$$

onde $\boldsymbol{R}_{\mathrm{H}, \mathrm{Tx}}$ é a matriz de covariância do canal do lado do transmissor, com dimensões $N_{\mathrm{T}} \times N_{\mathrm{T}}, \otimes$ simboliza o produto de Kronecker e $\boldsymbol{R}_{\mathrm{H}, \mathrm{Rx}}$ é a matriz de covariância do canal do lado receptor, com dimensões $N_{\mathrm{R}} \times N_{\mathrm{R}}$.

Considerando que as matrizes de correlação de antena são presumidas, e apresentadas na próxima seção, a correlação de antena da Equação 4.8 pode ser modelada na matriz de canal de cada painel, fazendo-se [56]

$$
\boldsymbol{H}_{k}=\boldsymbol{R}_{\mathrm{H}, \mathrm{Rx}}{ }^{1 / 2} \boldsymbol{H}_{\mathrm{w}_{k}}\left(\boldsymbol{R}_{\mathrm{H}, \mathrm{Tx}}{ }^{1 / 2}\right)^{\mathrm{T}},
$$

onde $\boldsymbol{H}_{k}$ é a matriz de canal do painel $k, \boldsymbol{R}_{\mathrm{H}, \mathrm{Rx}}$ é a matriz de covariância do canal do lado receptor, com dimensões $N_{\mathrm{R}} \times N_{\mathrm{R}}, \boldsymbol{H}_{\mathrm{w}_{k}}$ é uma matriz de canal com elementos independentes de desvanecimento Rayleigh, com dimensões $N_{\mathrm{R}} \times N_{\mathrm{T}}, \boldsymbol{R}_{\mathrm{H}, \mathrm{Tx}}$ é a matriz de covariância do canal lado do transmissor, com dimensões $N_{\mathrm{T}} \times N_{\mathrm{T}}$, e $(\cdot)^{\mathrm{T}}$ é a matriz transposta.

A construção das matrizes de covariâncias dos arranjos de antenas é detalhada nas Seções 4.4 e 4.5, com a especificação da matriz de covariância para arranjos lineares e a matriz de covariância para painel quadrado de antenas, respectivamente.

\section{4 - MATRIZ DE COVARIÂNCIA PARA ARRANJO LINEAR DE ANTENAS}

As matrizes de covariância para arranjos lineares de antenas foram implementadas de forma semelhante ao proposto por [22], fazendo-se

$$
\boldsymbol{R}_{i j}=\rho^{|i-j|},
$$

onde $\rho$ é o grau de correlação entre antenas adjacentes, $i$ é o índice da linha e $j$ é o índice da coluna.

O resultado da Equação 4.10, para recepção, é uma matriz de Toeplitz, com dimensões $N_{\mathrm{R}} \times N_{\mathrm{R}}$, onde $N_{\mathrm{R}}$ é o número de antenas de recepção em cada arranjo, os elementos da diagonal da matriz representam a potência do sinal recebido em cada antena e $\rho$ representa a correlação com a antena adjacente. A distância entre as antenas é proporcional ao expoente $|i-j|$ que caracteriza a separação entre elementos. 
Esta abordagem também foi feita em [57], resultando na seguinte matriz normalizada de covariância circulante de recepção, ou resumidamente, matriz de covariância de recepção, $\boldsymbol{R}_{\mathrm{H}, \mathrm{Rx}}$

$$
\boldsymbol{R}_{\mathrm{H}, \mathrm{Rx}}=\left[\begin{array}{ccccc}
\rho_{\mathrm{Rx}}{ }^{0} & \rho_{\mathrm{Rx}}{ }^{1} & \rho_{\mathrm{Rx}}{ }^{2} & \ldots & \rho_{\mathrm{Rx}}{ }^{N_{\mathrm{R}}-1} \\
\rho_{\mathrm{Rx}}{ }^{1} & \rho_{\mathrm{Rx}}{ }^{0} & \rho_{\mathrm{Rx}}{ }^{1} & \rho_{\mathrm{Rx}}{ }^{2} & \vdots \\
\rho_{\mathrm{Rx}}{ }^{2} & \rho_{\mathrm{Rx}}{ }^{1} & \ddots & \ddots & \rho_{\mathrm{Rx}}{ }^{2} \\
\vdots & \rho_{\mathrm{Rx}}{ }^{2} & \ddots & \rho_{\mathrm{Rx}}{ }^{0} & \rho_{\mathrm{Rx}}{ }^{1} \\
\rho_{\mathrm{Rx}}{ }^{N_{\mathrm{R}}-1} & \cdots & \rho_{\mathrm{Rx}}{ }^{2} & \rho_{\mathrm{Rx}}{ }^{1} & \rho_{\mathrm{Rx}}{ }^{0}
\end{array}\right],
$$

Neste trabalho optou-se pelo uso do mesmo parâmetro de correlação entre as antenas de recepção e de transmissão, de forma que $\rho_{\mathrm{Rx}}=\rho_{\mathrm{Tx}}$. A razão por tal escolha é devido à suposição de que ambos arranjos de antenas possuem espalhadores semelhantes em seus arredores. Por conseguinte o modelo pode se manter de forma singela.

A matriz de covariância de transmissão $\boldsymbol{R}_{\mathrm{H}, \mathrm{Tx}}$, por sua vez, tem dimensões $N_{\mathrm{T}} \times N_{\mathrm{T}}$, onde $N_{\mathrm{T}}$ é o número de antenas de transmissão em cada arranjo, da forma que

$$
\boldsymbol{R}_{\mathrm{H}, \mathrm{Tx}}=\left[\begin{array}{ccccc}
\rho_{\mathrm{Tx}}{ }^{0} & \rho_{\mathrm{Tx}}{ }^{1} & \rho_{\mathrm{Tx}}{ }^{2} & \cdots & \rho_{\mathrm{Tx}}{ }^{N_{\mathrm{T}}-1} \\
\rho_{\mathrm{Tx}}{ }^{1} & \rho_{\mathrm{Tx}}{ }^{0} & \rho_{\mathrm{Tx}}{ }^{1} & \rho_{\mathrm{Tx}}{ }^{2} & \vdots \\
\rho_{\mathrm{Tx}}{ }^{2} & \rho_{\mathrm{Tx}}{ }^{1} & \ddots & \ddots & \rho_{\mathrm{Tx}}{ }^{2} \\
\vdots & \rho_{\mathrm{Tx}}{ }^{2} & \ddots & \rho_{\mathrm{Tx}}{ }^{0} & \rho_{\mathrm{Tx}}{ }^{1} \\
\rho_{\mathrm{Tx}}{ }^{N_{\mathrm{T}}-1} & \cdots & \rho_{\mathrm{Tx}}{ }^{2} & \rho_{\mathrm{Tx}}{ }^{1} & \rho_{\mathrm{Tx}}{ }^{0}
\end{array}\right] .
$$

O nível de correlação entre as antenas depende do valor do parâmetro $\rho$, que pode variar de $0 \leq \rho \leq 1$. Ele pode ser interpretado de forma que, quando houver correlação total entre os sinais recebidos, tem-se $\rho=1$. Quando os sinais forem completamente descorrelatados, tem-se $\rho=0$.

Como foi pressuposto que $\rho_{\mathrm{Rx}}=\rho_{\mathrm{Tx}}$, as matrizes de covariância de recepção serão geradas de forma idêntica às de transmissão, simplificando o processamento relacionado. Os níveis de correlação estabelecidos neste trabalho foram de $\rho=0,25$, $\rho=0,50$ e $\rho=0,75$, pois tais valores permitem abranger uma maior gama de cenários. A partir destes valores pode-se simular condições de pequena, média e grande correlação entre as antenas. 


\section{5 - MATRIZ DE COVARIÂNCIA PARA PAINEL QUADRADO DE ANTENAS}

As matrizes de covariância para painéis quadrados de antenas foram implementadas calculando-se as distâncias euclidianas entre todas as antenas do painel.

A computação da distância euclidiana é feita a cada linha e coluna. Por exemplo, dado um painel de antenas $2 \times 2$, a matriz de covariância resultante terá dimensões $4 \times$ 4, e é calculada da forma

$$
\begin{aligned}
\boldsymbol{R}_{\mathrm{H}, \mathrm{Rx}} & =\left[\begin{array}{llll}
\rho^{\sqrt{(1-1)^{2}+(1-1)^{2}}} & \rho^{\sqrt{(1-1)^{2}+(1-2)^{2}}} & \rho^{\sqrt{(1-2)^{2}+(1-1)^{2}}} & \rho^{\sqrt{(1-2)^{2}+(1-2)^{2}}} \\
\rho^{\sqrt{(1-1)^{2}+(2-1)^{2}}} & \rho^{\sqrt{(1-1)^{2}+(2-2)^{2}}} & \rho^{\sqrt{(1-2)^{2}+(2-1)^{2}}} & \rho^{\sqrt{(1-2)^{2}+(2-2)^{2}}} \\
\rho^{\sqrt{(2-1)^{2}+(1-1)^{2}}} & \rho^{\sqrt{(2-1)^{2}+(1-2)^{2}}} & \rho^{\sqrt{(2-2)^{2}+(1-1)^{2}}} & \rho^{\sqrt{(2-2)^{2}+(1-2)^{2}}} \\
\rho^{\sqrt{(2-1)^{2}+(2-1)^{2}}} & \rho^{\sqrt{(2-1)^{2}+(2-2)^{2}}} & \rho^{\sqrt{(2-2)^{2}+(2-1)^{2}}} & \rho^{\sqrt{(2-2)^{2}+(2-2)^{2}}}
\end{array}\right] \\
& =\left[\begin{array}{llll}
\rho^{0} & \rho^{1} & \rho^{1} & \rho^{\sqrt{2}} \\
\rho^{1} & \rho^{0} & \rho^{\sqrt{2}} & \rho^{1} \\
\rho^{1} & \rho^{\sqrt{2}} & \rho^{0} & \rho^{1} \\
\rho^{\sqrt{2}} & \rho^{1} & \rho^{1} & \rho^{0}
\end{array}\right] .
\end{aligned}
$$

Assim, para um painel quadrado de antenas de recepção com dimensões $N_{\mathrm{R}} \times N_{\mathrm{R}}$, a matriz de covariância resultante, $\boldsymbol{R}_{\mathrm{H}, \mathrm{Rx}}$, terá dimensões ${N_{\mathrm{R}}}^{2} \times{N_{\mathrm{R}}}^{2}$, resultando em

$$
\boldsymbol{R}_{\mathrm{H}, \mathrm{Rx}}=\left[\begin{array}{cccc}
\rho_{\mathrm{Rx}}{ }^{0} & \rho_{\mathrm{Rx}}{ }^{1} & \cdots & \rho_{\mathrm{Rx}}{ }^{\sqrt{2\left(N_{\mathrm{R}}-1\right)^{2}}} \\
\rho_{\mathrm{Rx}}{ }^{1} & \rho_{\mathrm{Rx}}{ }^{0} & & \vdots \\
\vdots & & \ddots & \rho_{\mathrm{Rx}}{ }^{1} \\
\rho_{\mathrm{Rx}} \sqrt{2\left(N_{\mathrm{R}}-1\right)^{2}} & \ldots & \rho_{\mathrm{Rx}}{ }^{1} & \rho_{\mathrm{Rx}}{ }^{0}
\end{array}\right]
$$

A criação da matriz de covariância de transmissão $\boldsymbol{R}_{\mathrm{H}, \mathrm{Tx}}$ também é realizada da mesma forma que a matriz de recepção, porém com dimensões ${N_{\mathrm{T}}}^{2} \times{N_{\mathrm{T}}}^{2}$ para um painel antenas com dimensões $N_{\mathrm{T}} \times N_{\mathrm{T}}$, resultando em

$$
\boldsymbol{R}_{\mathrm{H}, \mathrm{Tx}}=\left[\begin{array}{cccc}
\rho_{\mathrm{Tx}}{ }^{0} & \rho_{\mathrm{Tx}}{ }^{1} & \cdots & \rho_{\mathrm{Tx}}{ }^{\sqrt{2\left(N_{\mathrm{T}}-1\right)^{2}}} \\
\rho_{\mathrm{Tx}}{ }^{1} & \rho_{\mathrm{Tx}}{ }^{0} & & \vdots \\
\vdots & & \ddots & \rho_{\mathrm{Tx}}{ }^{1} \\
\rho_{\mathrm{Tx}} \sqrt{2\left(N_{\mathrm{T}}-1\right)^{2}} & \cdots & \rho_{\mathrm{Tx}}{ }^{1} & \rho_{\mathrm{Tx}}{ }^{0}
\end{array}\right]
$$




\section{6 - REDUÇÃO DE DIMENSÕES}

Neste estudo foi considerado um sistema o MIMO massivo com um grande número de antenas receptoras com pequeno espaçamento entre os elementos. Tal condição presume a existência de grande correlação entre os sinais recebidos, característica que habilita o uso de técnicas de redução de dimensões com pouca perda de informação.

Adotou-se a transformada de Karhunen-Loève em vez da decomposição em valores singulares, pois estas são intercambiáveis e amplamente usadas na literatura. Em [39], por exemplo, a KLT e a análise de componentes principais são descritas e pode-se observar que ambas as abordagens são equivalentes uma vez que os ganhos de canal têm uma média nula. Também foi escolhida a transformada discreta de cossenos, pelas razões anteriormente apresentadas, para efeito de comparação.

Para o uso das transformações lineares nesta compressão com perdas, é necessária a seleção de um encurtado número de dimensões que contenham informações relevantes, pressupondo o perfeito conhecimento da matriz de covariância das antenas de recepção. Como se trata de uma métrica estatística de longo prazo aplicado a um receptor fixo, esta suposição pode ser considerada aceitável.

Após a execução da transformação linear, KLT ou DCT, deve-se efetuar uma seleção dos $D$ componentes de maior energia, na qual a quantidade de componentes selecionados depende da capacidade dos enlaces de fronthaul e das perdas admissíveis, caracterizadas pela taxa de erro tolerável pelo sistema de comunicação.

Esta seleção dos componentes de maior energia equivale a uma compressão com perdas, porque a informação dos componentes mais fracos é descartada. Por outro lado, apesar do descarte de amostras, deve-se ressaltar que o ruído contido nestes componentes também é descartado [19].

Por ter sido idealizado um sistema com painéis de antenas distribuídas, foi utilizada a KLT distribuída [22] [58] [59]. Ela se diferencia da KLT tradicional pela divisão dos dados em subgrupos. A KLT é realizada em cada subconjunto individual e, posteriormente, o sinal é reconstruído em um decodificador central pela união de cada subconjunto processado. No caso deste trabalho, os subconjuntos representam os diferentes painéis de antenas, tal como mostrado na Figura 4.3. 
A transformação é realizada com base na decomposição em valores singulares da matriz de covariância, cuja saída são valores singulares em ordem decrescente de energia e seus correspondentes vetores singulares.

Se a decomposição em valores singulares for aplicada em uma matriz de covariância, quadrada e simétrica, $\boldsymbol{R}$, os autovetores singulares à esquerda e à direita serão os mesmos, assim, os autovetores singulares $\boldsymbol{U}$ e $\boldsymbol{V}$ serão idênticos. Por isso será adotado emprego dos vetores singulares esquerdos.

Neste trabalho a matriz de covariância das antenas de recepção foi decomposta, tal que

$$
\boldsymbol{R}_{\mathrm{Rx}}=\boldsymbol{U} \boldsymbol{\Lambda} \boldsymbol{U}^{\mathrm{H}},
$$

onde $\boldsymbol{U}$ é uma matriz unitária com dimensões $N_{\mathrm{R}} \times N_{\mathrm{R}}$, cujas colunas representam os vetores singulares esquerdos, $\boldsymbol{\Lambda}$ é uma matriz diagonal com valores singulares $\lambda_{1} \geq \lambda_{2} \geq$ $\cdots \geq \lambda_{N}$, e $\boldsymbol{U}^{\mathrm{H}}$ é transposta Hermitiana da matriz $\boldsymbol{U}$, também conhecida como conjugado transposto ou matriz adjunta.

Com o conhecimento da matriz de covariância, é realizada uma transformação linear no sinal de entrada de cada painel de antenas $k$, de tal modo que as saídas são descorrelatadas entre si. Isto é feito pela aplicação da seguinte transformação em cada painel de antenas

$$
\boldsymbol{z}_{k}=\boldsymbol{U}^{\mathrm{H}} \boldsymbol{y}_{k}
$$

que resulta em um vetor $\boldsymbol{z}_{k}$ de $N_{\mathrm{R}}$ sinais descorrelatados, para os $k$ painéis de antenas, com valores listados em ordem decrescente de potência e correspondentes aos valores singulares $\lambda_{i}$.

Dependendo do grau de correlação, a potência estará concentrada em um número reduzido de componentes e, com isso, pode-se realizar a redução de dimensões pela remoção de parte destes componentes que não têm contribuição relevante para a reconstrução do sinal. Enquanto o número de dimensões for maior ou igual ao número de feixes espaciais, a detecção dos sinais espacialmente multiplexados ainda será possível.

Na etapa de redução de dimensões o tamanho do sinal é reduzido de $N_{\mathrm{R}}$ para $D$ dimensões, onde $D<N_{\mathrm{R}}$, conforme mostrado na Figura 4.3. 


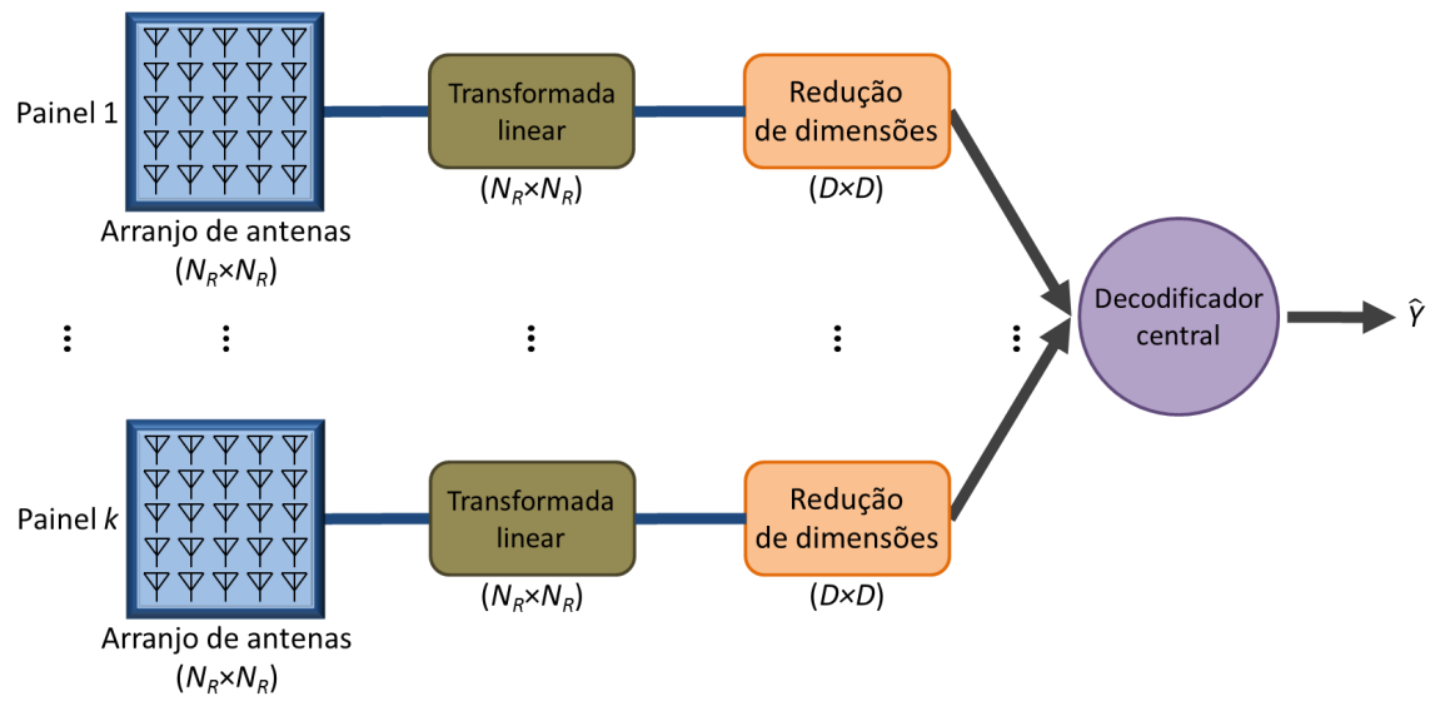

Figura 4.3 - Redução de dimensões no MIMO massivo distribuído

Para representar essa redução de dimensões é necessário criar uma matriz de transformação de redução $\boldsymbol{T}$. Esta matriz de redução deve ter dimensões $D \times N_{\mathrm{R}}$, e sua concepção deve ser a concatenação de uma matriz identidade de ordem $D$ com uma matriz nula de dimensões $D \times\left(N_{\mathrm{R}}-D\right)$, da forma que

$$
\boldsymbol{T}=\left[\boldsymbol{I}_{D} \mid \mathbf{0}_{\left[D \times\left(N_{\mathrm{R}}-D\right)\right]}\right]_{\left[D \times N_{\mathrm{R}}\right]},
$$

onde $\boldsymbol{I}_{D}$ é uma matriz identidade e $\mathbf{0}_{\left[D \times\left(N_{\mathrm{R}}-D\right)\right]}$ é uma matriz nula.

Com a redução das dimensões, todos os elementos passam a ser identificados pelo índice $R E D U C, k$, para expressar a redução de dimensões com a seleção de $D$ componentes descorrelatados.

Assim, a seleção de dimensões é realizada a partir do produto entre a matriz de transformação de redução e o vetor com os componentes descorrelatados, representada como

$$
\boldsymbol{y}_{R E D U C, k}=\boldsymbol{T} \boldsymbol{z}_{k},
$$

onde $\boldsymbol{y}_{R E D U C, k}$ é o vetor do sinal com dimensões reduzidas após a transformação linear, $k$ é o índice do painel, $\boldsymbol{T}$ é a matriz de transformação de redução e $\boldsymbol{z}_{k}$ é o vetor de sinais descorrelatados. 
A partir desta redução de dimensões é possível a diminuição da capacidade dos enlaces de fronthaul entre os arranjos de antenas e o decodificador central. Esta redução também ajuda a diminuir o processamento na estação central, já que o número de dimensões é significativamente menor que o sinal original, todavia, ao custo do processamento da transformação e redução de dimensões junto aos painéis de antenas.

A substituição da Equação 4.17 na 4.19, resulta em

$$
\boldsymbol{y}_{R E D U C, k}=\boldsymbol{T} \boldsymbol{U}^{\mathrm{H}} \boldsymbol{y}_{k} .
$$

Após a redução de dimensões, sendo $D$ o número de dimensões selecionadas posteriormente à transformação linear, a matriz de canal passa a ter $D \times D$ dimensões. $\mathrm{O}$ vetor de ruído gaussiano também passa a ter as mesmas dimensões reduzidas.

Assim, a representação do sinal reduzido para $D \times D$ dimensões passa a ser

$$
\boldsymbol{y}_{R E D U C, k}=\boldsymbol{H}_{R E D U C, k} \boldsymbol{x}+\boldsymbol{n}_{R E D U C, k},
$$

onde $\boldsymbol{y}_{R E D U C, k}$ é o vetor do sinal com dimensões reduzidas, $\boldsymbol{H}_{R E D U C, k}$ é a matriz de canal com dimensões $D \times D$, sendo $D$ o número de dimensões selecionadas após a transformação, $\boldsymbol{x}$ é o vetor do sinal transmitido e $\boldsymbol{n}_{R E D U C, k}$ é o vetor de ruído gaussiano branco aditivo com dimensões reduzidas.

\section{7 - DETECÇÃO DE SINAL}

A estimação de sinais pode ser dividida em métodos de detecção ótima, na qual se inclui a detecção de máxima probabilidade a posteriori, ou maximum a posteriori (MAP), e a estimação por máxima verossimilhança, ou maximum likelihood (ML), e métodos subótimos, que podem ser lineares, tais como o zero forcing (ZF) e o mínimo erro médio quadrático, ou minimum mean square error (MMSE), ou então métodos não lineares.

Após a redução de dimensões, os sinais comprimidos são transmitidos e reconstituídos no decodificador central. Esses sinais têm forma da Equação 4.21, e representam um sistema MIMO para $D$ antenas receptoras descorrelatadas. 
Como este trabalho emprega sistemas MIMO massivo distribuídos, que têm como característica o emprego de vários painéis de antenas dispersos em uma região, cada painel receberá um conjunto de sinais, que será processado e reduzido o número de dimensões. Este sinal reduzido $\boldsymbol{y}_{R E D U C, k}$ resultante de cada arranjo é enviado, por meio de enlaces de fronthaul, a um decodificador central.

Neste decodificador central, os diversos sinais recebidos devem ser concatenados e posteriormente, por meio de esquemas de detecção de multiplexação espacial, o sinal recebido pode então ser detectado. Este trabalho considerou exclusivamente dois métodos de detecção linear: o ZF e o MMSE.

Como os sinais reduzidos possuem dimensões $D \times D$ e são $K$ painéis de antenas empregados no sistema, o resultado desta concatenação é uma matriz de dimensões $(K \cdot D) \times D$. Assim, as matrizes utilizadas na detecção terão estas dimensões e serão identificadas pelo índice CONCAT,K. As matrizes $\boldsymbol{H}_{C O N C A T, k}$ e $\boldsymbol{z}_{C O N C A T, k}$ representam a matriz concatenada de canal e o vetor concatenado de sinais descorrelatados.

Neste estudo, o equalizador zero forcing foi investigado, e sua forma de ser calculado é dada por

$$
\widehat{\boldsymbol{x}}_{\mathrm{ZF}}=\boldsymbol{H}_{\mathrm{CONCAT,k}}^{\dagger} \boldsymbol{z}_{\mathrm{CONCAT,k}},
$$

onde $\widehat{\boldsymbol{x}}_{\mathrm{ZF}}$ é o sinal estimado pelo método $\mathrm{ZF}, \boldsymbol{H}_{\mathrm{CONCAT}, k}$ é a matriz de canal concatenada, $k$ é o índice do painel de antenas, $(\cdot)^{\dagger}$ é a pseudo-inversa de Moore-Penrose e $\boldsymbol{z}_{\text {CONCAT,k}}$ é o vetor concatenado de sinais descorrelatados com dimensões reduzidas.

Outro método linear de detecção do sinal utilizado neste trabalho foi o método minimum mean square error (MMSE), que pode ser calculado da forma

$$
\widehat{\boldsymbol{x}}_{\mathrm{MMSE}}=\left[\left(\boldsymbol{H}_{\mathrm{CONCAT}, k}^{\dagger} \boldsymbol{H}_{\text {CONCAT,k}}+\frac{1}{E_{S} / N_{0}}\right)^{\dagger} \boldsymbol{H}_{\text {CONCAT,k }}^{\dagger}\right] \mathbf{z}_{\text {CONCAT,k}},
$$

onde $\widehat{\boldsymbol{x}}_{\text {MMSE }}$ é o sinal estimado pelo método MMSE, e $E_{S} / N_{0}$ é a razão entre a energia de símbolo e a densidade espectral da potência do ruído. 
A computação destes dois métodos faz uso de álgebra linear, e algumas operações necessitam de maior processamento, como a pseudo-inversa de Moore-Penrose, também conhecida como pseudo-inversa, que é uma generalização da matriz inversa para matrizes complexas, mesmo que não sejam necessariamente quadradas.

Os dois métodos escolhidos apresentam resultados próximos, porém é sabido que o MMSE é um estimador melhor que o ZF.

Por esta razão, parte dos resultados obtidos pelo método zero forcing serão parcialmente omitidos no decorrer do Capítulo 5, em benefício de uma melhor visualização dos resultados do método minimum mean square error. 


\section{5 - SIMULAÇÕES DO MODELO}

\section{1 - CENÁRIOS SIMULADOS}

As simulações deste trabalho foram realizadas por meio do software MATLAB, da MathWorks. Para efeito do cômputo de perdas no enlace de uplink, a frequência portadora adotada foi de $6 \mathrm{GHz}$, em um cenário de propagação urbano NLOS com multipercursos, modelo de propagação WINNER+, ruído gaussiano branco aditivo, multiplexação espacial e modulação binary phase-shift keying (BPSK). A recepção é efetuada por um grande número de antenas e a detecção pelos métodos de estimação zero forcing e minimum mean square error.

A fim de avaliar o desempenho da redução de dimensões de sistemas MIMO distribuídos foram realizadas simulações tanto sem compressão, quanto com compressão baseada na KLT e na DCT.

Os níveis de compressão foram estipulados em percentuais de acordo com o total de antenas receptoras. Os níveis de compressão de $40 \%$ e $60 \%$ foram definidos para representar níveis de compressão intermediários e fortes, além do desempenho de referência, sem compressão.

Essas simulações utilizaram diferentes parâmetros covariância $\rho$, tanto para arranjos lineares quanto para painéis quadrados de antenas. Tais resultados permitem a análise concomitante do desempenho dos sistemas, bem como o desempenho das compressões.

Similarmente, para comparação dos métodos de transformação linear, foram simulados cenários com compressão baseada na DCT, com diferentes parâmetros covariância $\rho$, para arranjos lineares e painéis quadrados.

As matrizes de covariância foram geradas com parâmetros de covariância de $\rho=0,25, \rho=0,50$ e $\rho=0,75$. Tais coeficientes foram adotados de forma a alcançar uma maior variação de cenários, pois com $\rho=0,25$ tem-se pouca correlação, com $\rho=0,50$ tem-se uma condição intermediária e com $\rho=0,75$ tem-se uma alta correlação entre as antenas. 
A comparação do desempenho foi baseada na taxa de erro de bit por $E_{b} / N_{0}$, que é a razão entre a energia por bit e a densidade espectral da potência do ruído.

Considerando que este trabalho propõe a utilização de transformações lineares para redução de dimensões, o que resulta em compressão com perdas, o desempenho baseia-se no fato de que esta perda de informação se reflete em erros, que no caso dos enlaces de fronthaul, correspondem ao aumento da taxa de erro do enlace.

Outra consideração relacionada às simulações é que, como os métodos ZF e MMSE apresentam desempenhos semelhantes, porém um pouco superiores para o MMSE, as simulações com ambos os métodos somente foram realizadas para condições intermediárias de correlação da antenas, ou seja, $\rho=0,50$. Para as demais correlações as simulações foram efetivadas exclusivamente para o MMSE.

Conforme ilustrado na Figura 4.3, cada painel realiza uma compressão com perdas no sinal multidimensional recebido e transmite esta informação reduzida a um decodificador central, que tenta detectar o sinal transmitido baseado na combinação da informação de todos os painéis.

Foram considerados dois cenários nas simulações. O primeiro é o de um usuário único, em que o UE está localizado no ponto médio entre dois painéis de antenas, distante 100 m de cada painel, conforme mostrado na Figura 5.1.

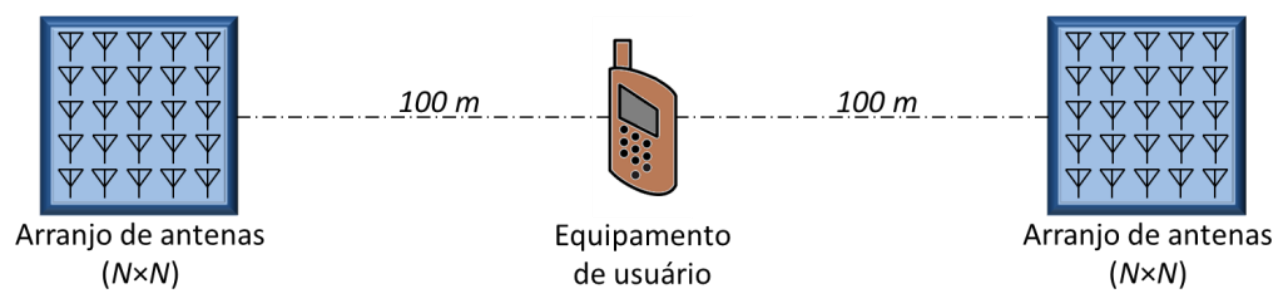

Figura 5.1 - Cenário simulado com usuário único

Nesta concepção, foi adotado que cada UE possui 4 antenas de transmissão, e que cada painel de antenas de recepção possui 25 elementos. De forma a permitir a comparação entre diferentes arranjos de antenas, foram realizadas simulações com um arranjo linear de antenas e com painéis quadrados $5 \times 5$. 
O segundo cenário simulado foi o de multiusuários, onde existem quatro equipamentos de usuário transmissores em uma disposição não simétrica, como mostrado na Figura 5.2.

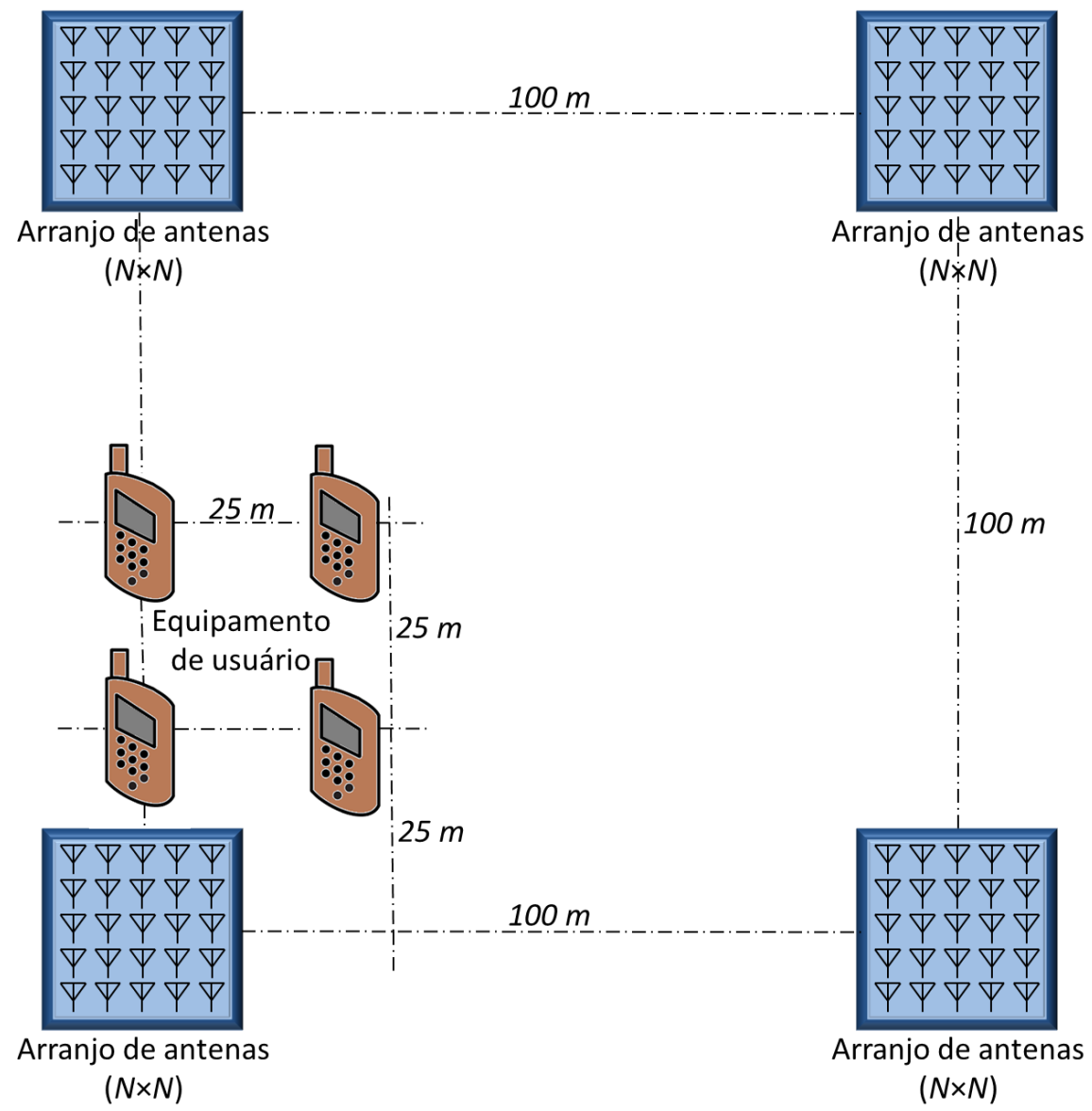

Figura 5.2 - Cenário simulado com multiusuários

$\mathrm{Na}$ recepção foram considerados quatro arranjos de antenas, cada um distante $100 \mathrm{~m}$ do painel adjacente e, similarmente, cada equipamento de usuário distante $25 \mathrm{~m}$ do UE vizinho. Com esta disposição os equipamentos de usuário não estão simetricamente dispostos, o que proporciona enlaces de diferentes distâncias entre cada UE e o painel de antenas.

A partir dos resultados das simulações, os diferentes métodos e cenários foram comparados, permitindo a avaliação de eventuais causas das variações de desempenho. Os resultados são apresentados nos itens subsequentes. 


\section{2 - RESULTADOS DAS SIMULAÇÕES COM O USO DA KLT}

As simulações realizadas com uso da transformada de Karhunen-Loève foram realizadas para arranjos lineares de antenas e para painéis quadrados de antenas. As matrizes de covariância foram geradas com valores de $\rho=0,25, \rho=0,50$ e $\rho=0,75$, de forma a cobrir uma maior quantidade de cenários. As reduções foram de 50 para 30 dimensões e de 50 para 20 dimensões, que representam compressões de 40 e $60 \%$, respectivamente.

O primeiro cenário simulado segue o modelo das Figuras 4.2a e 5.1, com um equipamento usuário e dois painéis lineares de antenas distantes 100 m, e os resultados são apresentados nas Figuras 5.3 a 5.5.

As curvas de taxa de erro de bit para um canal com o parâmetro covariância das antenas de $\rho=0,50$ são mostradas na Figura 5.3. Nela é possível confirmar que, como esperado, o desempenho do sistema se deteriora quando se reduz o número de dimensões a ser transmitido pelos enlaces de fronthaul.

Também é possível conferir na Figura 5.3 que o desempenho dos métodos de estimação ZF e MMSE são muito próximos, motivo pelo qual somente o MMSE será avaliado para outros níveis de correlação.

Relativamente à compressão, a deterioração do desempenho não é tão significativa, pois mesmo com uma redução de $60 \%$, que é o caso da diminuição de 50 para 20 dimensões, é possível se atingir baixas taxas de erro para altos $E_{b} / N_{0}$. Embora os níveis de BER tolerados por sistemas de comunicação sejam bastante singulares, é notório que taxas de erro inferiores a $10^{-5}$ são suficientes para a operação de diversos sistemas.

Apesar de se verificar que a taxa de erro aumenta com a redução de dimensões, tal fato não desqualifica o método, principalmente quando se considera a enorme redução na taxa de dados. 


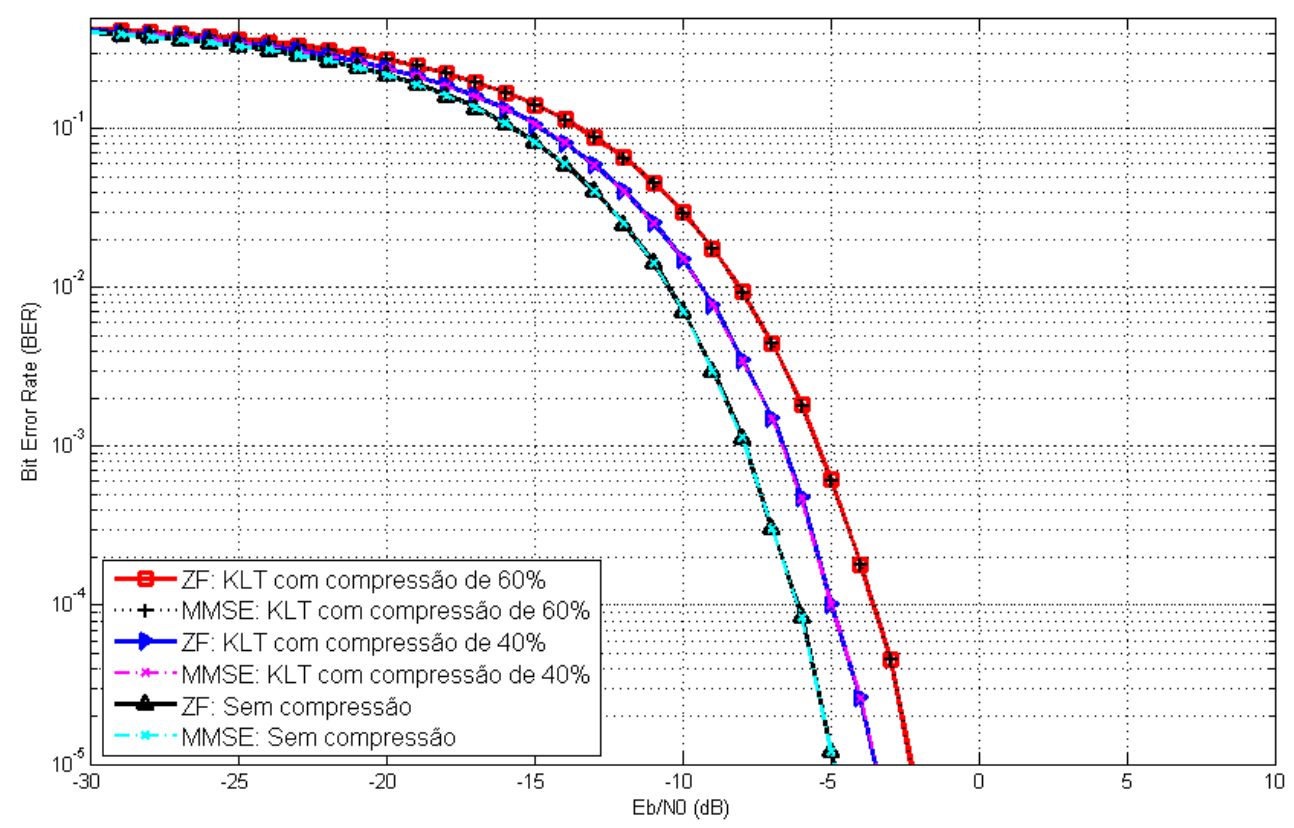

Figura 5.3 - BER para arranjos lineares de antenas $\operatorname{com} \rho=0,50$, utilizando-se a KLT

Nas Figuras 5.4 e 5.5 foram realizadas simulações com a mesma configuração, porém com os parâmetros de covariância de $\rho=0,25$ e $\rho=0,75$, para estimação por MMSE.

A partir da comparação do desempenho do sistema nas simulações apresentadas nas Figuras 5.4 e 5.5, pode-se constatar que a simulação com parâmetro $\rho=0,25$, ou seja, menor correlação entre as antenas, tem desempenho melhor que o sistema com parâmetro de covariância $\rho=0,75$.

Também pode ser constatado que o desempenho do método de compressão quando há maior correlação, $\rho=0,75$, os resultados para a compressão de $40 \%$ e $60 \%$ são próximos. 


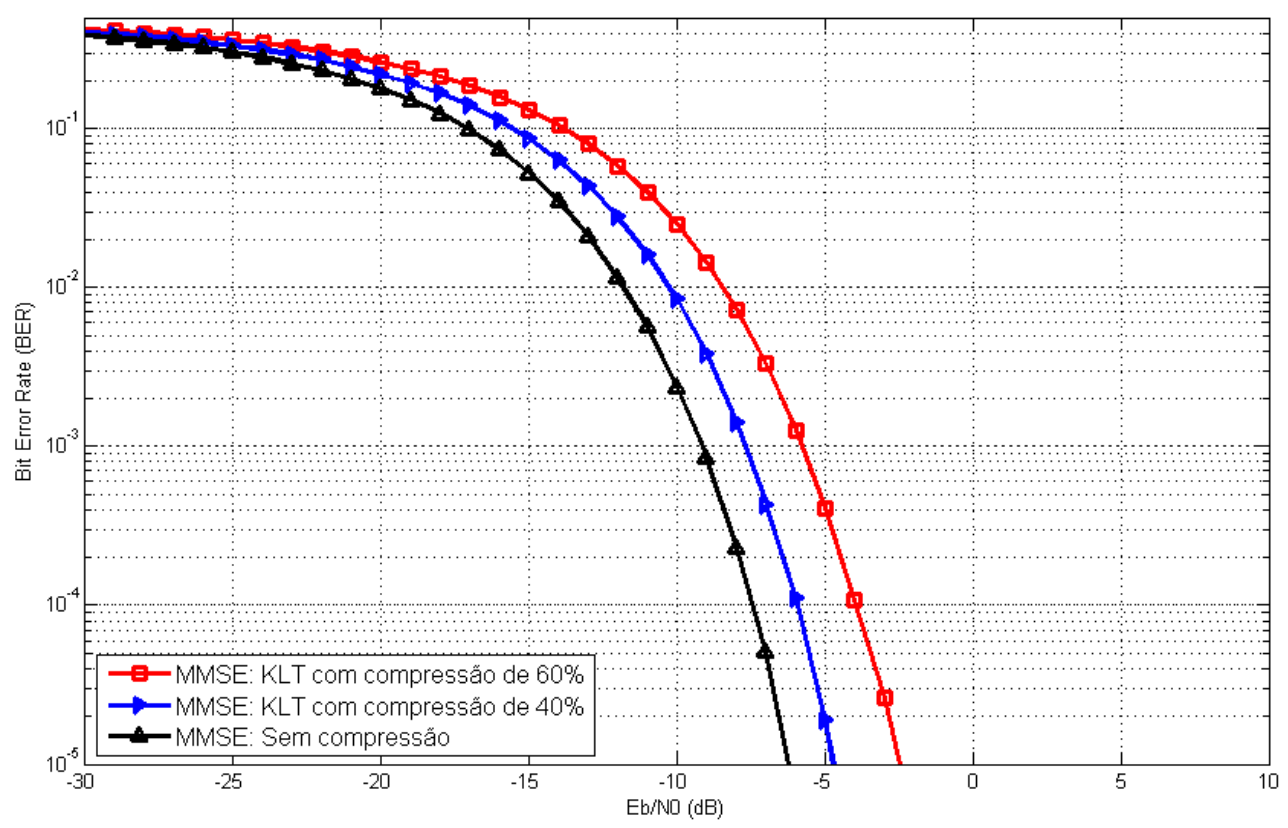

Figura 5.4 - BER para arranjos lineares de antenas com $\rho=0,25$, utilizando-se a KLT

Conforme exposto em outros capítulos deste trabalho, uma maior correlação dos sinais está associada a uma maior redundância, que por sua vez, habilita uma maior compressão.

Apesar disso, os resultados apresentados nas Figuras 5.3 a 5.5 mostram que, quanto menor o fator de correlação das antenas, melhor o desempenho do sistema. Isto se deve ao fato que a diversidade é maior quando o fator de correlação das antenas é menor.

Também pode ser observado que, conforme esperado, a redução de dimensões resulta em pior desempenho, mas esta diferença entre um sistema sem compressão e outro com compressão diminui quando a correlação das antenas aumenta, pois, neste caso há uma maior redundância, que permite uma compressão mais eficaz. 


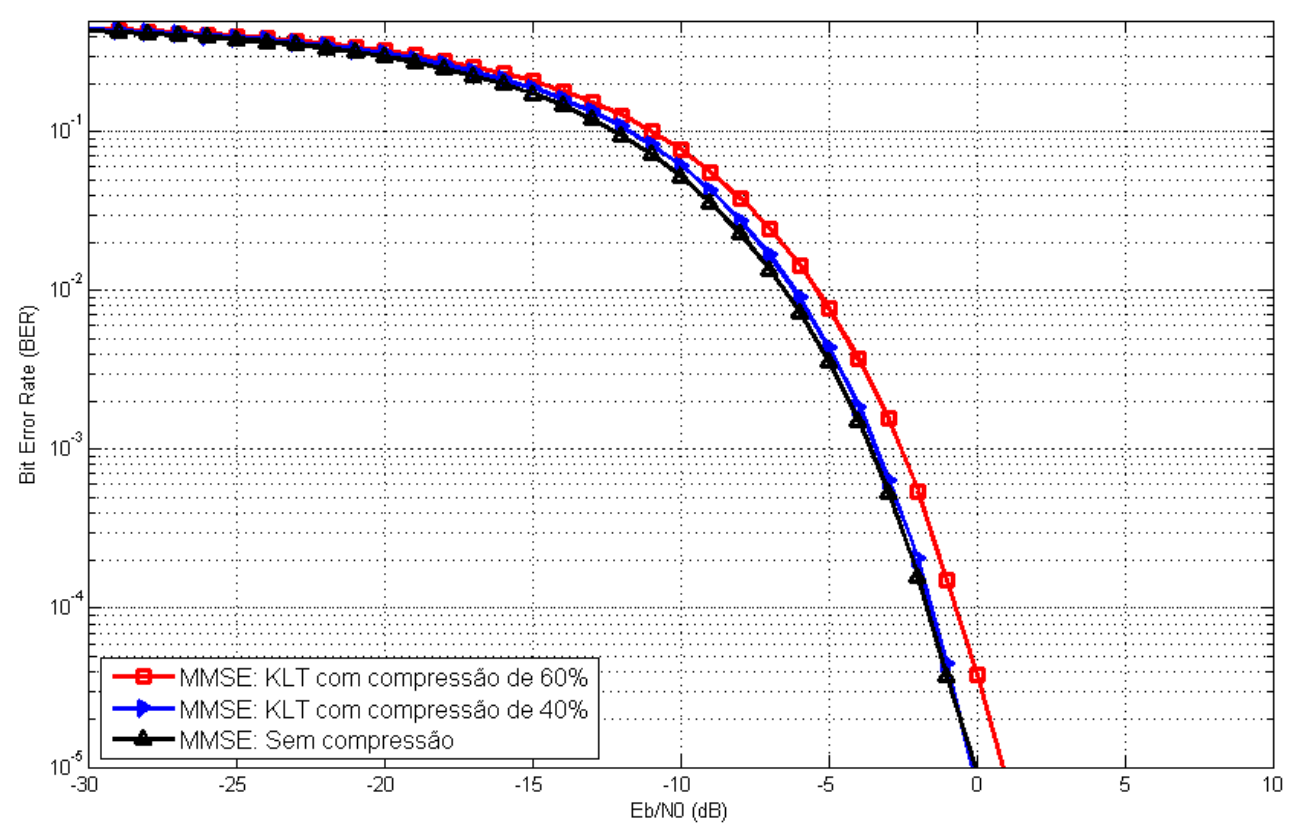

Figura 5.5 - BER para arranjos lineares de antenas com $\rho=0,75$, utilizando-se a KLT

As simulações do segundo cenário, um sistema com painéis de antenas, tal como ilustrado nas Figuras 4.2b e 5.1, têm desempenho semelhante às simulações com arranjo linear, porém o desempenho de sistemas com painéis de antenas, em configuração $5 \times 5$, é levemente melhor que o arranjo linear, conforme mostrado nas Figuras 5.6 a 5.8.

Comparando-se os resultados da simulação do painel de antenas com $\rho=0,50$, conforme Figura 5.6, com os resultados para o arranjo linear com mesmo parâmetro, mostrado na Figura 5.3, pode-se confirmar que o desempenho do sistema com painel é um pouco melhor que o com arranjo linear.

Com relação aos métodos de estimação, tanto o ZF quanto o MMSE têm desempenhos equivalentes, porém este último é um pouco superior. 


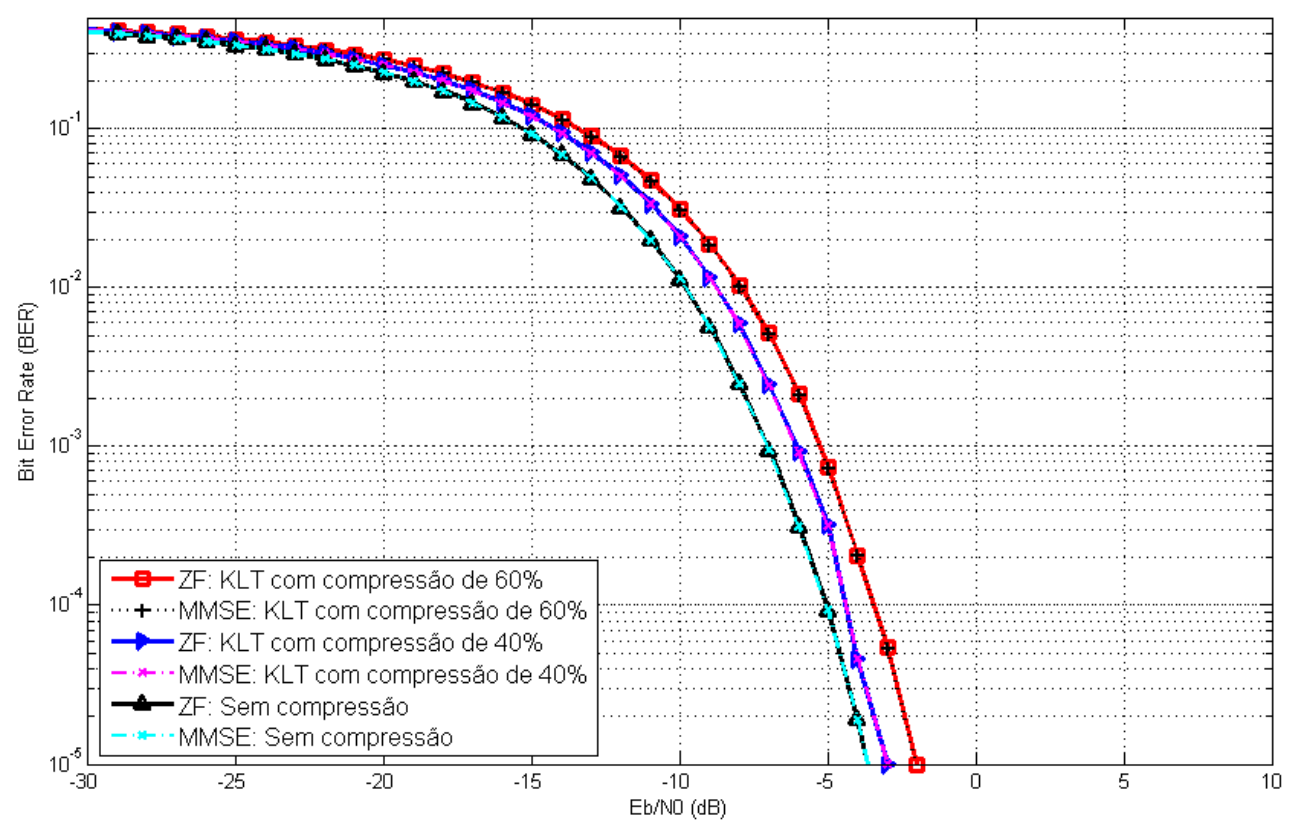

Figura 5.6 - BER para painéis de antenas $\operatorname{com} \rho=0,50$, utilizando-se a KLT

Na simulação com $\rho=0,25$, apresentada na Figura 5.7, é de fácil identificação a diferença de desempenho entre os níveis de compressão. Ao longo de grande parte da excursão de valores de $E_{b} / N_{0}$ a diferença fica entre $1 \mathrm{~dB}$ e $1,5 \mathrm{~dB}$.

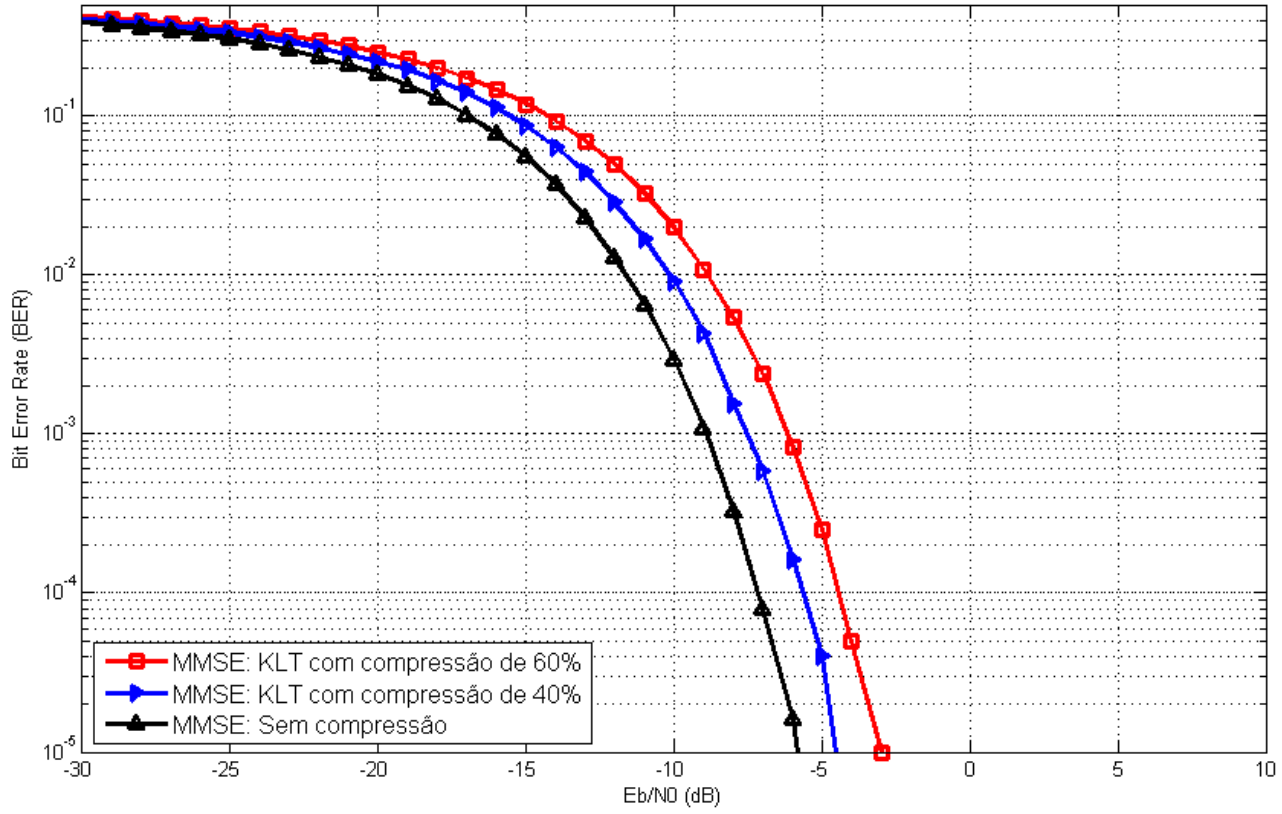

Figura 5.7 - BER para painéis de antenas com $\rho=0,25$, utilizando-se a KLT 
Quando a correlação entre as antenas é mais alta, o desempenho do sistema é pior que um sistema com menor correlação, assim como ocorre no arranjo linear. Na Figura 5.8 é apresentado o desempenho para $\rho=0,75$.

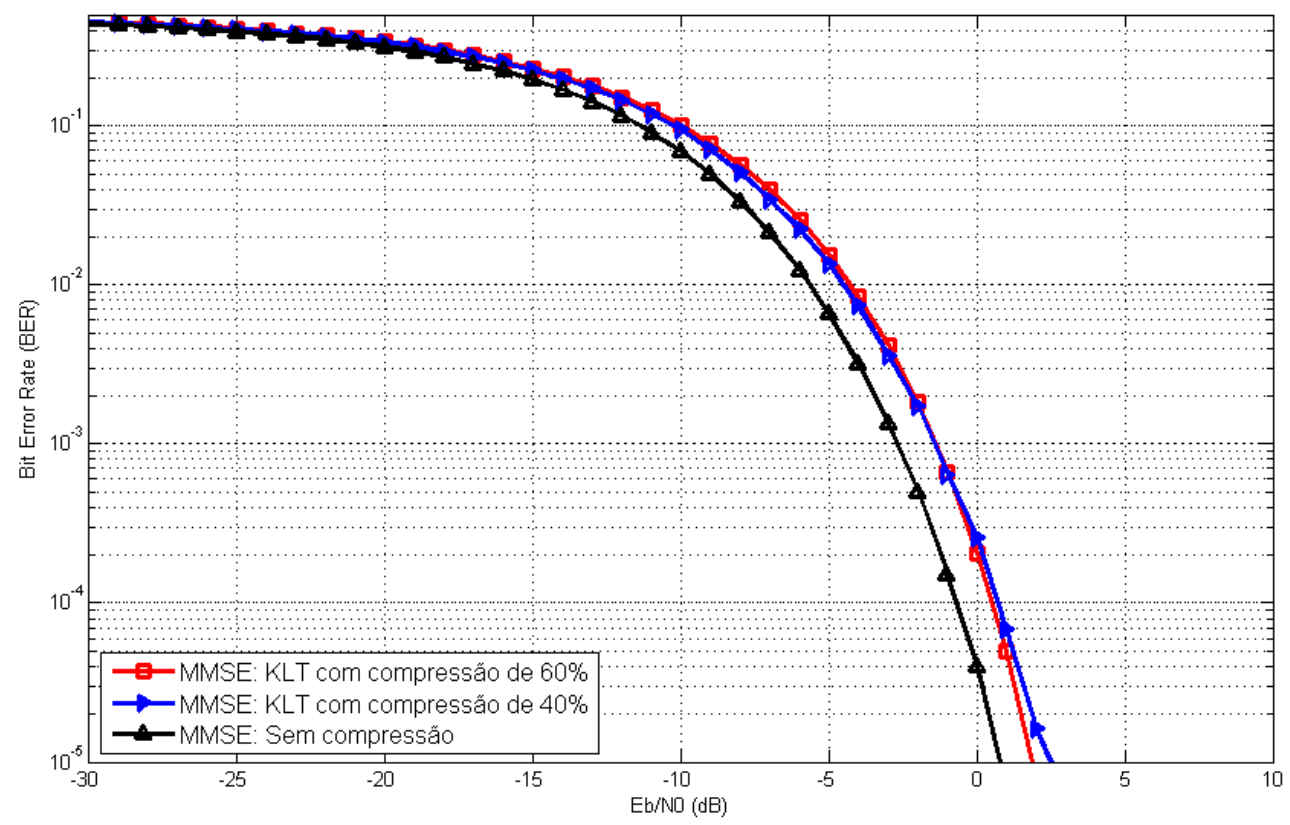

Figura 5.8 - BER para painéis de antenas $\operatorname{com} \rho=0,75$, utilizando-se a KLT

Ao se comparar três cenários com a mesma covariância $(\rho)$, ou seja, sem redução, com compressão de $40 \%$ e com compressão de $60 \%$, pode-se verificar que o sistema de antenas distribuídas e compressão por KLT apresenta, como esperado, pequenas perdas quando comparado ao sistema sem compressão.

É de se presumir que quando há mais antenas de recepção, há uma maior gama de sinais recebidos, e na redução de dimensões pode-se selecionar os sinais mais fortes que chegam a cada painel, reduzindo-se significativamente a quantidade de sinais requeridos na reconstituição. Essa compressão empregada permite que maior quantidade de dados seja transportada pelo mesmo enlace, devido à compressão com perdas.

Por meio desta técnica, enlaces de fronthaul podem trafegar um volume maior de dados sem necessidade de ampliação de banda, desde que tenha alguma tolerância relacionada à piora no desempenho da taxa de erro de bit. 
O limite de redução de dimensões sem que haja grande perda de desempenho dependerá da tolerância do sistema à degradação e também da implementação de códigos corretores de erros.

Conjuntamente, a matriz de covariância de canal e a relação sinal-ruído desempenham fatores limitantes nos sistemas, porém, estes parâmetros são intrínsecos, o que torna limitado o controle destes fatores no esforço de melhoria de desempenho.

Na tentativa de identificar um ponto de inflexão no qual o sistema apresenta uma melhora súbita no desempenho, foram simulados três cenários com $E_{b} / N_{0}$ fixos com o objetivo de analisar o comportamento do sistema.

A Figura 5.9 apresenta os resultados da simulação com o parâmetro de covariância das antenas de $\rho=0,50$ e $E_{b} / N_{0}$ fixados em $0 \mathrm{~dB}, 5 \mathrm{~dB}$ e $10 \mathrm{~dB}$, para arranjo linear de 25 antenas, baseado na KLT.

Neste cenário selecionado pode-se observar que o desempenho dos sistemas melhora com o aumento do número de dimensões, e que a partir de um valor específico o desempenho é bruscamente melhorado. Este ponto é facilmente visualizado para altas $E_{b} / N_{0}$ e, neste cenário simulado, foi de aproximadamente 10 dimensões. Nas demais curvas este ponto de inflexão é muito sutil.

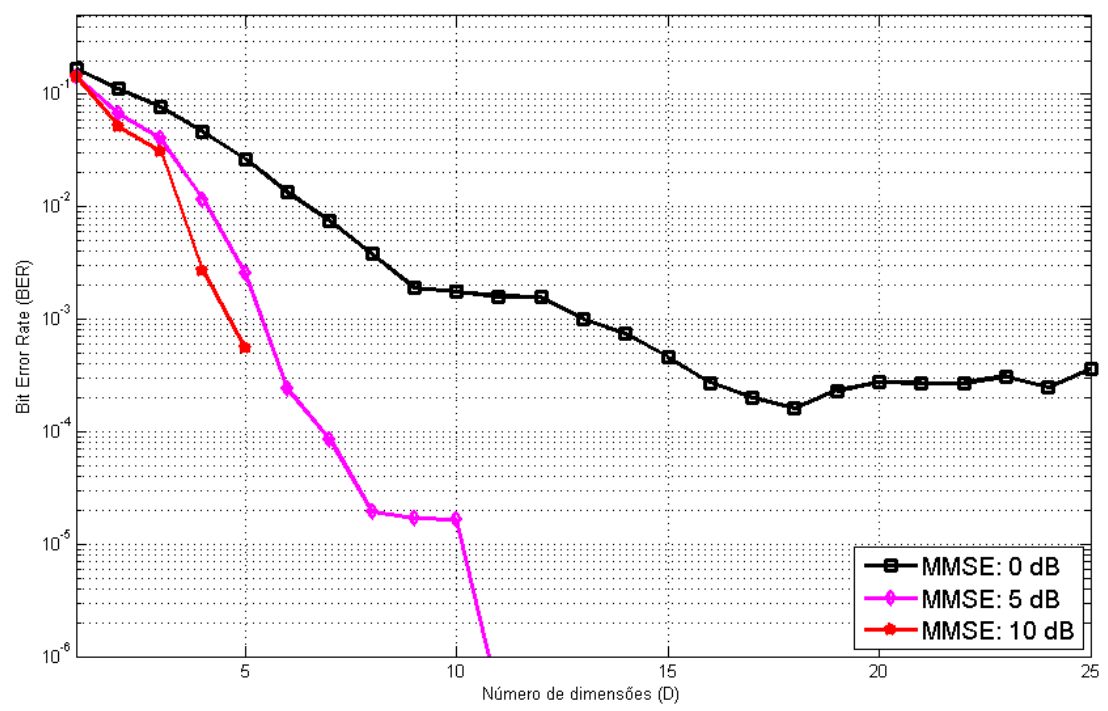

Figura 5.9 - BER em função do número de dimensões, para arranjos lineares de antenas, $\rho=0,50$ e $E_{b} / N_{0}$ fixos, utilizando-se a KLT 
Nas simulações anteriores, foram consideradas compressões de $40 \%$ e $60 \%$, porém, para efeito de comparação, é apresentada na Figura 5.10 uma compressão mais intensa, como a redução de 50 para 6 dimensões, que representa $88 \%$ de compressão, e também de 50 para 4 dimensões, que caracteriza 92\% de compressão. Nestes exemplos pode-se constatar que as taxas de erro de bit são consideravelmente mais elevadas.

Nota-se que a BER para compressão de $88 \%$ é muito alta e não é conveniente a sistemas de comunicação usuais. Também a BER para compressão de 92\%, é extremamente alta e inviável para enlaces típicos de comunicação de dados.

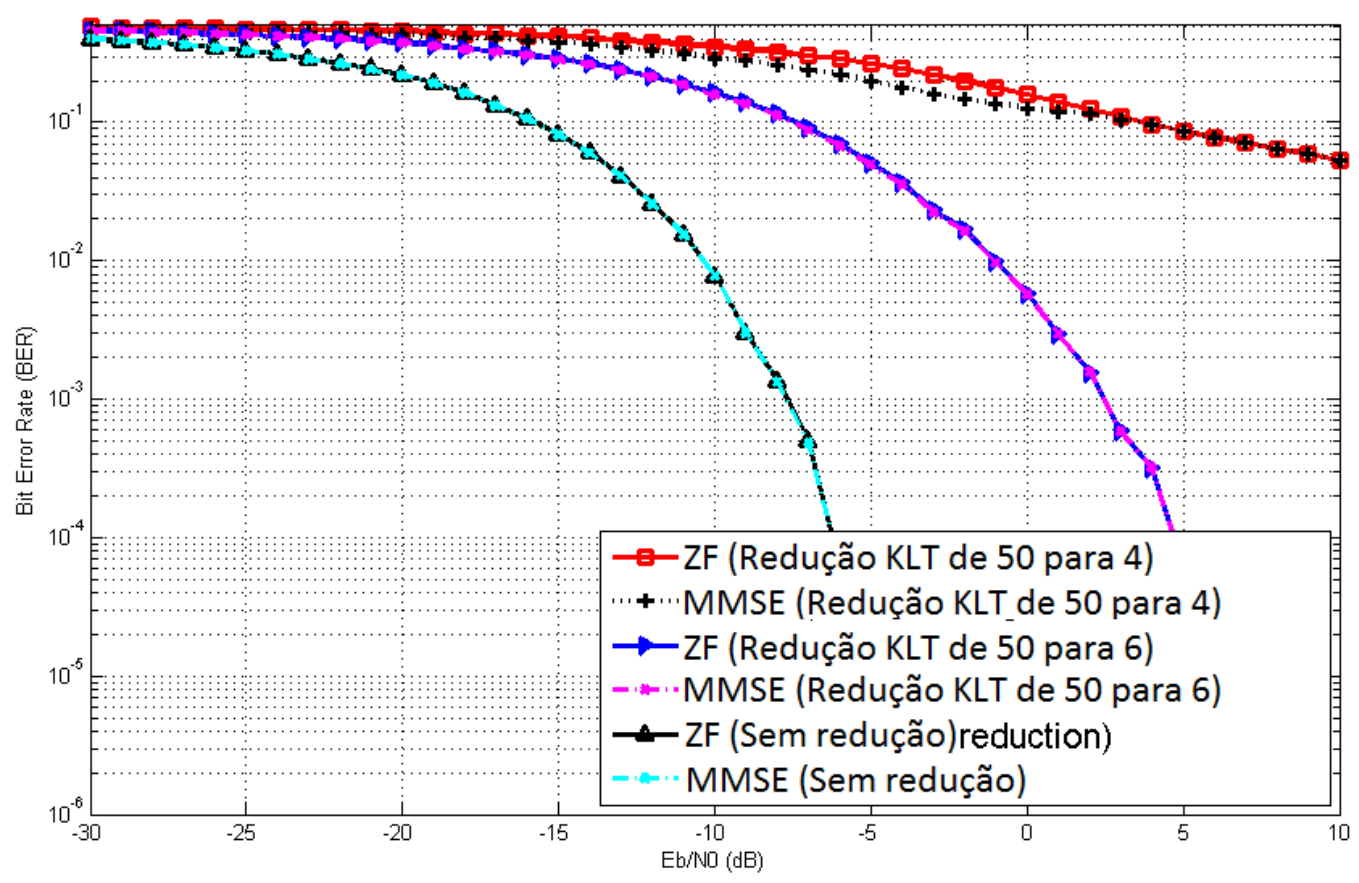

Figura 5.10 - BER para arranjos lineares de antenas $\operatorname{com} \rho=0,50$, utilizando-se a KLT

As simulações do segundo cenário foram realizadas com quatro equipamentos de usuário, contendo 4 antenas de transmissão cada, e quatro painéis $5 \times 5$ de antenas de recepção, tal como ilustrado nas Figuras 4.2b e 5.2. As condições de simulação foram as mesmas que o primeiro cenário, com arranjos lineares de antenas.

As curvas de taxa de erro de bit para um canal com o parâmetro covariância das antenas de $\rho=0,50$ são mostradas na Figura 5.11. Ao se comparar com o desempenho do outro cenário, ilustrado na Figura 5.3, pode-se verificar que o desempenho do sistema é muito superior, por exemplo, considerando o sistema sem compressão. 
A Figura 5.11 apresenta, para comparação, as curvas de BER para sistemas sem compressão, com redução de 100 para 40 antenas (60\% de compressão), com redução de 100 para 20 (80\% de compressão), redução de 100 para 8 (92\% de compressão) e redução de 100 para 4 (96\% de compressão).

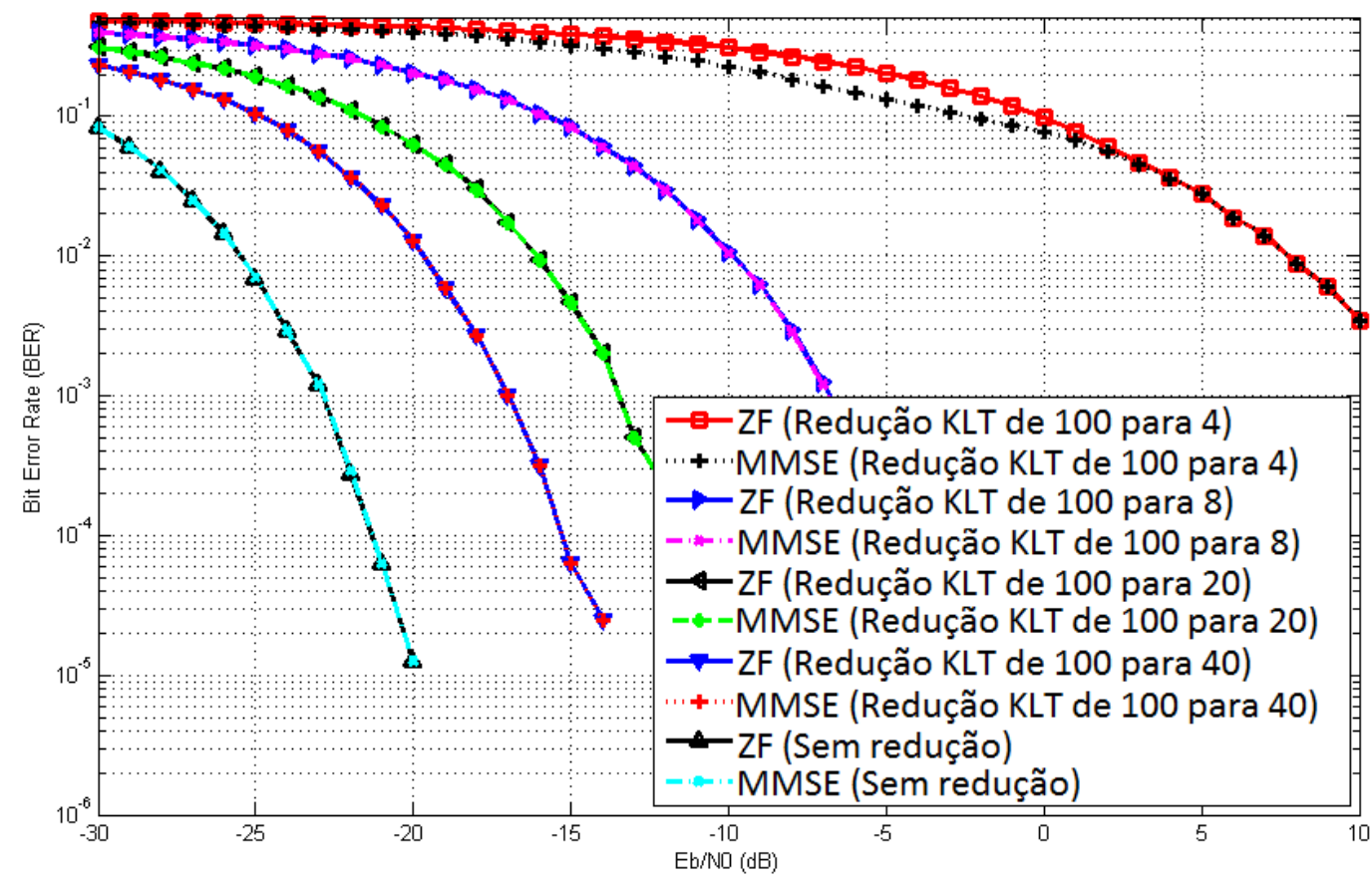

Figura 5.11 - BER para painéis de antenas $\operatorname{com} \rho=0,50$, utilizando-se a KLT

Quando comparado o desempenho do sistema com compressão nos dois cenários, Figuras 5.3 e 5.11, verifica-se que a superioridade se mantém para o sistema com 4 painéis quadrados 5×5, que totalizam 100 antenas de recepção.

Nessa comparação é possível comprovar que o desempenho do sistema com 4 painéis realizando uma redução de 100 para 8 antenas, ou seja, uma compressão de $92 \%$, tem taxa de erro equivalente ao sistema com 2 arranjos lineares e com uma compressão de 50 para 30 antenas, ou seja, compressão de $40 \%$.

Essa melhoria de desempenho em sistemas com mais arranjos de antenas, que não é linear, é basicamente devida à maior quantidade de sinais recebidos pelos painéis, que resulta em maior diversidade dos sinais. 
A maior diversidade de sinais favorece o uso da técnica de redução de dimensões abordada neste trabalho, uma vez que a transformada de Karhunen-Loève, em resumo, lista os sinais por ordem decrescente de energia. Em seguida, é realizada a seleção dos sinais mais fortes, conforme o esquema da Figura 4.3.

O segundo cenário apresenta um melhor desempenho do que o primeiro pois o decodificador central estima o sinal a partir de uma maior quantidade de amostras relevantes, quando comparado ao primeiro cenário, já que há uma maior diversidade de sinais recebidos. Essa maior quantidade de sinais relevantes se reflete na melhor taxa de erro do sistema, ou seja, menor BER.

\section{3 - RESULTADOS DAS SIMULAÇÕES COM O USO DA DCT}

Assim como nas simulações que fizeram uso da transformada de Karhunen-Loève também foram realizadas simulações equivalentes utilizando-se a transformada discreta de cossenos para as matrizes de covariância em arranjos lineares de antenas e em painéis quadrados de antenas. Nas simulações foi utilizada a transformada DCT-II.

De forma análoga ao sistema descrito na seção anterior, as matrizes foram geradas com diferentes parâmetros covariância das antenas, $\rho$, com valores de $\rho=0,25, \rho=0,50$ e $\rho=0,75$. As curvas de taxa de erro de bit geradas apresentam os resultados para os métodos de estimação MMSE considerando o desempenho sem compressão, e as compressões com perdas, de $40 \%$ e $60 \%$.

Os resultados de simulações de um cenário com um equipamento de usuário transmissor e dois arranjos lineares de antenas de recepção são apresentados nas Figuras 5.12 a 5.14 .

As curvas de BER para o parâmetro covariância das antenas de $\rho=0,25$ são mostradas na Figura 5.12. Além dos resultados que empregam a DCT também são apresentadas as curvas que utilizam a KLT, para efeito de comparação.

Pode-se verificar que, conforme esperado, o desempenho do sistema também se deteriora com a redução do número de dimensões transmitidas pelos enlaces de fronthaul. 
Essa deterioração com o uso da DCT, embora aceitável, apresenta um desempenho pior que a outra técnica, e pode ser interpretado como uma maior taxa de erro para a mesma $E_{b} / N_{0}$. O desempenho do sistema com a DCT é de cerca de 3 dB abaixo dos resultados que utilizam a KLT.

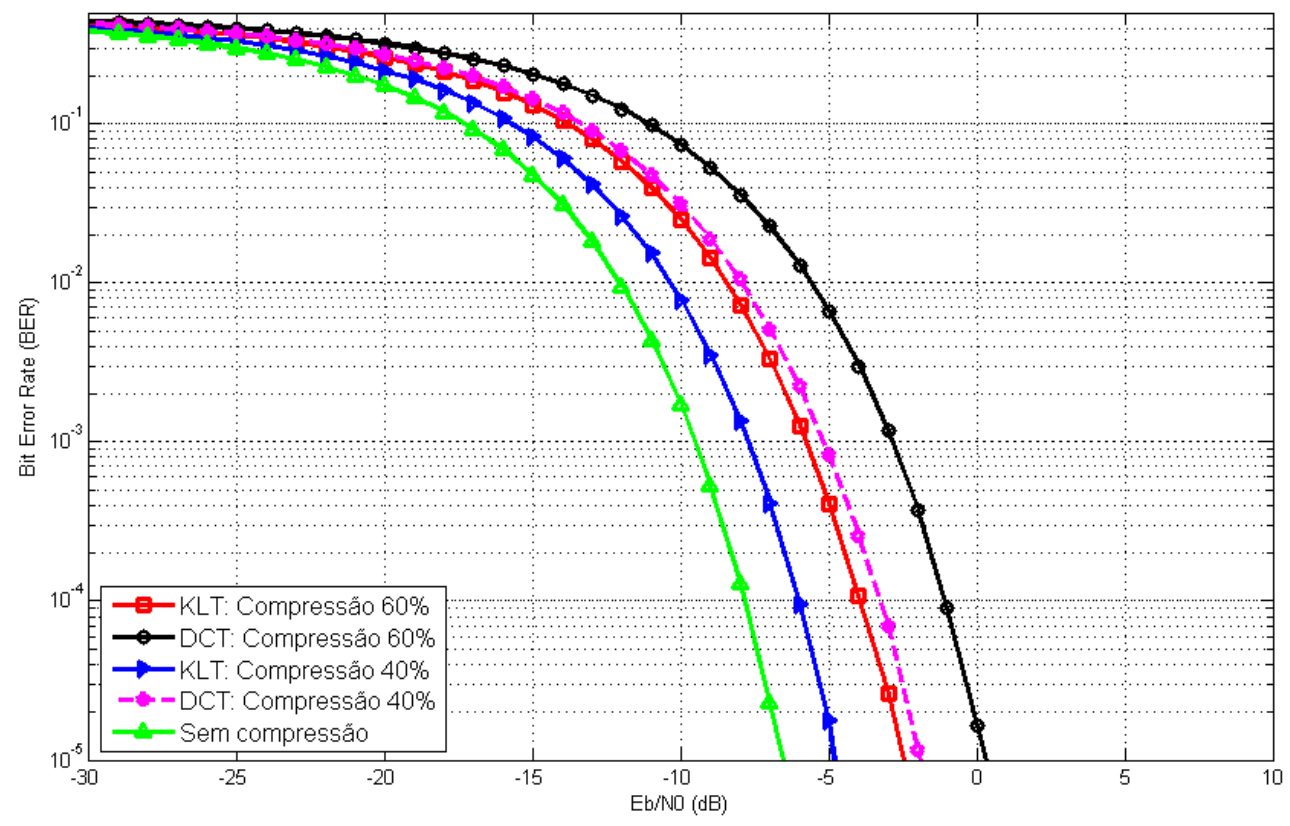

Figura 5.12 - BER para arranjos lineares de antenas com $\rho=0,25$, utilizando-se a DCT

As Figuras 5.13 e 5.14 apresentam os resultados para as mesmas simulações com um arranjo linear de antenas, mas para sistemas com maior correlação entre as antenas, isto é, $\rho=0,50$ e $\rho=0,75$.

Na simulação de um sistema com maior correlação, como o caso da Figura 5.13, na qual $\rho=0,50$, é possível verificar que o desempenho do sistema que emprega DCT é muito inferior quando comparado ao de menor correlação.

Comparando-se o sistema utilizador da DCT com o da KLT é possível verificar que o primeiro tem um desempenho da ordem de 5 a $7 \mathrm{~dB}$ abaixo do segundo sistema. Também pode-se perceber que o sistema da KLT com compressão de $40 \%$ tem desempenho próximo ao sistema sem compressão. 


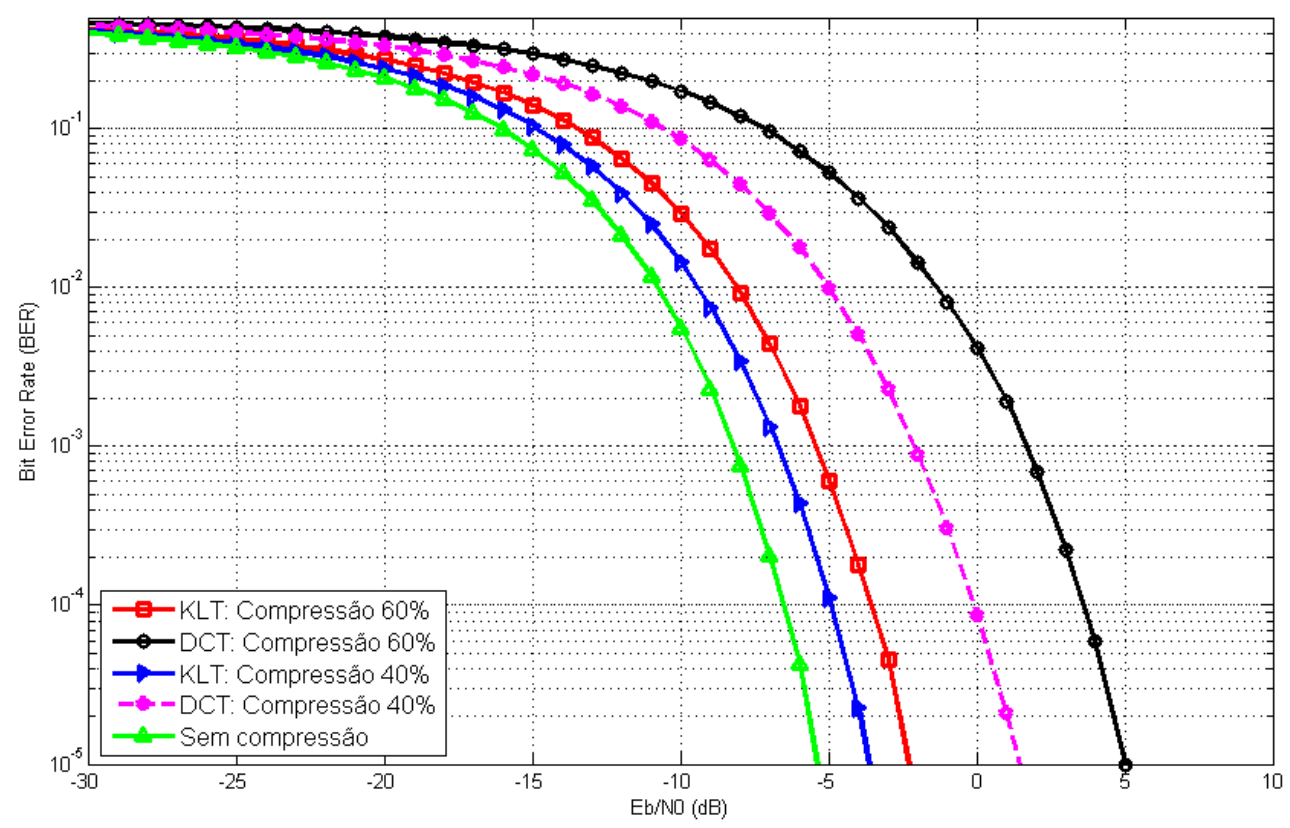

Figura 5.13 - BER para arranjos lineares de antenas $\operatorname{com} \rho=0,50$, utilizando-se a DCT

Assim como na simulação ilustrada na Figura 5.13, com o aumento da correlação piora-se o desempenho do sistema. Na simulação $\operatorname{com} \rho=0,75$ os resultados são muito piores que $\operatorname{com} \rho=0,50$.

Quando se compara o desempenho do sistema que usa a DCT e o da KLT, Figura 5.14 , é possível verificar que aquele tem desempenho da ordem de 7 a $10 \mathrm{~dB}$ abaixo deste em grande parte da SNR. Confirma-se assim, que o sistema da KLT com compressão de 40\% tem desempenho bastante próximo ao do sistema sem compressão. 


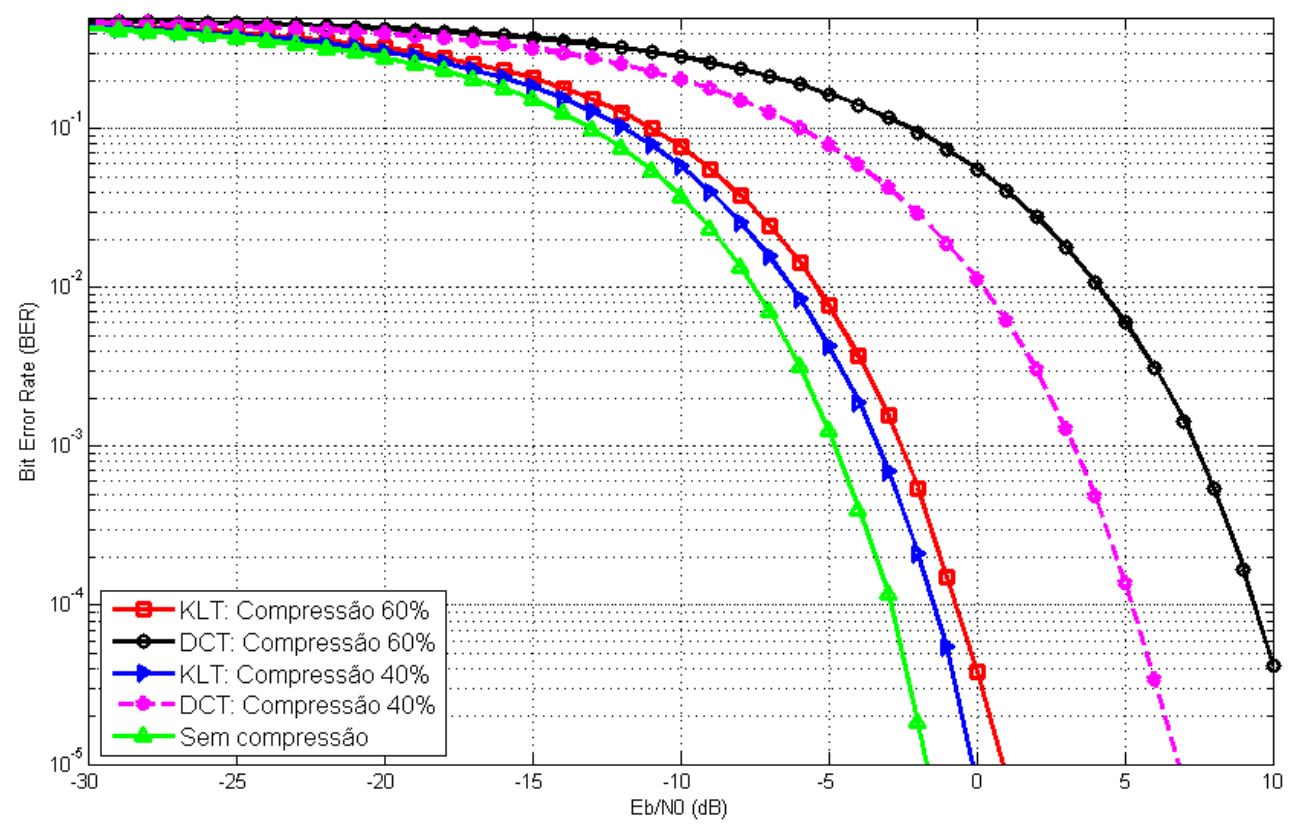

Figura 5.14 - BER para arranjos lineares de antenas $\operatorname{com} \rho=0,75$, utilizando-se a DCT

Os resultados das simulações para dois painéis com 25 antenas de recepção, em um arranjo 5×5, são apresentadas nas Figuras 5.15 a 5.17 .

Na comparação de desempenho entre os sistemas que empregam a DCT e a KLT, Figura 5.15, é possível identificar que o primeiro tem um desempenho de cerca de $4 \mathrm{~dB}$ abaixo do segundo sistema. 


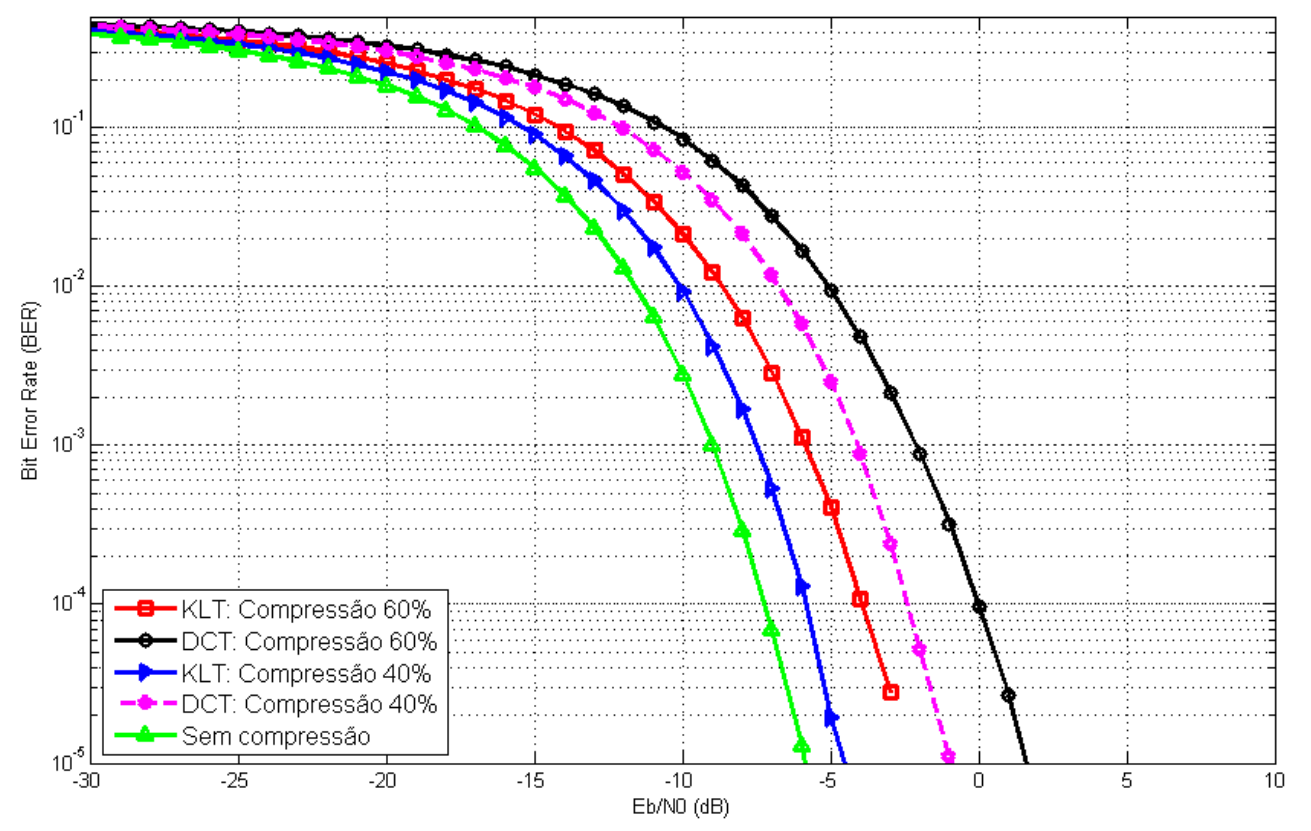

Figura 5.15 - BER para painéis de antenas com $\rho=0,25$, utilizando-se a DCT

O comportamento das simulações com o painel quadrado de antenas é similar ao comportamento do sistema com arranjo linear já que o sistema baseado na KLT tem o seu desempenho melhorado com o aumento do fator de covariância enquanto que o sistema baseado na DCT tem o seu desempenho piorado.

Entretanto, quando é confrontado o desempenho do sistema com painel quadrado, Figura 5.16, com o sistema com arranjo linear, Figura 5.13, é possível verificar que o desempenho do sistema com painel é pior que o sistema com arranjo linear.

Isto pode ser interpretado da forma que a correlação entre os elementos do painel de antenas é maior que a correlação entre os elementos do arranjo linear, pois as distâncias entre as antenas são menores no primeiro sistema. 


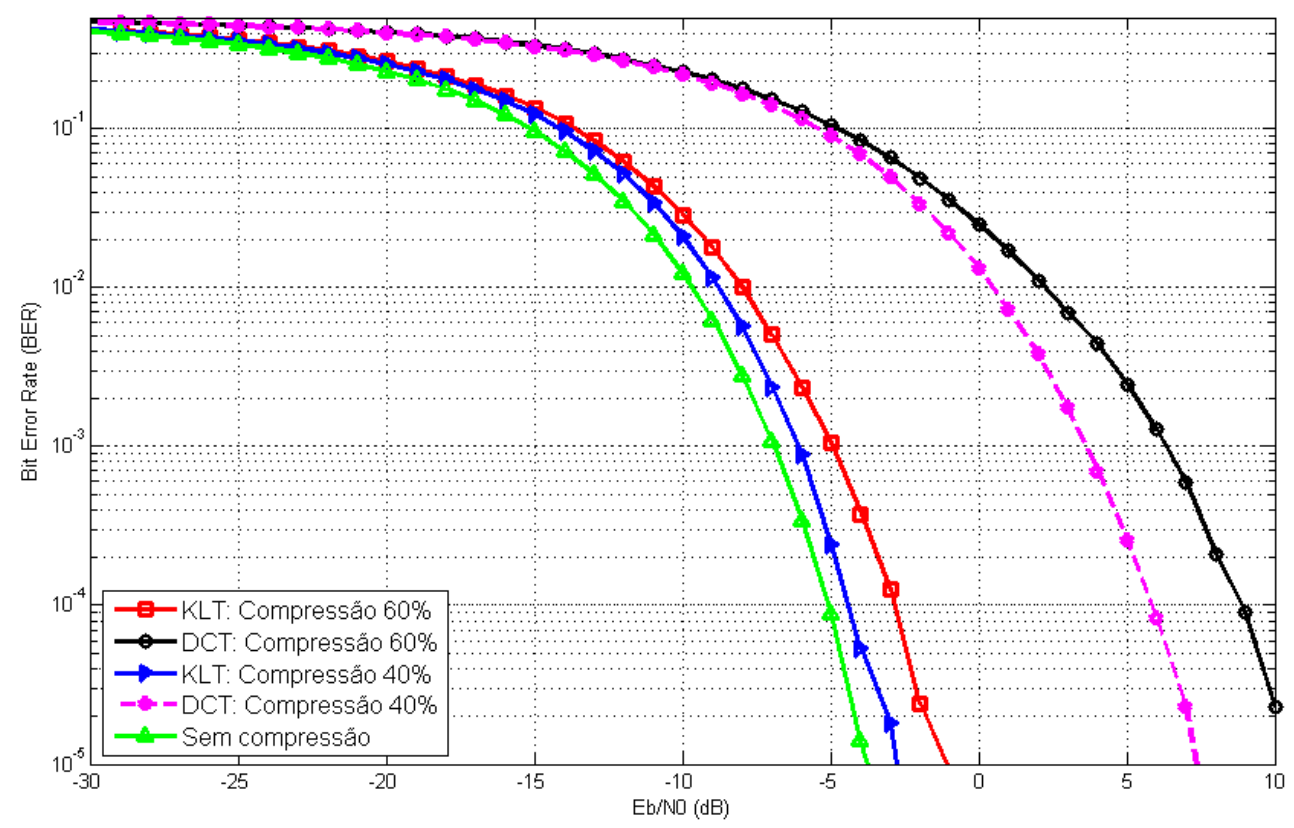

Figura 5.16 - BER para painéis de antenas $\operatorname{com} \rho=0,50$, utilizando-se a DCT

A Figura 5.17 apresenta a simulação com $\rho=0,75$ e é possível verificar que o desempenho é muito inferior ao sistema com o parâmetro de covariância $\rho=0,50$.

É possível comprovar que, para parâmetros de covariância mais altos, o desempenho do sistema que emprega a DCT piora, enquanto que o desempenho de compressão do sistema que usa a KLT melhora. 


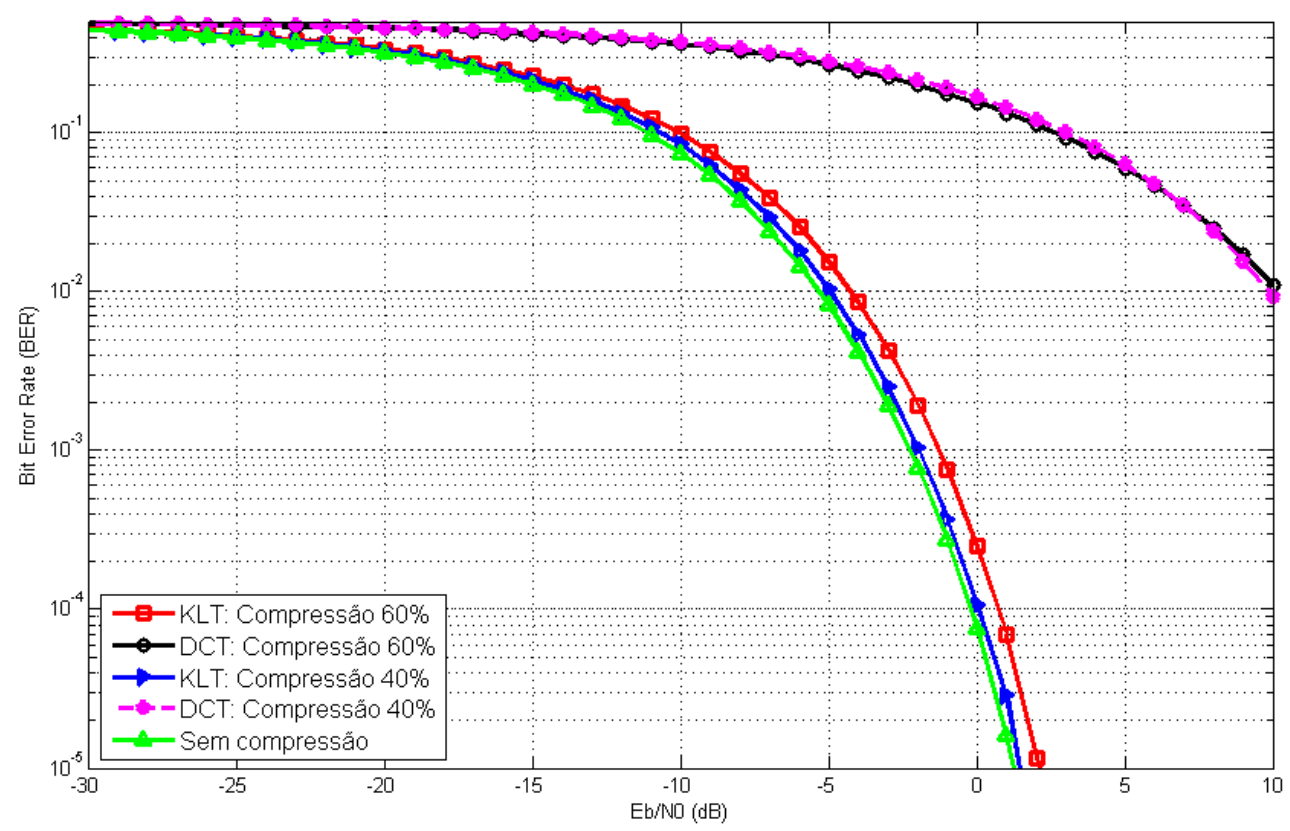

Figura 5.17 - BER para painéis de antenas $\operatorname{com} \rho=0,75$, utilizando-se a DCT

A Figura 5.18 apresenta os resultados da simulação com o parâmetro de covariância das antenas de $\rho=0,50$ e $E_{b} / N_{0}$ fixados em $0 \mathrm{~dB}, 5 \mathrm{~dB}$ e $10 \mathrm{~dB}$, para arranjos lineares, baseado na DCT.

A partir da comparação entre os métodos de compressão nota-se que com a KLT identifica-se facilmente os pontos de inflexão em que o desempenho é subitamente melhorado, enquanto que com o método da DCT estes pontos são de difícil identificação ou não são precisos. 


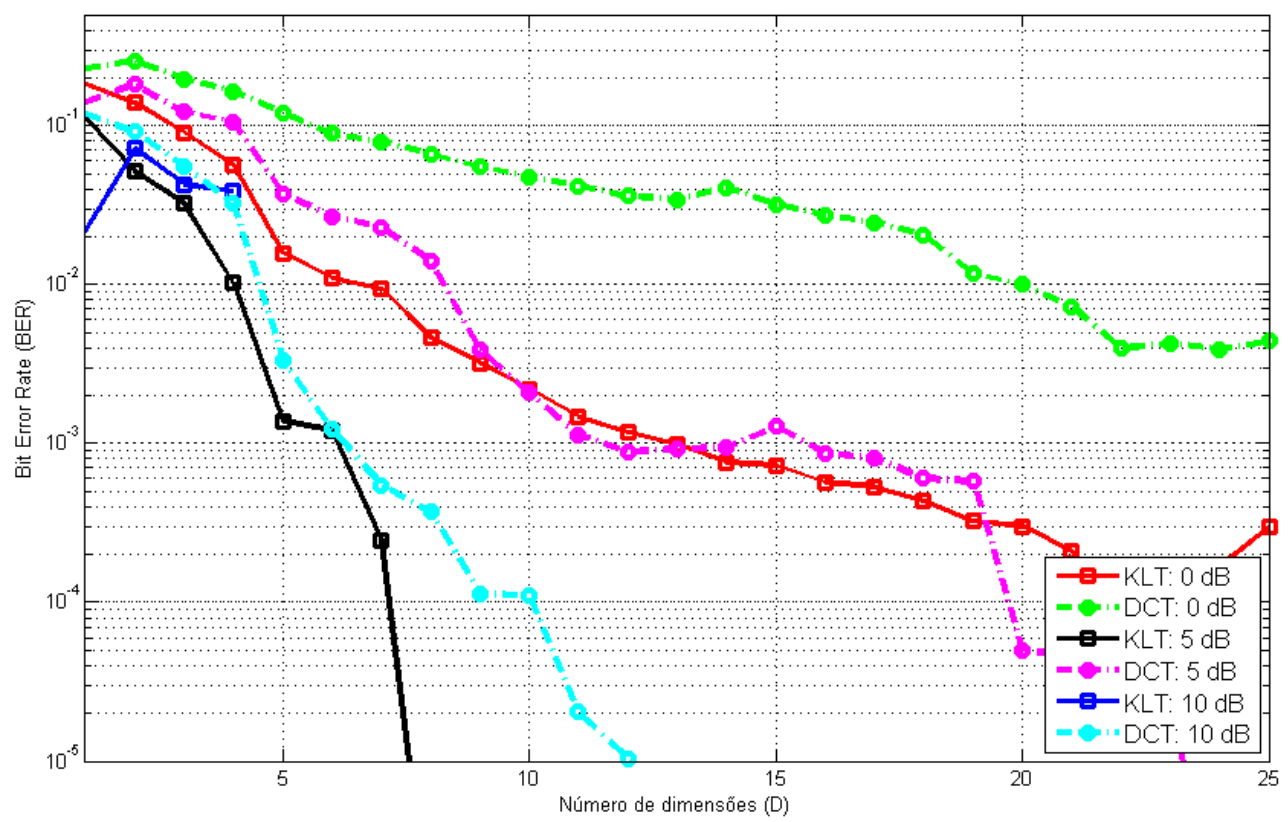

Figura 5.18 - BER em função do número de dimensões, para arranjos lineares de antenas,

$$
\rho=0,50 \text { e } E_{b} / N_{0} \text { fixo, utilizando-se a DCT }
$$

A partir das simulações pode-se constatar que os limites de redução de dimensões do método de compressão baseado na DCT não são tão evidentes quanto os da KLT. Apesar de apresentar um desempenho satisfatório em modelos com baixa correlação entre os sinais recebidos, o desempenho é prejudicado quando a correlação aumenta.

Outro aspecto percebido por meio das simulações é que o método baseado na DCT é muito dependente do formato e disposição das antenas. Isto pode ser verificado quando se compara o desempenho do sistema com arranjo linear e o sistema com painel quadrado, no qual só alteram a disposição das antenas, mantendo-se todas as demais características.

Comparando-se os resultados da transformada de Karhunen-Loève com os da transformada discreta de cossenos, pode-se verificar que as tendências de comportamento acerca da correlação dos sinais são semelhantes nas duas transformações.

Também é possível confirmar que a KLT tem desempenho significativamente melhor que a DCT, contudo a implementação do algoritmo da KLT é mais complexo. 


\section{4 - RESULTADOS DAS SIMULAÇÕES COM REDUÇÃO DE ANTENAS}

A proposta deste trabalho é a redução da taxa de fronthaul pelo uso de transformações lineares, na qual são estudados dois métodos: a transformada de KarhunenLoève e a transformada discreta de cossenos. Esses métodos permitem a redução das dimensões do sinal original, porém tais sistemas necessitam de mais recursos, como equipamentos, antenas, processamento computacional e enlaces de fronthaul.

Conforme verificado nas Seções 5.2 e 5.3, essa redução de dimensões resulta em redução de desempenho, embora também reduza a taxa de dados nos enlaces de fronthaul.

Outra solução natural para essa redução da taxa é o emprego de um número menor de antenas, pois resulta em menor número de dimensões e consequentemente menor taxa de dados. Assim, uma forma de se avaliar a viabilidade do método proposto neste trabalho é por meio da comparação entre os métodos, um que faça uso da redução de dimensões por transformações lineares, mais complexo, e outro que adote a redução de antenas, mais simples.

Esta comparação foi realizada por meio de simulações com um fator de covariância intermediário, $\rho=0,50$, e os resultados apresentados nas Figuras 5.19 e 5.20, nas quais são confrontados um sistema de duplo arranjos lineares de antenas, cada um com 25 antenas de recepção, que utiliza a transformada de Karhunen-Loève e a transformada discreta de cossenos para viabilizar a redução de dimensões, e outro sistema com duplo arranjo de apenas 15 ou 10 antenas de recepção sem nenhum processamento ou redução de dimensões.

$\mathrm{Na}$ simulação foi considerado que o tamanho do arranjo linear não se alterou, porém, como o número de antenas diminuiu, o espaçamento entre as mesmas obrigatoriamente será maior. A implicação disso é que a correlação entre as antenas diminui, alterando a matriz de covariância.

A matriz de covariância ajustada, em que considera o aumento do espaçamento entre antenas, é uma adaptação da Equação 4.10 e é implementada da forma 


$$
\boldsymbol{R}_{i j}=\rho^{\left(\text {Fator }_{A n t} \cdot|i-j|\right)},
$$

onde $\rho$ é o grau de correlação entre antenas adjacentes, Fator ${ }_{A n t}$ é o fator de ajuste de espaçamento entre as antenas, $i$ é o índice da linha e $j$ é o índice da coluna.

O fator de ajuste de espaçamento entre as antenas é dado por

$$
\text { Fator }_{A n t}=\frac{D}{N_{\mathrm{R}}-1}
$$

onde Fator $_{A n t}$ é o fator de ajuste de espaçamento entre as antenas, D é o comprimento do arranjo de antenas e $N_{\mathrm{R}}$ é o número de antenas de recepção.

A primeira comparação, mostrada na Figura 5.19, foi realizada com um sistema composto por 25 antenas de recepção e redução para 15 e 10 dimensões por meio do emprego da KLT e DCT, ou seja, uma compressão de $40 \%$ e $60 \%$, e outro sistema exclusivamente com 15 antenas de recepção em cada painel.

A partir dos resultados é possível verificar que o sistema com painéis de 15 antenas receptoras, sem processamento, apresenta desempenho superior aos sistemas que utilizam a DCT, tanto para compressão de $40 \%$ como a de $60 \%$.

Também é possível verificar que este sistema com painéis com 15 antenas apresenta desempenho inferior aos sistemas que utilizam a KLT, tanto para compressão de $40 \%$ como a de $60 \%$. 


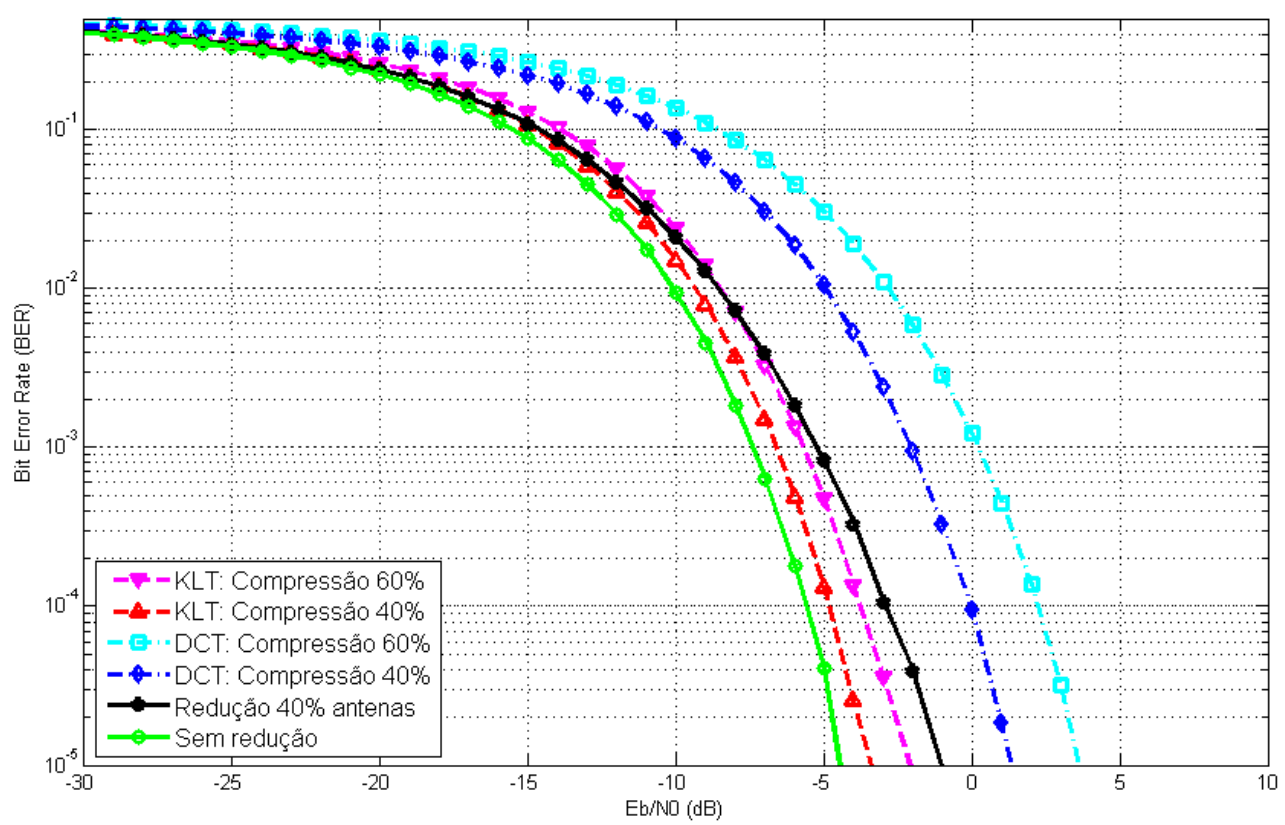

Figura 5.19 - BER para painéis de antenas $\operatorname{com} \rho=0,50$, utilizando-se a KLT, DCT e redução para 15 antenas

Os resultados da segunda comparação são mostrados na Figura 5.20, e as simulações consideraram um sistema composto por 25 antenas de recepção e redução para 15 e 10 dimensões por meio do uso da KLT e DCT, ou seja, uma compressão de $60 \%$ e $40 \%$, e outro sistema exclusivamente com 10 antenas receptoras em cada painel.

É possível verificar que o sistema com painéis de 10 antenas receptoras, sem processamento, também apresenta desempenho superior aos sistemas que utilizam a DCT, tanto para compressão de $40 \%$ como a de $60 \%$, porém o mesmo apresenta desempenho inferior aos sistemas que utilizam a KLT, tanto para compressão de $40 \%$ como a de $60 \%$. 


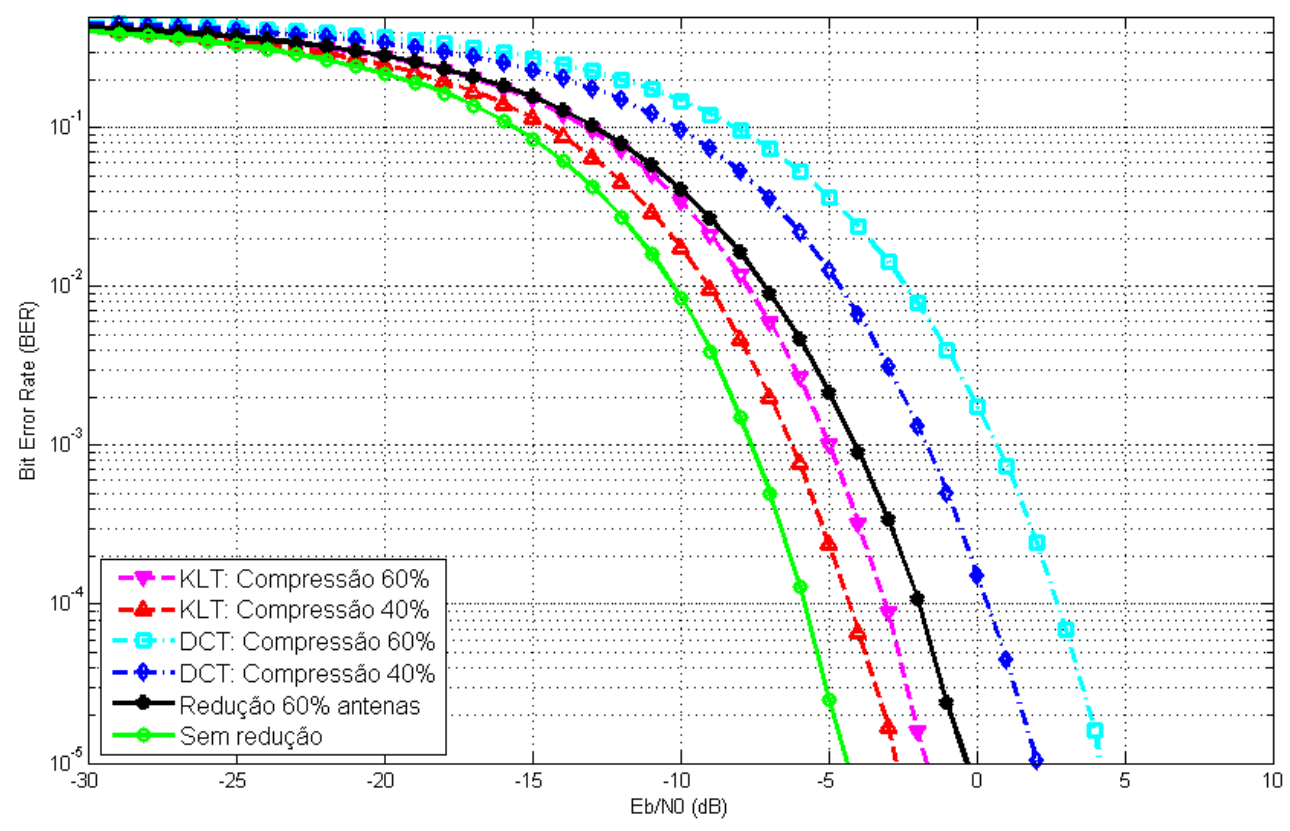

Figura 5.20 - BER para painéis de antenas $\operatorname{com} \rho=0,50$, utilizando-se a KLT, DCT e redução para 10 antenas

A partir das simulações pode-se verificar que o desempenho do sistema com menor número de antenas receptoras nos painéis apresenta desempenho intermediário entre os sistemas que empregam a KLT e a DCT, contando com um desempenho levemente inferior que os sistemas KLT com compressão de $60 \%$.

Baseado nos resultados das simulações desta seção é possível depreender que, considerando um fronthaul de determinada capacidade, é preferível a instalação de mais antenas com o respectivo processamento para redução de dimensões por meio da KLT do que a implementação de sistemas com redução de antenas.

\section{5 - COMPARAÇÃO ENTRE AS TRANSFORMAÇÕES}

A comparação entre o desempenho das transformações lineares utilizadas neste trabalho, a KLT e a DCT, é apresentada na Figura 5.21. A simulação comparou o resultado de dois sistemas, um que emprega a transformada KLT na matriz de covariância e outro que emprega a DCT no sinal recebido, da mesma forma que utilizada neste trabalho, sendo 
possível verificar a eficiência dos métodos de transformação, quanto à concentração de energia.

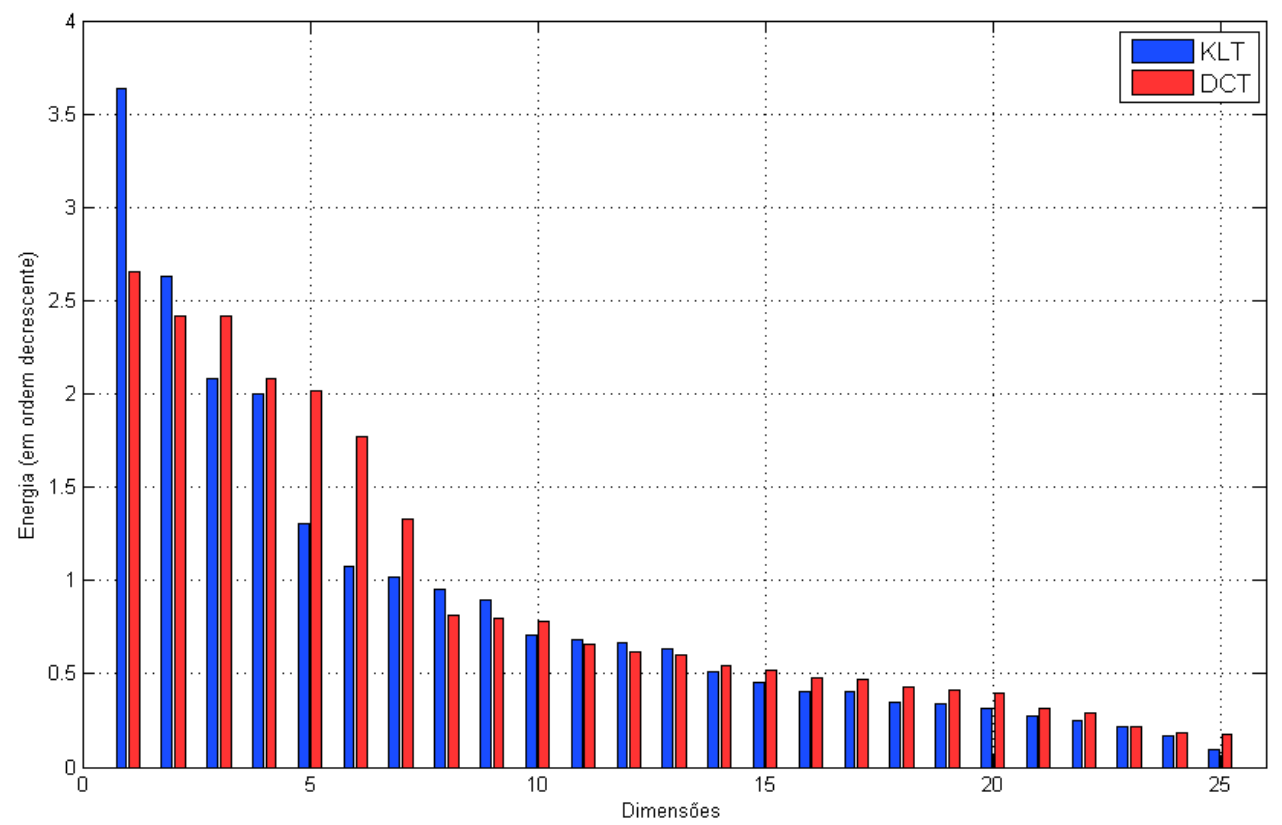

Figura 5.21 - Concentração de energia para a KLT e a DCT

Segundo os resultados é possível confirmar que a diferença de desempenho entre os métodos de transformação é pequena, porém com o emprego da KLT a energia fica mais concentrada em menos dimensões.

Esta superioridade da transformada de Karhunen-Loève também pode ser verificada mediante comparação dos resultados prévios, na qual a KLT sempre apresentou resultados melhores que a transformada discreta de cossenos. 


\section{6- CONCLUSÕES}

Neste trabalho foi investigada a viabilidade da utilização de compressão com perdas baseada em métodos de transformação linear, a transformada de Karhunen-Loève e a transformada discreta de cossenos, em sistemas MIMO massivo distribuídos.

Partindo da premissa que os enlaces de fronthaul possuem limitações de capacidade e também que a expansão dos mesmos representa aumento de custos às operadoras de telecomunicações, o emprego desta técnica de redução de dimensões é bastante desejável, pois permite reduzir a quantidade de dados trafegados nestes enlaces sem que haja perda significativa de desempenho.

Para isso, esses métodos de transformação estudados realizam uma transformação linear no sinal multidimensional recebido pelas antenas, descorrelacionando-as e dispondo em ordem decrescente. A compressão é realizada com a redução de dimensões, que se caracteriza pela seleção de algumas amostras de maior energia e o descarte das demais.

Neste estudo também foi possível verificar que, para a KLT, a taxa de erro de bit depende da correlação dos sinais recebidos pelas antenas, e que quanto menor o fator de correlação das antenas, melhor será o desempenho do sistema, devido ao aumento de diversidade. Por outro lado, o aumento da correlação resulta em diminuição da redundância, e consequente aumento de perdas na compressão.

Apesar de a DCT-II não ser uma transformada ótima no descorrelacionamento dos sinais recebidos, ela se aproxima da KLT em algumas situações. Por outro lado, a DCT é de implementação mais simples, já que seu algoritmo é mais leve e rápido, o que permite sua execução em tempo real.

Também foi constatado que o desempenho do sistema pode ser melhorado pelo aumento do número de antenas e de painéis, pois aumenta a diversidade espacial. Para a DCT, o desempenho pode ser melhorado pela modificação do formato e disposição dos elementos das antenas, de forma a alterar a correlação entre as antenas. 
Além disso verificou-se que, apesar de possuírem as mesmas tendências de comportamento, o desempenho da transformada de Karhunen-Loève é melhor que o da transformada discreta de cossenos, relativamente ao correlacionamento dos sinais.

Outro aspecto apurado foi que a redução de dimensões com o emprego da KLT se mostrou mais eficiente do que a simples redução do número de elementos dos arranjos de antenas. Tal fato corrobora a superioridade do método de redução, ainda que necessite de recursos adicionais para sua implementação.

O trabalho constata que a técnica é viável, mesmo para reduções significativas de dimensões, sendo então um método promissor que pode ter papel fundamental no futuro da $5^{\text {a }}$ geração de sistemas de comunicação móvel. Contudo, mais estudos e investigações ainda se fazem necessários.

\section{1 - ESTUDOS FUTUROS}

Como complementação a esta pesquisa, propõe-se, em investigações posteriores, o estudo de:

- uma matriz de covariância mais realista, estimada de acordo com o ambiente considerado, e não suposto o perfeito conhecimento da mesma;

- outras transformadas semelhantes à KLT, mas que requeiram menor esforço computacional e sejam de rápida execução;

- comparação com métodos não lineares;

- sistemas banda larga, como OFDM;

- modelo de canal mais realista;

- métodos que determinem o número de dimensões necessárias na compressão com perdas;

- códigos corretores de erro para implementação conjunta com a técnica deste trabalho, de forma a compensar as perdas da compressão;

- outros cenários de propagação, em ambientes indoor e outdoor. 


\section{REFERÊNCIAS BIBLIOGRÁFICAS}

[1] S. Chen, J. Zhao, "The requirements, challenges, and technologies for 5G of terrestrial mobile telecommunication," IEEE Commun. Mag., vol. 52, no. 5, pp. 3643, May 2014.

[2] J. G. Andrews, S. Buzzi, W. Choi, S. V. Hanly, A. Lozano, A. C. K. Soong, J. C. Zhang, "What will 5G be?," IEEE J. Select. Areas Commun., vol. 32, no. 6, pp. 1065-1082, Jun. 2014.

[3] Cisco, "Cisco Visual Networking Index: Forecast and Methodology, 2015-2020," White Paper, Jul. 2016.

[4] GSMA Intelligence, "Understanding 5G: Perspectives on future technological advancements in mobile," White Paper, Dec. 2014.

[5] NGMN Alliance, "NGMN 5G White Paper," White Paper, Feb. 2015.

[6] 5G-PPP, "5G Vision - The 5G Infrastructure Public Private Partnership: the next generation of communication networks and services," Brochure, Fev. 2015.

[7] METIS2020, “Deliverable D8.4: METIS final project report," Report, Apr. 2015.

[8] A. N. Barreto, B. Faria, E. P. L. Almeida, I. Rodriguez, M. Lauridsen, R. Amorim, R. D. Vieira, "5G - Wireless Communications for 2020," J. Commun. Inform. Syst. SBrT, vol. 31, no. 1, pp. 146-163, Jul. 2016.

[9] F. Boccardi, R. W. Heath Jr., A. Lozano, T. L. Marzetta, P. Popovski, "Five disruptive technology directions for 5G," IEEE Commun. Mag., vol. 52, no. 2, pp. 74-80, Feb. 2014.

[10] T. Marzetta, "Massive MIMO: An Introduction," Bell Labs Tech. J., vol. 20, pp. 1122, Mar. 2015.

[11] X. Ge, S. Tu, G. Mao, C. Wang, T. Han, "5G Ultra-Dense Cellular Networks," IEEE Wireless Commun., v. 23, n. 1, p. 72-79, Mar. 2016.

[12] T. L. Marzetta, "Noncooperative Cellular Wireless with Unlimited Numbers of Base Station Antennas," IEEE Trans. Wireless Commun., vol. 9, no. 11, pp. 3590-3600, Nov. 2010.

[13] M. Kamel, W. Hamouda, A. Youssef, "Ultra-Dense Networks: A Survey," IEEE Commun. Surveys \& Tutorials, p. 1-1, May 2016.

[14] M. Z. Shakir, M. A. Imran, X. Wang, J. Wu, A. Ghosh, H. Lundqvist, L. Liu, "Smart backhauling and fronthauling for 5G networks: from precoding to network architecture [Guest editorial]," IEEE Wireless Commun., vol. 22, no. 5, pp. 10-12, Oct. 2015.

[15] Z. Gao, L. Dai, D. Mi, Z. Wang, M. A. Imran, M. Z. Shakir, "mmWave massiveMIMO-based wireless backhaul for the 5G ultra-dense network," IEEE Wireless Commun., vol. 22, no. 5, pp. 13-21, Oct. 2015.

[16] J. Guey, P. Liao, Y. Chen, A. Hsu, C. Hwang, G. Lin, "On 5G radio access architecture and technology [Industry Perspectives]," IEEE Wireless Commun., vol. 22 , no. 5, pp. 2-5, Oct. 2015. 
[17] D. Wang, J. Wang, X. You, Y. Wang, M. Chen, X. Hou, "Spectral Efficiency of Distributed MIMO Systems," IEEE J. Select. Areas Commun., vol. 31, no. 10, pp. 2112-2127, Oct. 2013.

[18] P. Marsch, G. Fettweis, "A framework for optimizing the uplink performance of distributed antenna systems under a constrained backhaul," Proc. IEEE Int. Conf. Commun., pp. 975-979, Jun. 2007.

[19] J. Jelitto, G. Fettweis, "Reduced dimension space-time processing for multi-antenna wireless systems," IEEE Wireless Commun., vol. 9, no. 6, pp. 18-25, Dec. 2002.

[20] M. S. Sim, J. Park, C. Chae, R. W. Heath Jr., "Compressed channel feedback for correlated massive MIMO systems," IEEE Globecom Workshops, pp. 327-332, Dec. 2014.

[21] K. Rao, P. Yip, Discrete cosine transform. Boston: Academic Press, 1990.

[22] M. Gastpar, P. L. Dragotti, M. Vetterli, "The distributed Karhunen-Loève transform," IEEE Trans. Inform. Theory, vol. 52, no. 12, pp. 5177-5196, Dec. 2006.

[23] R. S. Adve, Receive diversity. Unpublished, May 2007.

[24] R. Janaswamy, Radiowave Propagation and Smart Antennas for Wireless Communications. Kluwer Academic Publishers, 2000.

[25] L. C. Godara, Handbook of Antennas for Wireless Communications. CRC Press, 2002.

[26] S. M. Alamouti, "A simple transmit diversity technique for wireless communications," IEEE J. Select. Areas Commun., v. 16, n. 8, p. 1451-1458, Oct. 1998.

[27] V. Tarokh, N. Seshadri, A. Calderbank, "Space-time codes for high data rate wireless communication: performance criterion and code construction," IEEE Trans. Inform. Theory, vol. 44, no. 2, pp. 744-765, Mar. 1998.

[28] D. Tse, P. Viswanath, Fundamentals of wireless communication, $1^{\text {st }}$ ed. Cambridge: Cambridge University Press, 2005.

[29] G. J. Foschini, M. J. Gans, "On Limits of Wireless Communications in a Fading Environment when Using Multiple Antennas," Wireless Personal Communications, New Jersey, vol. 6, pp. 311-335, 1998.

[30] R. N. Souza, "Modulação Espacial em Sistemas de Comunicação sem Fio: Compromisso Complexidade-Desempenho," Dissertação, Dep. Eng. Elétrica, Universidade Estadual de Londrina, Londrina, 2013.

[31] F. Rusek, D. Persson, B. K. Lau, E. Larsson, T. Marzetta, F. Tufvesson, "Scaling Up MIMO: Opportunities and Challenges with Very Large Arrays," IEEE Signal Process. Mag., vol. 30, no. 1, pp. 40-60, Jan. 2013.

[32] B. Panzner, W. Zirwas, S. Dierks, M. Lauridsen, P. Mogensen, K. Pajukoski, D. Miao, "Deployment and implementation strategies for massive MIMO in 5G," IEEE Globecom Workshops (GC Wkshps), pp. 346-351, Dec. 2014.

[33] A. Checko, H. L. Christiansen, Y. Yan, L. Scolari, G. Kardaras, M. S. Berger, L. Dittmann, "Cloud RAN for Mobile Networks - A Technology Overview, " IEEE Commun. Surveys \& Tutorials, pp. 405-426, Sep. 2014. 
[34] V. Suryaprakash, P. Rost, G. Fettweis, "Are Heterogeneous Cloud-Based Radio Access Networks Cost Effective?," IEEE J. Select. Areas Commun., vol. 33, no. 10, pp. 2239-2251, Oct. 2015.

[35] China Mobile Research Institute, "C-RAN: The road towards green RAN," White paper, v. 2.5, Oct. 2011.

[36] K. Zheng, L. Zhao, J. Mei, B. Shao, W. Xiang, L. Hanzo , "Survey of Large-Scale MIMO Systems," IEEE Commun. Surveys \& Tutorials, vol. 17, no. 3, pp. 17381760, 2015.

[37] A. del Coso, S. Simoens, "Distributed compression for MIMO coordinated networks with a backhaul constraint," IEEE Trans. Wireless Commun., vol. 8, no. 9, pp. 46984709, Sep. 2009.

[38] Y. Zhou, W. Yu, "Optimized backhaul compression for uplink cloud radio access network," IEEE J. Select. Areas Commun., vol. 32, no. 6, pp. 1295-1307, Jun. 2014.

[39] J. J. Gerbrands, "On the relationships between SVD, KLT and PCA," Pattern Recognition, vol. 14, no. 1-6, pp. 375-381, 1981.

[40] J. Bartelt, P. Rost, D. Wübben, J. Lessmann, B. Melis, G. Fettweis, "Fronthaul and backhaul requirements of flexibly centralized radio access networks," IEEE Wireless Commun., vol. 22, no. 5, pp. 105-111, Oct. 2015.

[41] D. Schulz, V. Jungnickel, C. Alexakis, M. Schlosser, J. Hilt, A. Paraskevopoulos, L. Grobe, P. Farkas, R. Freund, "Robust Optical Wireless Link for the Backhaul and Fronthaul of Small Radio Cells," IEEE/OSA J. Lightw. Technol., vol. 34, no. 6, pp. 1523-1532, Feb. 2016.

[42] J. Liu, S. Xu, S. Zhou, Z. Niu, "Redesigning fronthaul for next-generation networks: beyond baseband samples and point-to-point links," IEEE Wireless Commun., vol. 22, no. 5, pp. 90-97, Oct. 2015.

[43] H. C. Andrews, C. L. Patterson III, "Singular Value Decomposition (SVD) Image Coding," IEEE Trans. Commun., vol. 24, no. 4, pp. 425-432, Apr. 1976.

[44] K. Karhunen, "Über lineare Methoden in der Wahrscheinlichkeitsrechnung," Annales Academia Scientiarum Fennica, Ser. A1, Math. Phys. 37, 1947.

[45] M. Loève, "Fonctions Aléatoires de Second Ordre," in Processus Stochastiques et Mouvement Brownien, P. Levy (Ed.), Paris: Hermann, 1948.

[46] H. Hotelling, "Analysis of a complex of statistical variables into principal components", J. Educ. Psychology, vol. 24, no. 6 and 7, pp. 417-441 and 498-520, 1933.

[47] I. T. Jolliffe, Principal Component Analysis, $2^{\text {nd }}$ ed. New York, NY: Springer, 2002.

[48] K. R. Rao, P. C. Yip, The transform and data compression handbook. Boca Raton, FL: CRC Press, 2001.

[49] L. Hogben (Ed.), Handbook of linear algebra. Boca Raton, FL: Chapman \& Hall/CRC, 2007.

[50] P. Waldemar, T. A. Ramstad, "Hybrid KLT-SVD image compression," IEEE Int. Conf. Acous., Speech, Signal Process., vol 4, pp. 2713-2716, Apr. 1997.

[51] CELTIC, “D5.3: WINNER+ Final Channel Models,” Report, 2010. 
[52] K. Yu, M. Bengtsson, B. Ottersten, D. McNamara, P. Karlsson, M. Beach, "Second Order Statistics of NLOS Indoor MIMO Channels Based on $5.2 \mathrm{GHz}$ Measurements," Global Telecomm. Conf., Nov. 2001.

[53] E. Bonek, H. Özcelik, M. Herdin, W. Weichselberger, J. Wallace, "Deficiencies of a popular stochastic MIMO radio channel model," International Symposium on Wireless Personal Multimedia Commun., WPMC, 2003.

[54] H. Özcelik, M. Herdin, H. Hofstetter, E. Bonek, "A comparison of measured 8x8 MIMO systems with a popular stochastic channel model at $5.2 \mathrm{GHz}$," International Conference on Telecomm. ICT 2003, vol. 2, pp. 1542-1546, 2003.

[55] K. Yu, "Multiple-input multiple-output radio propagation channels characteristics and models," Ph.D. dissertation, Dept. of signals, sensors and systems, Royal Institute of Technology, Stockholm, Sweden, 2005.

[56] K. Yu, M. Bengtsson, B. Ottersten, D. McNamara, P. Karlsson, M. Beach, "A wideband statistical model for NLOS indoor MIMO channels," IEEE Veh. Technol. Conf., pp. 370-374, May 2002.

[57] R. J. Clarke, "Relation between the Karhunen Loève and cosine transforms," IEE Proceedings F-Commun., Radar Signal Process., vol. 128, no. 6, pp. 359-360, Nov. 1981.

[58] N. Goela M. Gastpar, "Distributed Karhunen-Loève Transform with nested subspaces," IEEE Int. Conf. Acous., Speech Signal Process., pp. 2405-2408, Apr. 2009.

[59] M. Gastpar, P. L. Dragotti, M. Vetterli, "The distributed Karhunen-Loève transform," IEEE Workshop on Multimedia Signal Process., pp. 57-60, Dec. 2002. 